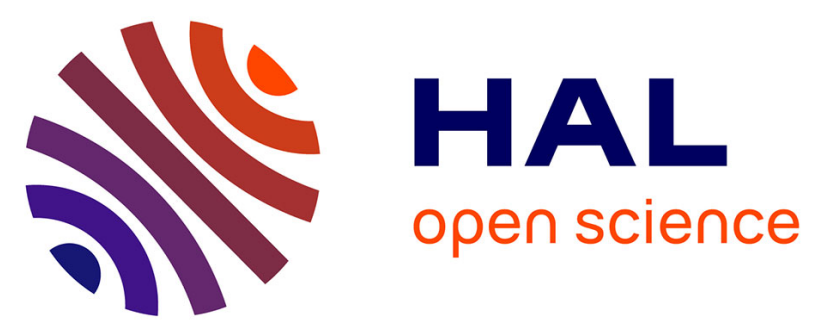

\title{
Vertical and meridional distribution of ethane, acetylene and propane in Saturn's stratosphere from CIRS/Cassini limb observations
}

Sandrine Guerlet, Thierry Fouchet, Bruno Bézard, Amy A. Simon-Miller, F. Michael Flasar

\section{To cite this version:}

Sandrine Guerlet, Thierry Fouchet, Bruno Bézard, Amy A. Simon-Miller, F. Michael Flasar. Vertical and meridional distribution of ethane, acetylene and propane in Saturn's stratosphere from CIRS/Cassini limb observations. Icarus, 2009, 203 (1), pp.214. 10.1016/j.icarus.2009.04.002 . hal00567274

\section{HAL Id: hal-00567274 \\ https://hal.science/hal-00567274}

Submitted on 20 Feb 2011

HAL is a multi-disciplinary open access archive for the deposit and dissemination of scientific research documents, whether they are published or not. The documents may come from teaching and research institutions in France or abroad, or from public or private research centers.
L'archive ouverte pluridisciplinaire HAL, est destinée au dépôt et à la diffusion de documents scientifiques de niveau recherche, publiés ou non, émanant des établissements d'enseignement et de recherche français ou étrangers, des laboratoires publics ou privés. 


\section{Accepted Manuscript}

Vertical and meridional distribution of ethane, acetylene and propane in Saturn's stratosphere from CIRS/Cassini limb observations

Sandrine Guerlet, Thierry Fouchet, Bruno Bézard, Amy A. Simon-Miller, F. Michael Flasar

PII:

S0019-1035(09)00166-3

DOI:

10.1016/j.icarus.2009.04.002

Reference:

YICAR 8996

To appear in:

Icarus

Received Date: $\quad 18$ December 2008

Revised Date: $\quad 3$ April 2009

Accepted Date: $\quad 13$ April 2009

Please cite this article as: Guerlet, S., Fouchet, T., Bézard, B., Simon-Miller, A.A., Flasar, F.M., Vertical and meridional distribution of ethane, acetylene and propane in Saturn's stratosphere from CIRS/Cassini limb observations, Icarus (2009), doi: 10.1016/j.icarus.2009.04.002

This is a PDF file of an unedited manuscript that has been accepted for publication. As a service to our customers we are providing this early version of the manuscript. The manuscript will undergo copyediting, typesetting, and review of the resulting proof before it is published in its final form. Please note that during the production process errors may be discovered which could affect the content, and all legal disclaimers that apply to the journal pertain. 


\title{
Vertical and meridional distribution of ethane, acetylene and propane in Saturn's stratosphere from CIRS/Cassini limb observations.
}

Sandrine Guerlet*,a, Thierry Fouchet ${ }^{\mathrm{a}}$, Bruno Bézard ${ }^{\mathrm{a}}$, Amy A. Simon-Miller ${ }^{\mathrm{b}}$, F. Michael Flasar ${ }^{\mathrm{b}}$

${ }^{a}$ LESIA - Observatoire de Paris, 92195 Meudon, France

${ }^{b}$ NASA/Goddard Space Flight Center, Code 693, Greenbelt, MD 207r1, USA

\begin{abstract}
Measuring the spatial distribution of chemical compounds in Saturn's stratosphere is critical to better understand the planet's photochemistry and dynamics. Here we present an analysis of infrared spectra in the range 600-1400 $\mathrm{cm}^{-1}$ acquired in limb geometry by the Cassini spacecraft between March 2005 and January 2008. We first determine the vertical temperature profiles from 3 to $0.01 \mathrm{hPa}$, at latitudes ranging from $70^{\circ} \mathrm{N}$ to $80^{\circ} \mathrm{S}$. We infer a similar meridional temperature gradient at $1-2 \mathrm{hPa}$ as in recent previous studies (Fletcher et al., 2007; Howett et al., 2007). We then retrieve the vertical profiles of $\mathrm{C}_{2} \mathrm{H}_{6}$ and $\mathrm{C}_{2} \mathrm{H}_{2}$ from 3 to $0.01 \mathrm{hPa}$ and of $\mathrm{C}_{3} \mathrm{H}_{8}$ around $1 \mathrm{hPa}$. At $1 \mathrm{hPa}$, the meridional variation of $\mathrm{C}_{2} \mathrm{H}_{2}$ is found to follow the yearly averaged solar insolation, except for a strong equatorial mole fraction of $8 \times 10^{-7}$, nearly two times higher than expected. This enhancement in abundance can be explained by the descent of hydrocarbon-rich air, with a vertical wind
\end{abstract}

Email address: Sandrine.Guerlet@obspm.fr (Sandrine Guerlet) 
speed at the equator of $0.25 \pm 0.1 \mathrm{~mm} / \mathrm{s}$ at $1 \mathrm{hPa}$ and $0.4 \pm 0.15 \mathrm{~mm} / \mathrm{s}$ at $0.1 \mathrm{hPa}$. The ethane distribution is relatively uniform at $1 \mathrm{hPa}$, with only a moderate $25 \%$ increase from $35^{\circ} \mathrm{S}$ to $80^{\circ} \mathrm{S}$. Propane is found to increase from north to south by a factor of 1.9, suggesting that its lifetime may be shorter than Saturn's year at $1 \mathrm{hPa}$. At high altitudes ( $1 \mathrm{~Pa}), \mathrm{C}_{2} \mathrm{H}_{2}$ and $\mathrm{C}_{2} \mathrm{H}_{6}$ abundances depart significantly from the photochemical model predictions of Moses and Greathouse (2005), except at high southern latitudes (62, 70 and $80^{\circ} \mathrm{S}$ ) and near the equator. The observed abundances are found strongly depleted in the $20-40^{\circ} \mathrm{S}$ region and enhanced in the $20-30^{\circ} \mathrm{N}$ region, the latter coinciding with the ring's shadow. We favor a dynamical explanation for these anomalies.

Key words: Saturn, Infrared observations, Atmospheres, Composition

\section{Introduction}

The stratosphere of Saturn harbors a rich photochemistry initiated by the photolysis of methane $\left(\mathrm{CH}_{4}\right)$ by solar ultraviolet light at high altitudes, just below the homopause level, leading to the formation of many hydrocarbons. These by-products are then transported downwards and reform methane in high-pressure regions. As Saturn undergoes its 29.5 earth year seasonal cycle, the incoming UV flux on the planet varies with latitude and season, modulating the hydrocarbon production and destruction rates. In addition, the meridional circulation in the stratosphere of Saturn, still poorly known, could strongly impact the global distribution of hydrocarbons. Their variations with latitude and altitude are thus governed by a chain of complex coupled chemical and dynamical mechanisms. 
Among the numerous by-products of methane, the two most abundant and stable two-carbon molecules are ethane $\left(\mathrm{C}_{2} \mathrm{H}_{6}\right)$ and acetylene $\left(\mathrm{C}_{2} \mathrm{H}_{2}\right)$. Ethane was the first to be detected in Saturn's stratosphere from its $\nu_{9}$ emission band at $12 \mu \mathrm{m}$ by Gillett and Forrest (1974), shortly after confirmed by Tokunaga et al. (1975). Acetylene was detected a few years later by Moos and Clarke (1979) through an absorption band at $1750 \AA$ using the International Ultraviolet Explorer (IUE). Since then, several disk-averaged determinations of the abundance of $\mathrm{C}_{2} \mathrm{H}_{6}$ and $\mathrm{C}_{2} \mathrm{H}_{2}$ have been performed, for instance: from the IUE (Winkelstein et al., 1983), from the Infrared Space Observatory (ISO) (de Graauw et al. (1997) and Moses et al. (2000a)), or using the spectrometer Celeste on the McMath-Pierce telescope (Sada et al., 2005) (see Table 1. in Howett et al. (2007) for a summary of recent measurements). In addition, the limited sensitivity achieved by the Voyager spacecraft restricted the determination of these molecules to a single latitudinal band centered at $35^{\circ} \mathrm{N}$, using the Infrared Spectrometer (IRIS) (Courtin et al. (1984), re-analyzed by Sada et al. (2005)). These techniques provided limited vertical information on the stratosphere. They allowed the retrieval of the temperature and/or the mixing ratio of a molecule at typically one or two pressure levels between 2 and $0.1 \mathrm{hPa}$.

One-dimensional photochemical models developed by Atreya and Romani (1985), Moses et al. (2000a) and Ollivier et al. (2000b) have been successful in reproducing the observed $\mathrm{C}_{2} \mathrm{H}_{6}$ and $\mathrm{C}_{2} \mathrm{H}_{2}$ planetary-averaged abundances. These models yield the vertical profiles of dozens of hydrocarbons, given their calculated production and destruction rates as well as vertical eddy diffusion profile. 
Recent spatially resolved observations at several latitudes have revealed part of Saturn's hydrocarbon meridional distribution (Ollivier et al. (2000a), Prangé et al. (2006), Howett et al. (2007) and Greathouse et al. (2005a)). In particular, Howett et al. (2007) and Greathouse et al. (2005a) have determined ethane (at 1 and $2 \mathrm{hPa}$ ) and acetylene (at 0.1, 1 and $2 \mathrm{hPa}$ ) abundances in the summer hemisphere, that is the southern hemisphere at the time of observations. In both studies, acetylene is found to slightly decrease from the equator towards the south pole, whereas ethane at $2 \mathrm{hPa}$ is found to increase from the equator to the south pole, by a factor of 2.5 by Howett et al., and of 1.8 by Greathouse et al.. Propane $\left(\mathrm{C}_{3} \mathrm{H}_{8}\right)$, the most abundant of the three-carbon species, has first been detected by Greathouse et al. (2006) from measurements at the NASA/Infrared Telescope Facility (IRTF). They have determined propane mole fractions at $5 \mathrm{hPa}$ of $2.7 \times 10^{-8}$ and $2.5 \times 10^{-8}$ at respectively $20^{\circ} \mathrm{S}$ and $80^{\circ} \mathrm{S}$.

Moses and Greathouse (2005) have used one-dimensional photochemical models that additionally include seasonal and meridional variations of the solar flux to predict the hydrocarbon vertical but also meridional distribution with season (in the lack of meridional circulation). One prediction of their model is that a molecule with a lifetime shorter than a saturnian season (7.5 Earth years) should have its meridional distribution controlled by the current insolation, whereas the distribution of longer lifetime species should follow the yearly-averaged insolation, e.g., decreasing from the equator towards both poles. Vertical diffusion plays an important role, as it can dominate species distributions at high altitudes and can introduce phase lags at lower altitudes.

At the pressure levels probed by Howett et al. (2007), Greathouse et al. 
(2005a) and Greathouse et al. (2006), the three molecules considered have long chemical lifetimes $\left(\sim 700\right.$ years for $\mathrm{C}_{2} \mathrm{H}_{6}$ and $\sim 100$ years for $\mathrm{C}_{2} \mathrm{H}_{2}$ at $2 \mathrm{hPa} ; \sim 600$ years for $\mathrm{C}_{3} \mathrm{H}_{8}$ at $5 \mathrm{hPa}$ ). Their abundances are thus expected to decrease towards the south pole at the time of observations. The aforementioned authors interpret the observed ethane enhancement towards the pole at 1 and $2 \mathrm{hPa}$ as well as the constant propane abundance at 5 $\mathrm{hPa}$ between $20^{\circ} \mathrm{S}$ and $80^{\circ} \mathrm{S}$ as the consequences of a meridional circulation from the equator to the south pole. The associated dynamical timescales are inferred to lie:

- Between the $\mathrm{C}_{2} \mathrm{H}_{6}$ and $\mathrm{C}_{2} \mathrm{H}_{2}$ chemical lifetimes at 1-2 hPa, as the $\mathrm{C}_{2} \mathrm{H}_{2}$ distribution mimics the yearly-averaged insolation at these pressure levels (meaning that $\mathrm{C}_{2} \mathrm{H}_{2}$ is more efficiently photochemically destroyed than dynamically transported) (Howett et al., 2007; Greathouse et al., 2005a) ;

- Between the $\mathrm{C}_{3} \mathrm{H}_{8}$ and $\mathrm{C}_{2} \mathrm{H}_{2}$ lifetimes at $5 \mathrm{hPa}$ (Greathouse et al., 2006), for similar reasons.

However, Moses et al. (2007) recently pointed out that ethane and acetylene are chemically coupled via the photolysis of $\mathrm{C}_{2} \mathrm{H}_{6}$. Hence, the transport of $\mathrm{C}_{2} \mathrm{H}_{6}$ should also lead to an enhancement of $\mathrm{C}_{2} \mathrm{H}_{2}$ towards the south pole, in contrast to the observed behavior.

Here we present new results about the vertical and meridional distribution of temperature as well as ethane, acetylene and propane abundances in the range $70^{\circ} \mathrm{N}$ to $80^{\circ} \mathrm{S}$. Our data analysis is complementary to previous observations and brings new and precious information at high altitudes, with a high 
vertical resolution as well as an extended latitudinal coverage, in particular in the winter hemisphere. We analyze spectra acquired by the Composite Infrared Spectrometer (CIRS) on board Cassini in limb-viewing geometry, which allow us to probe the atmosphere not only around the 1-and 2-hPa pressure levels, but also up to $10^{-3} \mathrm{hPa}$. We retrieve the vertical profiles of both the temperature and the volume mixing ratio of hydrocarbons at several latitudes. The temperature structure as well as the ethane abundance crosssection between $45^{\circ} \mathrm{N}$ and $45^{\circ} \mathrm{S}$ are discussed in Fouchet et al. (2008). As the various hydrocarbons have different lifetimes that vary with altitude, simultaneous vertical and meridional information on these three molecules can provide new constraints on the photochemistry and trace dynamical phenomena. In section 2, we present the characteristics of the instrument and the data we use. Details about our model and the retrieval algorithm are developed in section 3. In section 4, the results are described and compared to previous measurements. Eventually, we compare our derived meridional distributions at several pressure levels to global predictions from photochemical models and discuss the possible implications in section 5 .

\section{Cassini/CIRS limb observations}

\subsection{The CIRS instrument}

Since its first orbit around Saturn in July 2004, the Cassini spacecraft, carrying twelve scientific instruments, has completed its 4-year nominal mission and is currently performing a 2-year extended mission. In this study, we focus on data acquired between March 2005 and January 2008 by the CIRS instrument. This infrared Fourier transform spectrometer comprises three 
focal planes called FP1, FP3 and FP4 that cover, respectively, the spectral ranges $10-600 \mathrm{~cm}^{-1}(17 \mu \mathrm{m}-1 \mathrm{~mm}), 600-1100 \mathrm{~cm}^{-1}(9-17 \mu \mathrm{m})$ and $1100-1400 \mathrm{~cm}^{-1}(7-9 \mu \mathrm{m})$. The spectral resolution can be set from 0.5 to $15.5 \mathrm{~cm}^{-1}$. As the hydrocarbon emissions of interest for this study lie in the mid-infrared region, we only make use of FP3 and 4. These focal planes consist of two parallel linear arrays of ten $\mathrm{HgCdTe}$ square detectors, each detector having a $0.27 \times 0.27$-mrad individual field of view (IFOV). A detailed overview of the CIRS instrument and its scientific objectives can be found in Kunde et al. (1996) and Flasar et al. (2004).

\subsection{Limb data}

To perform this work, we only select spectra acquired in limb-viewing geometry, where the parallel arrays of FP3 and FP4 are set approximately perpendicular to the limb of the planet (see Fig. A in supplementary material for an illustration of the pointing geometry). In this configuration, the lines of sight of the $2 \times 10$ detectors have equally-spaced tangent heights projected on Saturn. The main advantage of limb observations is that the pathlength along the line of sight is greater than compared to nadir sounding, increasing the opacity. As a result, it increases the sensitivity to minor species and allows us to probe lower pressure levels. Typically, as long as the corresponding path is optically thin, the thermal emission received by a CIRS detector mostly comes from an atmospheric layer centered at the tangent height of the line of sight (see the functional derivatives in section 3.2). In addition, the angular resolution of 0.27 -mrad per detector results in a vertical resolution of 50 to 100 kilometers on Saturn (depending on the spacecraft distance to the planet), which corresponds to about one to two scale heights. The horizontal 
resolution is about $0.5^{\circ}$ of latitude and $4-8^{\circ}$ of longitude on the planet.

Table 1 summarizes the characteristics of each dataset analyzed in this study: acquisition date, planetographic latitude and spectral resolution (15.5 $\mathrm{cm}^{-1}$ for most of them). The span of time from March 2005 to January 2008 corresponds to solar longitudes from $L_{s}=300^{\circ}$ to $L_{s}=340^{\circ}$, meaning that it was mid-summer in the southern hemisphere of Saturn during these observations (solstice occurred in December 2002 and equinox will take place in August 2009). The latitudinal coverage ranges from $80^{\circ} \mathrm{S}$ to $70^{\circ} \mathrm{N}$, with a particularly good coverage of the $45^{\circ} \mathrm{S}-45^{\circ} \mathrm{N}$ region, where data were acquired every $5^{\circ}$ and most latitudes have been sampled two or three times at different dates. Each limb acquisition actually consists of two observations overlapping in altitude via a linear offset of the arrays along their long axis, so that a sufficient range in altitude is probed (Fig. A). For each observation, we coadd the individual spectra recorded by each detector in order to increase the signal-to-noise ratio. For a $15.5 \mathrm{~cm}^{-1}$ resolution acquisition, this represents about 35 to 50 individual spectra per detector and a total integration time of 350 to 500 seconds. Due to the viewing geometry, the individual spectra have different longitudes, but we make the hypothesis that zonal variations in temperature or abundance are negligible. Thereafter, we will only consider quantities averaged over a detector field of view and study their variations with latitude.

[Table 1 about here.]

Examples of spectra acquired at $20^{\circ} \mathrm{S}$ corresponding to the spectral ranges of FP3 and FP4 are shown in Fig. 1, for several detectors and thus different 
tangent heights. Throughout the text and figures, all quoted tangent heights are relative to the 1-bar $\left(10^{5} \mathrm{~Pa}\right)$ pressure level. Despite the limited spectral resolution $\left(15.5 \mathrm{~cm}^{-1}\right)$ and the low temperatures of the stratosphere (typically $140 \mathrm{~K}$ at $1 \mathrm{hPa}$ ), the signatures of the major hydrocarbons are clearly seen through the $\nu_{4}$ emission band of methane (centered at $1304 \mathrm{~cm}^{-1}$ ) in FP4, the $\nu_{9}$ emission band of ethane (centered at $822 \mathrm{~cm}^{-1}$ ) and the $\nu_{5}$ emission band of acetylene (centered at $730 \mathrm{~cm}^{-1}$ ) in FP3. The propane $\nu_{26}$ emission band at $748 \mathrm{~cm}^{-1}$, situated in the wing of acetylene $\nu_{5}$ band, does not appear as an individual band at the spectral resolution of $15.5 \mathrm{~cm}^{-1}$, but still contributes to the total radiance in this spectral region. The large continuum emission observed at wavenumbers shortward of $660 \mathrm{~cm}^{-1}$ is due to the short-lifetime transition induced by collisions between $\mathrm{H}_{2}$ and other molecules (mostly itself, He and $\mathrm{CH}_{4}$ ). Emission from the $\nu_{8}$ band of diacetylene $\left(\mathrm{C}_{4} \mathrm{H}_{2}\right)$ at $628 \mathrm{~cm}^{-1}$ and from the $\nu_{9}$ band of methylacetylene $\left(\mathrm{C}_{3} \mathrm{H}_{4}\right)$ at $633 \mathrm{~cm}^{-1}$ are seen in the $620-640 \mathrm{~cm}^{-1}$ region, but cannot be disentangled at a resolution of $15.5 \mathrm{~cm}^{-1}$.

[Figure 1 about here.]

At first glance, we notice that the signal increases with decreasing altitude, as the gas density and atmospheric opacity become larger. However, when the opacity along the path becomes larger than one, the thermal emission mostly comes from an atmospheric level higher than the corresponding tangent height and the signal saturates, which defines our lower sensitivity level in altitude. For example, we can see in Fig. 1(b) that the Q-branch of methane at $1304 \mathrm{~cm}^{-1}$ saturates at pressures between 0.3 and $1.8 \mathrm{hPa}$, 
whereas the $\mathrm{P}$ and $\mathrm{R}$-branch radiances continue to increase with increasing pressure. This is due to the larger absorption cross-section of the Q-branch with respect to the $\mathrm{P}$ and R-branches. Typically, saturation for hydrocarbon emission bands occurs between 1 and $5 \mathrm{hPa}$. The highest altitude level probed depends on the atmospheric conditions (temperature, abundances) and on the quality of the observation (pointing, integration time). For most data, a satisfactory signal-to-noise ratio is obtained up to a few tenths of Pa.

Pointing errors of up to tenths of a milliradian are expected and can alter the tangent heights by an excess of $\sim 50 \mathrm{~km}$ (a scale height). In addition, the raw altitudes of the tangent heights are calculated given the pointing geometry and using the 1-bar radius defined by the NAIF reference ellipsoid, which is a poor approximation of the real planetary shape. As the tangent heights are crucial parameters that can have strong impacts on the temperature and abundance retrievals, we have to correct for this error (see section 3.2). We emphasize that the tangent heights and altitudes displayed in all the figures are the corrected altitudes.

For each latitude probed, we thus end up with a set of spectra acquired at different pressure levels, each one representative of the local thermal and chemical conditions of the atmosphere, with tangent heights altogether spanning the whole stratosphere from $\sim 10 \mathrm{hPa}$ to $\sim 10^{-3} \mathrm{hPa}$, with a vertical resolution of about one scale height. This extensive piece of information allows us to retrieve the vertical profiles of the temperature and of the abundance of the main hydrocarbons. 


\section{Data analysis}

\subsection{Forward radiative transfer model}

We have built a line-by-line radiative transfer model adapted to spherical geometry in order to compute synthetic spectra, given a temperature vertical profile, abundance profiles and the viewing geometry. Our model atmosphere consists of 360 layers equally spaced in terms of $\log$ (pressure), at pressure levels ranging from $10^{6} \mathrm{~Pa}$ to $10^{-3} \mathrm{~Pa}$. The opacity of each layer is calculated from the absorption coefficients and vertical abundance profiles of the following gaseous compounds: $\mathrm{CH}_{4}, \mathrm{CH}_{3} \mathrm{D}, \mathrm{C}_{2} \mathrm{H}_{6}, \mathrm{C}_{2} \mathrm{H}_{2}, \mathrm{C}_{3} \mathrm{H}_{4}, \mathrm{C}_{3} \mathrm{H}_{8}$ and $\mathrm{C}_{4} \mathrm{H}_{2}$. Absorption coefficients are computed at a spectral resolution of $10^{-3}$ $\mathrm{cm}^{-1}$ given the spectroscopic line parameters of the GEISA 2003 database (Jacquinet-Husson et al., 2005) for $\mathrm{CH}_{4}, \mathrm{CH}_{3} \mathrm{D}, \mathrm{C}_{2} \mathrm{H}_{2}, \mathrm{C}_{3} \mathrm{H}_{8}$ and $\mathrm{C}_{3} \mathrm{H}_{4}$. It is noted that the GEISA 2003 linelist only includes the fundamental (cold) band of propane but its intensity has been set to that measured at room temperature by Giver et al. (1984), which includes contribution from both cold and hot bands. To account for this problem, we do not include, for consistency, the vibrational part of the partition function when calculating the temperature dependence of the line strengths. Ethane line parameters come from a recent database computed by Vander Auwera et al. (2007). $\mathrm{C}_{4} \mathrm{H}_{2}$ line data are computed using the band intensities of Koops (1984) and molecular constants of Arié and Johns (1992). Opacity induced by collisions between $\mathrm{H}_{2}-\mathrm{H}_{2}, \mathrm{H}_{2}-\mathrm{He}$ and $\mathrm{H}_{2}-\mathrm{CH}_{4}$ is also included following the method of Borysow et al. (1985, 1988) and Borysow and Frommhold (1986).

We use a constant hydrogen and helium mole fraction of respectively 0.86 and 0.1355 as obtained by Conrath and Gautier (2000) from Voyager 
measurements. The methane vertical profile is set independently of latitude and results from a volume mixing ratio of $4.5 \times 10^{-3}$ under the $400 \mathrm{hPa}$ pressure level (as retrieved by Flasar et al. (2005) using CIRS far-infrared data), followed by a slight decrease with altitude resulting from molecular diffusive separation above the homopause (Moses et al., 2000a). The D/H ratio in methane is set to $1.7 \times 10^{-5}$ as determined by Lellouch et al. (2001) from ISO observations. No haze opacity is included since it has been shown to degrade the quality of the fits in the FP3 and FP4 wavenumber ranges for nadir data (Howett et al., 2007). Limb spectra could possibly be sensitive to an upper stratospheric haze layer, but this has not been observed yet.

The pressure-altitude grid is calculated at each latitude by solving the hydrostatic equilibrium equation, for a given temperature profile. We take into account the latitudinal-dependent gravitational field due to the rapid rotation and oblate geometry of Saturn (Lindal et al., 1985, appendix). We do not take into account the influence of the zonal winds on the gravity field because no comprehensive meridional information on the zonal winds exists regarding the stratosphere.

In limb geometry, the incoming radiation varies significantly across the IFOV. To account for this effect, the radiance and contribution functions are calculated along nine lines of sight per detector, equally spaced in the vertical direction. These quantities are then averaged and the resulting synthetic spectra are eventually convolved with the instrumental line spread function at the appropriate resolution. 


\subsection{Retrieval of the temperature and tangent altitudes}

Starting from an a priori temperature profile and a priori values of the tangent heights, synthetic spectra are computed. Their comparison with observed spectra, using an inversion algorithm, leads to the retrieval of the actual temperature profile and tangent heights consistent with the best fit of the data. We shall first introduce the information content of the data.

\subsubsection{Information content of the data and a priori information}

To retrieve the temperature, we use the radiance of the $\nu_{4}$ methane band in the $1200-1350 \mathrm{~cm}^{-1}$ region and the collision-induced emission in the 590 - $660 \mathrm{~cm}^{-1}$ region, excluding the $620-640 \mathrm{~cm}^{-1}$ interval where the coupled emission of $\mathrm{C}_{3} \mathrm{H}_{4}$ and $\mathrm{C}_{4} \mathrm{H}_{2}$ is prominent. The information content of the data is given by the functional derivatives $\partial I_{i} / \partial T_{j}$, where $I_{i}$ is the radiance at a wavenumber $\nu_{i}$ and $T_{j}$ is the temperature at a pressure level $p_{j}$. These $(i, j)$ elements of the $m \times n$ kernels ( $m$ wavenumbers, $n$ pressure levels) represent the sensitivity of the radiance at a given wavenumber to an atmospheric parameter (here, the temperature) at a given pressure. For instance, we plot in Fig. 2 the functional derivative $\partial I_{i} / \partial T_{j}$ at wavenumbers $\nu_{i}=605$ $\mathrm{cm}^{-1}, \nu_{i}=1250 \mathrm{~cm}^{-1}$ and $\nu_{i}=1305 \mathrm{~cm}^{-1}$ as a function of pressure for a set of eight different tangent altitudes. It shows that the incoming radiation has a maximum sensitivity to the temperature at a given altitude (close to the tangent altitude) that depends on the absorption cross-section at this wavenumber. In this example, by combining the different wavenumbers and tangent altitudes, we have access to information on the temperature at best in the range $20 \mathrm{hPa}$ to $0.3-0.4 \mathrm{~Pa}$. The $\mathrm{CH}_{4} \nu_{4}$ typically probes pressure levels between $3 \mathrm{hPa}$ and a few tenths of $\mathrm{Pa}$, and the collision-induced continuum 
between 20 and $1 \mathrm{hPa}$.

[Figure 2 about here.]

Our a priori temperature profile is based on the profile inferred by Lindal et al. (1985) from Voyager radio occultation. We also use a 'warmer' version of this profile as it is sometimes closer to the actual atmospheric conditions in the southern hemisphere. The latter is characterized by temperatures $20 \mathrm{~K}$ warmer than the former above the 1-hPa pressure level. Both profiles are shown in Fig. 3(a).

Our a priori tangent heights consist of those determined by the navigation. As mentioned in section 2, they suffer from pointing errors and their calculation depends on the approximately known level of the $10^{5}$-Pa radius. Moreover, the temperature profile is unknown between $10^{5} \mathrm{~Pa}$ and $20 \mathrm{hPa}$, leading in errors in the integration of the hydrostatic equation. In order to determine the actual tangent altitudes/pressure levels of the observations, we use information contained in the level of saturation of both the methane (see Fig. 1) and the collision-induced continuum emission, which are precisely constrained by the theory of radiative transfer.

Finally, our reference hydrocarbon abundance profiles are taken from the photochemical models of Moses et al. (2000a) and Moses and Greathouse (2005), which were constrained by ISO observations. These profiles are shown in Fig. 3(b) for $\mathrm{CH}_{4}, \mathrm{C}_{2} \mathrm{H}_{6}, \mathrm{C}_{2} \mathrm{H}_{2}, \mathrm{C}_{3} \mathrm{H}_{4}, \mathrm{C}_{3} \mathrm{H}_{8}$ and $\mathrm{C}_{4} \mathrm{H}_{2}$.

[Figure 3 about here.] 


\subsubsection{Retrieval algorithm}

The retrieval of temperature (or abundance) vertical profiles is a wellknown ill-posed problem. To address this problem, we adapted a retrieval algorithm detailed in Conrath et al. (1998). The guideline is that the radiance can be linearized as

$$
\Delta I_{i}=\sum_{j=1}^{n} \frac{\partial I_{i}}{\partial T_{j}} \Delta T_{j}+\frac{\partial I_{i}}{\partial z} \Delta z
$$

in the case where the radiance $I$ depends on the temperature profile $T$ and on the tangent height $z . \Delta I_{i}$ is the difference between the observed and synthetic radiance at a wavenumber $\nu_{i} ; \Delta T_{j}$ and $\Delta z$ are the differences between the actual values of the parameters and their a priori values used to calculate the synthetic spectra. The temperature is represented by a vector (index $j$ refers to the pressure level $p_{j}$ ) whereas $\Delta z$ is a scalar, a shift to be applied to all spectra. This equation can be transformed in a vectorial form: $\Delta \mathbf{I}=K \boldsymbol{\Delta} \mathbf{T}+K^{\prime} \Delta z$ where $K$ and $K^{\prime}$ are the functional derivative matrices with respect to the corresponding parameters $(T, z)$. The formal solution, using appropriate constraints, can be written:

$$
\left\{\begin{array}{lll}
\Delta \mathbf{T}=U \Delta \mathbf{I} & \text { where } & U=\alpha S K^{T}\left(\alpha K S K^{T}+\beta K^{\prime} K^{\prime T}+E^{2}\right)^{-1} \\
\Delta z=\mathbf{V} \cdot \Delta \mathbf{I} & \text { where } & V=\beta K^{\prime T}\left(\alpha K S K^{T}+\beta K^{\prime} K^{\prime T}+E^{2}\right)^{-1}
\end{array}\right.
$$

In these expressions, $S$ is a correlation matrix used to smooth the vertical profile via a correlation length $L$ (in scale heights units). A larger value of $L$ will force a smoother vertical profile. The matrix $E$ is diagonal and contains the measurement error. The factors $\alpha$ and $\beta$ assign a relative weight to the data with respect to the a priori values. These parameters are determined 
through numerical experiment. We find that the best values of the parameters correspond to similar traces of $E^{2}, \alpha K S K^{T}$ and $\beta K^{\prime} K^{\prime T}$ matrices.

We proceed by successive iterations: from a priori values $\left(\mathbf{T}_{\mathbf{0}}, z_{0}\right)$, the inversion process is run simultaneously on a set of spectra acquired by the range of detectors. Resolution of Eq. 2 yields retrieved values such as $\mathbf{T}_{\mathbf{0}}+$ $\Delta \mathbf{T}, z_{0}+\Delta z$, which define updated values to be given as inputs in the next run of the forward model. New synthetic spectra are computed, as well as the corresponding functional derivatives. An updated pressure-altitude grid is also calculated at each step, as it depends on the temperature profile through the hydrostatic equation. At each iteration, we estimate the quality of the fit by calculating the quantity $\chi^{2}=\sum \frac{\Delta I_{i}}{E_{i}}{ }^{2}$ and our convergence criterion is achieved when the change in $\chi^{2}$ from an iteration to another is less than $1 \%$ (our dataset has about 100 independent points).

\subsubsection{Test of the method, example and error analysis}

The robustness of the method is tested using the following protocol:

- We build an arbitrary temperature profile (hereafter referred to as fictitious profile) and calculate synthetic spectra for a set of tangent heights

- We add noise randomly and we shift the tangent heights by $50 \mathrm{~km}$ downwards or upwards to simulate pointing errors ;

- We run our retrieval algorithm starting from the two different a priori temperature profiles and using $\mathrm{L}=1.5$.

An example of fits to the synthetic spectra in the region of the $\nu_{4}$ methane band and of the $\mathrm{H}_{2}$-He continuum is displayed in Fig. 4. The correspond- 
ing retrieved temperature profiles are compared to the fictitious profile in Fig. 5(a). Starting from two different a priori temperature profiles provides a way to check our information content and retrieval method: in the altitude range where the functional derivatives are maximum $\left(10-10^{-2} \mathrm{hPa}\right)$, the two retrieved profiles coincide within error bars, regardless of the a priori temperature profile. Similarly, the two altitude shifts retrieved simultaneously by our method lie close (less than $4 \mathrm{~km}$ away) to our initial pointing error of $50 \mathrm{~km}$.

[Figure 4 about here.]

[Figure 5 about here.]

We can thus apply our method on each limb dataset. For each latitude, we run several retrievals corresponding to different combinations of $L$ and $\alpha$. Among these different solutions, we keep the temperature profile that leads to the best fit of the data (the minimum $\chi^{2}$ ). If several satisfactory fits are obtained for various values of $L$, we keep the solution with the longer correlation length. A value of $L=1.5$ scale height is often found optimal. Typical retrieved altitude shifts lie between 0 and $80 \mathrm{~km}$. We notice that the highest altitude corrections are found at mid-latitudes. This result reinforces the hypothesis that the NAIF reference ellipsoid is not an appropriate approximation.

[Figure 6 about here.]

Examples of observed spectra at $30^{\circ} \mathrm{N}$, at several tangent altitudes, and best-fit synthetic spectra are displayed in Fig. 6. The corresponding retrieved 
temperature profile is plotted in Fig. 5(b). We also show in Fig. 6, for comparison, synthetic spectra calculated with a temperature profile set to the solution profile \pm its error envelop.

Error analysis

Several sources of uncertainty affect our retrievals. First, we take into account the error measurement $E$, which is a combination of the Noise Equivalent Spectral Radiance (NESR) in our sample of $p$ co-added spectra and of the number $d$ of deep space spectra used for calibration. Secondly, we include a smoothing error, which is an error linked to the limited spatial resolution. Indeed, the kernels consist of averages over the field of view, with a half-width of about one scale height, rather than punctual measures. The combination of the two leads to an error on the retrieved profile of the form: $\sigma_{T}=S-S K^{T}\left(K S K^{T}+E^{2}\right)^{-1} K S$ (Rodgers, 2000). As a result, the retrievals have small errors around $1 \mathrm{hPa}$ (typically $\pm 0.5 \mathrm{~K}$ ) and larger errors above $0.1 \mathrm{hPa}( \pm 1 \mathrm{~K}$ at $0.01 \mathrm{hPa})$.

Another source of error comes from the methane abundance, which is known $\pm 20 \%$. To calculate the error in temperature induced by this methane uncertainty, we run our model using two extreme methane profiles with an abundance that departs from the a priori methane abundance by $\pm 20 \%$. The differences between the corresponding retrieved temperature profiles and the former solution profile are used to define upper and lower error bars.

According to a re-analysis of Voyager UVS stellar occultations (Moses and Vervack, 2006), not only is the methane abundance unknown, but the homopause level is also likely to vary with latitude and/or time. We calculated synthetic methane spectra at different tangent heights for two $\mathrm{CH}_{4}$ homopause levels, 
one that corresponds to the nominal model of Moses et al. (2000a) and one that is a decade of pressure downwards. The differences in the methane radiance between the two models are of the order of magnitude of the noise level (see Fig. B in supp. material), resulting in rather small uncertainties in the retrieved temperatures. In addition, we find that the resulting error in temperature is maximum between 0.5 and $0.1 \mathrm{hPa}$, although the change in methane abundance - when varying the homopause level - is the greatest at high altitudes.

The helium mole fraction also suffers from large uncertainties. In their study, Conrath and Gautier (2000) have found a value that lies between 0.11 and 0.16. However, a recent analysis combining CIRS observations and radio occultations (Flasar et al., 2008) suggests that the helium mole fraction could be down to 0.08. We proceeded in the same manner as for the methane error analysis, setting the helium mole fraction to extreme values of 0.08 and 0.16 . As can be expected, the error deduced on the temperature is the greatest below the 1-hPa level.

Eventually, we take into account the error in temperature due to the uncertainty in the altitude shift, which is typically of order $5 \mathrm{~km}$. Shifting synthetic spectra by $\pm 5 \mathrm{~km}$ and retrieving only the temperature leads to small errors, only significant from 5 to $1 \mathrm{hPa}$.

Table 2 summarizes the effects of all sources of uncertainty in the retrieved temperature and their dependence with pressure. Among these individual errors, we consider that the uncertainties on helium and methane mole fractions are part of systematic errors. When added quadratically, all the uncertainties lead to the error envelops in Fig. 5 of about $\pm 1.5 \mathrm{~K}$. 
[Table 2 about here.]

Note that at some latitudes, the $600-700 \mathrm{~cm}^{-1}$ region is not fitted satisfactorily for spectra around $1 \mathrm{hPa}$ (see Fig. 6(b)). It could be due to instrumental problems, like the heterogeneous detector spatial response. However, at this pressure level, methane spectra dominate the information content, so that an incorrect fit of the continuum at $1 \mathrm{hPa}$ has little influence on the retrieved temperature.

\subsection{Hydrocarbon retrievals}

In a second step, the retrieved temperature profile and altitude shift are set in the model and the volume mixing ratio profiles of hydrocarbons are retrieved from their molecular bands.

\subsubsection{Information content}

We first retrieve $\mathrm{C}_{2} \mathrm{H}_{6}$ volume mixing ratio profiles using the radiance in the spectral range $780-860 \mathrm{~cm}^{-1}$. Then, we retrieve $\mathrm{C}_{2} \mathrm{H}_{2}$ and $\mathrm{C}_{3} \mathrm{H}_{8}$ volume mixing ratio profiles using the radiance in the spectral range 700$760 \mathrm{~cm}^{-1}$ and assuming the previously retrieved ethane profile. Functional derivatives at $820 \mathrm{~cm}^{-1}, 730 \mathrm{~cm}^{-1}$ and $750 \mathrm{~cm}^{-1}$ are given in Fig. 7. They show that we are sensitive to $\mathrm{C}_{2} \mathrm{H}_{6}$ and $\mathrm{C}_{2} \mathrm{H}_{2}$ from typically $5 \mathrm{hPa}$ to $0.1-0.3$ $\mathrm{Pa}$ and that the radiance at $750 \mathrm{~cm}^{-1}$ provides information on the $\mathrm{C}_{3} \mathrm{H}_{8}$ abundance at about 2-3 pressure levels, centered at $\sim 1 \mathrm{hPa}$. Hydrocarbon a priori profiles come from the photochemical model of Moses et al. (2000a) as shown in Fig. 3(b).

[Figure 7 about here.] 


\subsubsection{Inversion algorithm}

The radiance in the spectral intervals $780-860 \mathrm{~cm}^{-1}$ and $700-760 \mathrm{~cm}^{-1}$ is assumed to depend on the abundance $q$ of either one or two molecules, respectively: $\mathrm{C}_{2} \mathrm{H}_{6}$ or $\mathrm{C}_{2} \mathrm{H}_{2}$ and $\mathrm{C}_{3} \mathrm{H}_{8}$. In the general case, taking two molecules into account noted by superscripts 1 and 2, the radiance can be linearized as:

$$
\Delta I_{i}=\sum_{j=1}^{n} \frac{\partial I_{i}}{\partial \ln \left(q_{j}^{1}\right)} \Delta \ln \left(q_{j}^{1}\right)+\sum_{j=1}^{n} \frac{\partial I_{i}}{\partial \ln \left(q_{j}^{2}\right)} \Delta \ln \left(q_{j}^{2}\right)
$$

This equation can be expressed in the following vectorial form: $\Delta \mathbf{I}=$ $M^{1} \Delta \ln \left(\mathbf{q}^{\mathbf{1}}\right)+M^{2} \boldsymbol{\Delta} \ln \left(\mathbf{q}^{\mathbf{2}}\right)$, where $M^{1}$ and $M^{2}$ are the functional derivatives matrices with respect to the logarithm of the mixing ratios of each molecule. The formal solution can therefore be written:

$$
\Delta \ln \left(\mathbf{q}^{\mathbf{i}}\right)=W^{i} \Delta \mathbf{I} \quad ; W^{i}=\gamma^{i} S M^{i T}\left(\gamma^{1} M^{1} S M^{1 T}+\gamma^{2} M^{2} S M^{2 T}+E^{2}\right)^{-1}
$$

where the factors $\gamma^{i}$ play roles similar to $\alpha, \beta$ defined in Eq. 2.

In the same manner as for the temperature, we start from a priori profiles $\mathbf{q}_{\mathbf{0}}^{\mathbf{i}}$. The resolution of Eq. 4 yields new abundance profiles $\mathbf{q}_{\mathbf{0}}^{\mathbf{i}}+\boldsymbol{\Delta} \ln \left(\mathbf{q}^{\mathbf{i}}\right)$ and we perform several iterations until the change in $\chi^{2}$ (defined in section 3.2.2) is less than $1 \%$.

\subsubsection{Test of the method, examples and error analysis}

As for the retrieval of the temperature and tangent heights, the robustness of the method is tested for the retrieval of hydrocarbons. We show that the model is able to retrieve hydrocarbon abundances starting from a priori 
profiles even an order of magnitude higher or lower than the fictitious profile. An example of fits to ethane spectra calculated from a fictitious profile is shown in Fig. 8(a). The retrieved abundance profiles, shown in Fig. 8(b) starting from two different a priori profiles, lie close to the fictitious profile. Similar examples of fits to the acetylene band calculated from fictitious profiles of both $\mathrm{C}_{2} \mathrm{H}_{2}$ and $\mathrm{C}_{3} \mathrm{H}_{8}$ are displayed in Fig. 9. We show that we are potentially sensitive to propane around $1 \mathrm{hPa}$, as the residuals of the fits that do not include the propane opacity are well above the 2- $\sigma$ level. The corresponding retrieved abundance profiles are compared to the fictitious profiles of $\mathrm{C}_{2} \mathrm{H}_{2}$ and $\mathrm{C}_{3} \mathrm{H}_{8}$ in Fig. 10 .

[Figure 8 about here.]

[Figure 9 about here.]

[Figure 10 about here.]

We can thus apply our method to observed spectra. Examples of fits to the observed ethane band at four tangent altitudes at $30^{\circ} \mathrm{N}$ are shown in Fig. C (supp. material). Examples of observed and calculated spectra in the range $700-760 \mathrm{~cm}^{-1}$, including propane or not, are shown in Fig. D (supp. material) along with the residual radiances. They show that propane is needed to ensure a correct fit of the observed $\mathrm{C}_{2} \mathrm{H}_{2}$ R-branch for spectra around $1 \mathrm{hPa}$. We thus retrieve simultaneously the two molecules. Ethane and acetylene vertical profiles obtained from the fit of these spectra, starting from different a priori profiles, are presented in Fig. E (supp. material). 
Another example and demonstration of the sensitivity to propane in the observed spectra is shown for higher resolution spectra in the supplementary material (Fig. F).

We perform a similar error analysis for hydrocarbons as for the temperature retrieval, except that in this case we have to take into account the propagation of the error in the temperature. We calculate two sets of error bars: one taking into account the temperature error due to all sources of uncertainty as listed in section 3.2.3 and one taking into account only the non-systematic sources of error on the temperature. The latter one leads to errors on abundances of about $20-30 \%$ at $1 \mathrm{hPa}$ and up to $50 \%$ at $10^{-2} \mathrm{hPa}$. Table 3 summarizes our estimation of the error on $\mathrm{C}_{2} \mathrm{H}_{6}, \mathrm{C}_{2} \mathrm{H}_{2}$ and $\mathrm{C}_{3} \mathrm{H}_{8}$ abundances at several pressure levels. Our region of maximum sensitivity to hydrocarbons is constrained by our sensitivity to the temperature. For example, in Fig. 7 we notice that at $30^{\circ} \mathrm{N}$ we are potentially sensitive to the abundance of $\mathrm{C}_{2} \mathrm{H}_{2}$ up to $10^{-3} \mathrm{hPa}$. However, as we only have information on temperature up to $3 \times 10^{-3} \mathrm{hPa}$ at this latitude, this level defines our actual upper limit in sensitivity for $\mathrm{C}_{2} \mathrm{H}_{2}$.

[Table 3 about here.]

\section{Results}

\subsection{Pressure-latitude temperature variations}

Our analysis provides a comprehensive temperature map in the range 3 $10^{-2} \mathrm{hPa}$ and from $80^{\circ} \mathrm{S}$ to $70^{\circ} \mathrm{N}$. At specific latitudes, our sensitivity extends up to $10^{-3} \mathrm{hPa}$ and/or down to $20 \mathrm{hPa}$. In Fig. 11 we present the meridional variation of the temperature at three pressure levels: $1,10^{-1}$ and $10^{-2} \mathrm{hPa}$. 
In addition, we overplot the results obtained at $1 \mathrm{hPa}$ by Fletcher et al. (2007, 2008) using nadir-viewing CIRS spectra.

The main feature of the derived meridional profile is a local equatorial maximum of the temperature at $1 \mathrm{hPa}$, followed by a local minimum at $10^{-1}$ hPa, characteristic of an equatorial stratospheric oscillation (Fouchet et al., 2008). Apart from the equatorial structure, we observe a global increase in temperature from $70^{\circ} \mathrm{N}$ to $80^{\circ} \mathrm{S}$ of $\sim 37 \mathrm{~K}$ at $1 \mathrm{hPa}$ and of $\sim 24 \mathrm{~K}$ at $10^{-1}$ hPa. The temperature at $10^{-2} \mathrm{hPa}$ exhibits several small-scale variations, meridional as well as possible temporal variations, especially in the range $20^{\circ} \mathrm{N}$ to $20^{\circ} \mathrm{S}$. It is thus more delicate to derive a global trend. For example, at $5^{\circ} \mathrm{S}$ and $15^{\circ} \mathrm{S}$, temperatures measured 1-year apart show a difference of 7 to $15 \mathrm{~K}$, much larger than the error bars. Also, temperatures inferred in December 2005 show strong differences $10^{\circ}$ apart. This points towards a wave activity whose amplitude increases with altitude (see discussion in section 5). As a consequence, the temperatures retrieved between $20^{\circ} \mathrm{N}$ and $20^{\circ} \mathrm{S}$ at $10^{-2}$ hPa may not be representative of the mean temperature. Outside this region, we note that the temperature is almost constant in the range $45^{\circ} \mathrm{N}$ to $25^{\circ} \mathrm{N}$ and equal to $152.0 \pm 0.6 \mathrm{~K}$ whereas in the range $25^{\circ} \mathrm{S}$ to $45^{\circ} \mathrm{S}$ it exhibits little variation with a mean temperature of $158 \pm 1 \mathrm{~K}$, suggesting a southern hemisphere slightly warmer than the northern one.

[Figure 11 about here.]

Greathouse et al. (2005b) reported evidence for a mesosphere on Saturn, from the observation of self-absorption cores on top of $\mathrm{CH}_{4}$ emission lines at $1245 \mathrm{~cm}^{-1}$, probing the region between 10 and $0.01 \mathrm{hPa}$. In contrast, our 
various temperature vertical profiles do not display a defined stratopause: the temperature clearly increases from 10 to $1 \mathrm{hPa}$ and is rather constant or slightly increasing from 1 to $10^{-2} \mathrm{hPa}$. The only counterexamples are found at 15 and $20^{\circ}$, where the temperature decreases between $10^{-1}$ and $10^{-2} \mathrm{hPa}$. This decrease does not correspond to a particularly cold region at $10^{-2} \mathrm{hPa}$, but rather corresponds to a particularly warm region at $10^{-1} \mathrm{hPa}$, encircling the cold equatorial region due to the equatorial oscillation. These exceptions are thus a local consequence of the equatorial oscillation but do not constitute a well defined mesosphere.

The temperatures retrieved here are in very good agreement with previous analyses of CIRS nadir observations. At 1 hPa, Fletcher et al. (2007, 2008) measured a north to south gradient similar to that we infer, although their retrieved temperatures display small differences from ours in the equatorial region (see Fig. 11). This is probably due to the strong temperature vertical oscillation in this region, which nadir observations are not able to probe at pressures $p<0.5 \mathrm{hPa}$. As a result, they underestimate the $1-\mathrm{hPa}$ temperature at the equator, and overestimate it in the tropics $\left(15^{\circ} \mathrm{N}\right.$ and $15^{\circ} \mathrm{S}$ ). Also using CIRS nadir data, Howett et al. (2007) measured a $9^{\circ} \mathrm{S}$ to $68^{\circ} \mathrm{S}$ gradient of $14 \mathrm{~K}$ at $2 \mathrm{hPa}$, in very good agreement with our $10^{\circ} \mathrm{S}$ to $70^{\circ} \mathrm{S}$ gradient of $13.8 \mathrm{~K}$ at the same pressure level.

\subsection{Hydrocarbon variations}

\subsubsection{Comparison to photochemical models.}

Our dataset provides information on $\mathrm{C}_{2} \mathrm{H}_{6}$ and $\mathrm{C}_{2} \mathrm{H}_{2}$ abundances at least in the range $3 \mathrm{hPa}$ to $10^{-2} \mathrm{hPa}$. We present in Figs. 12, 13 and 14 the meridional distribution of these two molecules at 1, 0.1 and $0.01 \mathrm{hPa}$. Because of 
the limited sensitivity to propane, we only present its meridional distribution at $1 \mathrm{hPa}$ in Fig. 12. At 1 and $0.01 \mathrm{hPa}$, we overplot the expected meridional distributions according to Moses and Greathouse (2005) photochemical model for a solar longitude of $320^{\circ}$, corresponding to early 2006 , close to the time of our observations. As we focus on meridional variations rather than absolute values, we have scaled their distributions to allow comparisons with our $1 \mathrm{hPa}$ distributions: the abundance values from Moses and Greathouse (2005) are divided by 1.7 for $\mathrm{C}_{2} \mathrm{H}_{2}$, multiplied by 1.8 for $\mathrm{C}_{3} \mathrm{H}_{8}$ and divided by 2 at $1 \mathrm{hPa}$ and by 1.5 at $0.01 \mathrm{hPa}$ for $\mathrm{C}_{2} \mathrm{H}_{6}$ (the use of two different scaling factors for $\mathrm{C}_{2} \mathrm{H}_{6}$ is justified in section 4.2.2).

[Figure 12 about here.]

In most cases, we note a good consistency (within error bars) between hydrocarbon mixing ratios retrieved from CIRS limb data acquired at the same latitude but at different dates. However, we notice strong variations of hydrocarbon abundances at high altitude (above $0.1 \mathrm{hPa}$ ), both meridional and temporal, especially in the range $20^{\circ} \mathrm{N}-20^{\circ} \mathrm{S}$ (see Fig. 14). They appear anti-correlated with the small-scale meridional and temporal variations of the temperature. For example, for latitudes and dates where we retrieved a high temperature $\left(15^{\circ} \mathrm{S}\right.$ and $5^{\circ} \mathrm{S}$ in February, 2006), we determined a low abundance of $\mathrm{C}_{2} \mathrm{H}_{6}$ and $\mathrm{C}_{2} \mathrm{H}_{2}$. We discuss the reality of these variations in section 5. Hereafter, we will only comment and discuss the meridional variations in latitudinal ranges where the abundances retrieved at different dates agree within error bars.

The ethane volume mixing ratio at $1 \mathrm{hPa}$ displays a smooth meridional distribution, with an almost constant value of $5.2 \times 10^{-6}$ in mid-latitudes re- 
gions $\left(10^{\circ}\right.$ to $40^{\circ}$, both hemispheres). We note a $\mathrm{C}_{2} \mathrm{H}_{6}$ maximum value at the equator $\left(7.4 \times 10^{-6}\right)$ and a minimum value at $70^{\circ} \mathrm{N}$ roughly half lower $\left(3.5 \times 10^{-6}\right)$. In the southern hemisphere, the slight increase in $\mathrm{C}_{2} \mathrm{H}_{6}$ from $5.2 \times 10^{-6}$ to $6.4 \times 10^{-6}$ is not significant, given the error bars. Acetylene abundances show a very different meridional behavior. The $\mathrm{C}_{2} \mathrm{H}_{2}$ distribution presents a sharp and narrow maximum centered at the equator. Its abundance is then more or less constant in the temperate latitudes, and decreases towards the poles with some asymmetry. We note a decrease of the $\mathrm{C}_{2} \mathrm{H}_{2}$ abundance by a factor of 1.7 from $5^{\circ} \mathrm{S}$ to $80^{\circ} \mathrm{S}$ and by a factor of 2.7 from $7^{\circ} \mathrm{N}$ to $70^{\circ} \mathrm{N}$.

The propane meridional distribution at $1 \mathrm{hPa}$ resembles neither the $\mathrm{C}_{2} \mathrm{H}_{6}$ nor the $\mathrm{C}_{2} \mathrm{H}_{2}$ distributions, exhibiting a global north-to-south increase (apart from a high abundance value at $\left.70^{\circ} \mathrm{N}\right)$. At mid-northern latitudes $\left(20-45^{\circ} \mathrm{N}\right)$, propane abundance is almost constant with a mean of $9 \times 10^{-8}$. At midsouthern latitudes $\left(20-45^{\circ} \mathrm{S}\right)$, it is also rather constant with an abundance $60 \%$ higher than at the equator: $1.45 \times 10^{-7}$. It then increases towards the south pole up to $2.4 \times 10^{-7}$ at $80^{\circ} \mathrm{S}$. It also features a local, narrow maximum at the equator.

In fact, at $1 \mathrm{hPa}$, the three species exhibit a global or local maximum value at the equator, coinciding with the region of greatest yearly-averaged insolation and greatest hydrocarbon production, thus apparently in agreement with photochemical models. However, the $\mathrm{C}_{2} \mathrm{H}_{2}$ maximum is more pronounced than for the other molecules and much stronger than expected: $\mathrm{C}_{2} \mathrm{H}_{2}$ increases by a factor of $2.7 \pm 0.4$ from $30^{\circ} \mathrm{S}$ to $0^{\circ}$ while the $\mathrm{C}_{2} \mathrm{H}_{6}$ abundance increases by a factor of $1.5 \pm 0.3$. The equatorial peak is also 
very narrow, while the yearly-average solar insolation varies smoothly with latitude. This points to a dynamical rather than chemical origin for this maximum, as will be discussed in section 5 .

[Figure 13 about here.]

While the meridional distributions of the various hydrocarbons exhibit very different trends at $1 \mathrm{hPa}$, they look similar for $\mathrm{C}_{2} \mathrm{H}_{6}$ and $\mathrm{C}_{2} \mathrm{H}_{2}$ at $0.1 \mathrm{hPa}$ (Fig. 13). At this pressure level, the photochemical model of Moses and Greathouse (2005) predicts that the two species have similar lifetimes. In addition, it also predicts that $\mathrm{C}_{2} \mathrm{H}_{6}$ and $\mathrm{C}_{2} \mathrm{H}_{2}$ are highly coupled chemically in this pressure region, with $\mathrm{C}_{2} \mathrm{H}_{6}$ photolysis controlling $\mathrm{C}_{2} \mathrm{H}_{2}$ production. Our measurements support these predictions since the two molecules display similar distributions. However, we note that the observed distributions exhibit more contrasted meridional variations at $0.1 \mathrm{hPa}$ than at $1 \mathrm{hPa}$, displaying: a decrease between $0^{\circ}$ and $30^{\circ} \mathrm{S}$; an increase from $30^{\circ} \mathrm{S}$ towards the south pole and a global decrease from the equator towards the north pole, except for an anomalously high abundance in the $20^{\circ} \mathrm{N}-35^{\circ} \mathrm{N}$ region. This local, narrow enrichment is not explained by the current photochemical model of Moses and Greathouse (2005). This feature may rather originate from a dynamical mechanism, as discussed in section 5 .

[Figure 14 about here.]

At $0.01 \mathrm{hPa}$, as mentioned above, the retrieved abundances in the region $20^{\circ} \mathrm{S}$ to $20^{\circ} \mathrm{N}$ are not straightforward to interpret and will be discussed in section 5. We represent by the gray shading in Fig. 14 the regions where our 
confidence level in the abundance retrieval is the greatest. In spite of large error bars at this pressure level, it appears clearly that a larger abundance is found in the $20^{\circ} \mathrm{N}-45^{\circ} \mathrm{N}$ region than in the $20^{\circ} \mathrm{S}-45^{\circ} \mathrm{S}$ region. At this pressure level, the chemical lifetimes of the species considered here remain longer than Saturn's year. However, the layers at and above the $10^{-3}-\mathrm{hPa}$ level have lifetimes shorter than Saturn's season. In addition, the vertical diffusion timescales between $10^{-3} \mathrm{hPa}$ and $10^{-2} \mathrm{hPa}$ are of the order of a few months (Moses and Greathouse, 2005). As a consequence, at $10^{-2}$ $\mathrm{hPa}$, as the short-lifetime upper molecules diffuse downwards, the meridional distributions of $\mathrm{C}_{2} \mathrm{H}_{2}$ and $\mathrm{C}_{2} \mathrm{H}_{6}$ should mimic the current solar insolation with a phase lag of a few months. According to photochemical models, we should thus observe stronger hydrocarbon abundances at summer (southern) mid-latitudes than at winter (northern) mid-latitudes (Fig. 14). Here we observe a $\mathrm{C}_{2} \mathrm{H}_{2}$ abundance almost 10 times greater at $25^{\circ} \mathrm{N}$ than at $25^{\circ} \mathrm{S}$, and about 3 times greater in the case of $\mathrm{C}_{2} \mathrm{H}_{6}$. This feature was already reported at $0.1 \mathrm{hPa}$, although attenuated, and will be discussed in section 5 .

It is interesting to note that the $\mathrm{C}_{2} \mathrm{H}_{6}$ abundance at $0.01 \mathrm{hPa}$ does not display an enhancement towards high southern latitudes with respect to the equatorial abundance, but is rather consistent with photochemical model predictions at this pressure level.

\subsubsection{Comparison to previous observations.}

Ethane and acetylene latitudinal variations can be compared to previous Cassini/CIRS nadir observations (Howett et al., 2007), to measurements made by the TEXES spectrograph mounted on the NASA/IRTF (Greathouse et al., 2005a, 2006) and to Keck/NIRSPEC observations (Kim et al., 
2006).

\section{Ethane}

The ethane abundance at $2.3 \mathrm{hPa}$ is shown in Fig. 15, along with results from TEXES and CIRS nadir observations, respectively performed in September 2002 and mid-2004. First, we note that our absolute retrieved values are roughly half those of previous observations from Greathouse et al. (2005a) and Howett et al. (2007). This could be explained, in part, by the fact that we use different spectral line data for the $\nu_{9}$ band of $\mathrm{C}_{2} \mathrm{H}_{6}$, in our case coming from a recent linelist generated by Vander Auwera et al. (2007) (which now replaces the $\mathrm{C}_{2} \mathrm{H}_{6}$ line data in the HITRAN database since July 2007). In order to strengthen this hypothesis, we performed additional ethane retrievals from spectra at $62^{\circ} \mathrm{S}, 40^{\circ} \mathrm{S}, 20^{\circ} \mathrm{S}$ and $0^{\circ}$ using an older list of $\mathrm{C}_{2} \mathrm{H}_{6}$ spectral data from the GEISA 2003 database. The $\nu_{9}$ ethane lines in GEISA 2003 are the same as in GEISA 1999 (used by Greathouse et al.). Table 4 shows that values retrieved at $2 \mathrm{hPa}$ using the Vander Auwera et al. (2007) database are smaller by a factor of $\sim 1.8$ than those retrieved using GEISA. In addition, synthetic spectra generated with the GEISA database provide a less satisfactory fit of the data. This is why Fig. 15 shows the results of Greathouse et al. and Howett et al. at $2.3 \mathrm{hPa}$ divided by a factor of 1.8 , to perform a more realistic comparison to our results. This also justifies the use of two different scaling factors for $\mathrm{C}_{2} \mathrm{H}_{6}$ when comparing our results to Moses and Greathouse (2005) model: the ratio of retrieved ethane abundances using the GEISA or Vander Auwera et al.'s databases was $\sim 2$ at 1 $\mathrm{hPa}$ and $\sim 1.5$ at $0.01 \mathrm{hPa}$.

[Figure 15 about here.] 
[Table 4 about here.]

Our results are comparable to previous studies in the range $0-30^{\circ} \mathrm{S}$ and globally display the same trends as previous measurements, albeit we do not observe the strong increase inferred by Howett et al. (2007) poleward of $55^{\circ} \mathrm{S}$. Our global trend agrees better with the smooth poleward increase from Greathouse et al. results, although the amplitude of the increase is about half lower in our case (a $10^{\circ}$ to $80^{\circ} \mathrm{S}_{2} \mathrm{H}_{6}$ increase of $25 \%$ in our study, with respect to an increase of $45 \%$ in the same range by Greathouse et al. (2005a)). We must stress that our study remains consistent with the results of Greathouse et al. within error bars and that 4 terrestrial years (half a saturnian season) separate TEXES ground-based observations from our limb observations at 62,70 and $80^{\circ} \mathrm{S}$ (acquired in mid- to end-2007). In any case, we reach the same conclusion that $\mathrm{C}_{2} \mathrm{H}_{6}$ does not decrease towards the south pole, in contradiction with $1-\mathrm{D}$ photochemical seasonal models (Moses and Greathouse, 2005).

Another comparison can be made at high altitude with Keck/NIRSPEC 2001 observations analyzed by Kim et al. (2006), centered at $40^{\circ} \mathrm{S}$. They determined the $\mathrm{C}_{2} \mathrm{H}_{6}$ abundance using its $\nu_{7}$ emission band at $3.3 \mu \mathrm{m}$ to be $9 \pm 4 \times 10^{-6}$ in the $10^{-2}$ to $10^{-4} \mathrm{hPa}$ region. This is in very good agreement with our retrieved value at $10^{-2} \mathrm{hPa}$ of $8 \pm 2 \times 10^{-6}$ (a mean of the abundances from $35^{\circ} \mathrm{S}$ to $\left.45^{\circ} \mathrm{S}\right)$.

Acetylene

A comparison of our results to $\mathrm{C}_{2} \mathrm{H}_{2}$ abundances retrieved by Greathouse et al. (2005a) and Howett et al. (2007) is displayed on Fig. 16 and 17, respectively at 1.1 and $0.12 \mathrm{hPa}$. We notice that our absolute retrieved values are sys- 
tematically lower than previous measurements. The larger differences lie in the range $40^{\circ} \mathrm{S}$ to $20^{\circ} \mathrm{S}$, where previous measurements both show a bump in $\mathrm{C}_{2} \mathrm{H}_{2}$ volume mixing ratio whereas our results show a slight depletion in $\mathrm{C}_{2} \mathrm{H}_{2}$ in this region, especially at $0.12 \mathrm{hPa}$. This might be due to temporal variations, as our observations were performed approximately 2 and 4 years after the Greathouse et al. (2005a) and Howett et al. (2007) measurements, respectively. We also investigated the possibility of a temperature effect. Greathouse et al. (2005a) and Howett et al. (2007) retrieved temperature profiles that were either constant above the 0.1 -hPa level or forced to relax to $140 \mathrm{~K}$ above this level, while our study reveals that the temperature continues to increase up to at least $0.01 \mathrm{hPa}$, with a mean value of $155 \mathrm{~K}$ in the southern hemisphere. We investigated how the knowledge of the temperature above the $0.1 \mathrm{hPa}$ level could impact the retrieval of hydrocarbon abundances. Results show that upper atmospheric temperatures do not significantly change the hydrocarbon abundances below the 0.1-hPa level. The large differences between our results and previous measurements thus cannot be explained by different temperature profiles at high altitudes.

Apart from these differences, we find the same overall increase by a factor of 3.5 from $80^{\circ} \mathrm{S}$ to the equator at $1.1 \mathrm{hPa}$ as Greathouse et al. (2005a). Our measurements also agree within error bars at high southern latitudes.

[Figure 16 about here.]

[Figure 17 about here.]

Propane 
Propane measurements can only be compared to Greathouse et al. (2006) observations, which were performed at $20^{\circ} \mathrm{S}$ and $80^{\circ} \mathrm{S}$ and correspond to the 5 -hPa region. They found values of respectively $2.7 \times 10^{-8}$ and $2.5 \times 10^{-8}$ at these latitudes and concluded that $\mathrm{C}_{3} \mathrm{H}_{8}$ had a constant abundance in the southern hemisphere. At $5 \mathrm{hPa}$, at the same latitudes, we determine the propane abundance to be respectively of $5.7 \times 10^{-8}$ and $6.2 \times 10^{-8}$, with error bars of $\sim 25 \%$. Although these values are more than twice those of Greathouse et al. (2006), our results are also compatible with a constant abundance at these two latitudes. However, a study of all datasets in which we have a sensitivity to $\mathrm{C}_{3} \mathrm{H}_{8}$ at $5 \mathrm{hPa}$ leads to a different conclusion: it shows that the propane abundance increases by $\sim 40 \%$ from $45^{\circ} \mathrm{N}$ to $80^{\circ} \mathrm{S}$.

The high absolute values we inferred for $\mathrm{C}_{3} \mathrm{H}_{8}$ with respect to Greathouse et al. results might be explained by the use of different vibrational partition functions, as discussed in section 3.1. If Greathouse et al. used the full partition function, they derived an approximately twice too small propane mole fraction. In any case, this would be a systematic effect and would not influence the deduced meridional variations.

\section{Discussion}

\subsection{Temperature variations}

The latitude-altitude temperature map between $45^{\circ} \mathrm{S}$ and $45^{\circ} \mathrm{N}$ has been analyzed in detail by Fouchet et al. (2008). The main features are the stratospheric equatorial oscillation associated with the temperature maximum at $1 \mathrm{hPa}$ and the temperature minima at 10 and $0.1 \mathrm{hPa}$, and the lack of northto-south seasonal temperature gradient at high altitude $(0.01 \mathrm{hPa})$. The 
equatorial oscillation is a wave-driven process similar to the terrestrial quasibiennial oscillation (QBO) in which the zonal wind at a given altitude oscillates from a westward regime to an eastward regime, and the temperature from local maxima to local minima. Orton et al. (2008) determined a period of 15 Earth years for the oscillation in Saturn's stratosphere. In the northern hemisphere, at mid-latitudes, Fouchet et al. (2008) interpreted the unexpectedly warm temperatures as an evidence for a downwelling motion associated with the shadow of the rings.

Our study extends the temperature maps to higher north and south latitudes, allowing us to further investigate the seasonal atmospheric response. We have determined a meridional temperature gradient at $1 \mathrm{hPa}$ very similar to that determined by Fletcher et al. (2007) and Howett et al. (2007). These studies used nadir CIRS observations obtained in 2004 and 2005, contemporaneous with most of our limb observations. This temperature gradient, a $15 \mathrm{~K}$ increase from the equator to the south pole, is larger than determined by Greathouse et al. (2005a) from 2002 ground-based observations, but is similar to the 2004 ground-based observations of Greathouse et al. (2005b). These temperature variations show that the temperature response effectively lags behind the solar heating (summer solstice occured in October 2002). In fact, we note that our measurements at high southern latitudes (from $62^{\circ} \mathrm{S}$ to $80^{\circ} \mathrm{S}$ ), which were obtained in 2007 , two years later than Fletcher et al. (2007) and Howett et al. (2007), do not depart significantly from the CIRS nadir measurements. Although this may suggest that the temperature response does not lag more than 2 - 3 years behind the solar forcing, we must stay cautious: temperature measurements obtained with two different view- 
ing geometry, nadir and limb, may suffer from different bias, in particular from the choice of the a priori profile at high altitudes in the retrieval process, making direct comparisons difficult.

[Figure 18 about here.]

As mentioned in Section 4.1, the temperatures inferred at $0.01 \mathrm{hPa}$ between $20^{\circ} \mathrm{S}$ and $20^{\circ} \mathrm{N}$ show strong temporal and meridional variations. This temporal variation corresponds to a change in the flux radiated in the $\mathrm{CH}_{4}$ band at high altitudes. An example is displayed in Fig. 18, where we compare the radiances measured for different altitudes at $5^{\circ} \mathrm{S}$ in March 2005 and February 2006 for the FP3 and FP4 detectors. Surprisingly, while the radiance in the $\mathrm{CH}_{4}$ band increased by a factor of 2.4 between March 2005 and February 2006 at $\sim 500 \mathrm{~km}$, the radiance observed within the hydrocarbon emission bands did not change significantly. When retrieving the hydrocarbon abundances, this situation induces a large temporal change in their abundances at the 0.01-hPa pressure level. Since at this altitude, the net photochemical lifetime and the transport timescales are longer than a year, it is difficult to regard this abundance variation as real.

We rather suggest that the FP4 and FP3 arrays, separated by $0.94 \mathrm{mrad}$, hence $\sim 300 \mathrm{~km}$ in the meridional direction, do not probe the same atmospheric temperature. Temperature differences on such a small lengthscale could be the signature of wave activity. The wave signature is not observed at lower altitudes because the wave amplitude usually decreases with increasing pressure. Atmospheric waves have been observed by stellar occultation in Saturn's upper atmosphere (Hubbard et al., 1997; Cooray et al., 1998), but 
their parameters (angular frequency, wave-vector) remain unconstrained. It is therefore difficult to assess our hypothesis.

\subsection{Hydrocarbon meridional variations}

In this section, we compare our retrieved meridional distributions with the predictions of the Moses and Greathouse (2005) 1-D seasonal model. Disagreements can highlight dynamical processes, as their model did not take into account meridional transport, vertical advection and meridional gradients in the vertical eddy mixing coefficient. Disagreements can also signal problems with the assumed chemistry.

\subsubsection{Lower stratosphere: 1-hPa level}

Overall meridional distributions of $\mathrm{C}_{2} \mathrm{H}_{2}$ and $\mathrm{C}_{2} \mathrm{H}_{6}$

Around $1 \mathrm{hPa}$, the $\mathrm{C}_{2} \mathrm{H}_{2}$ meridional distribution is in good agreement with photochemical model predictions, implying that its distribution is mostly governed by chemistry rather than dynamics. As its net chemical lifetime lies in the range 150 - 200 years at this pressure level, we can infer that there are no large-scale and noticeable meridional motions on a timescale shorter than 150 years. On the other hand, the $\mathrm{C}_{2} \mathrm{H}_{6}$ distribution departs from the photochemical model in the southern hemisphere, displaying a slight increase (constant within error bars) from $35^{\circ} \mathrm{S}$ to $80^{\circ} \mathrm{S}$ whereas the model predicts a strong decrease. As already suggested by Greathouse et al. (2005a), this situation suggests that $\mathrm{C}_{2} \mathrm{H}_{6}$ is more efficiently transported than photochemically destroyed in this latitude range. This constrains the meridional transport to occur on a timescale shorter than ethane lifetime at $1 \mathrm{hPa}$ (400-450 years). However, preliminary models coupling photochemistry and meridional trans- 
port fail to reproduce the observed hydrocarbon distributions (Moses et al., 2007): a more consistent scheme still has to be found.

Our study complements the work of Greathouse et al. (2005a) in the northern hemisphere, which was hidden behind the rings during their groundbased observations. The northern meridional pattern mimics that in the southern hemisphere: the abundance is fairly constant for $\mathrm{C}_{2} \mathrm{H}_{6}$, while it decreases towards the north pole for $\mathrm{C}_{2} \mathrm{H}_{2}$. While the $\mathrm{C}_{2} \mathrm{H}_{6}$ abundance at $70^{\circ} \mathrm{N}$ is lower than at northern mid-latitudes, it remains compatible within error bars. To first order, $\mathrm{C}_{2} \mathrm{H}_{2}$ and $\mathrm{C}_{2} \mathrm{H}_{6}$ meridional distributions are symmetric with respect to the equator. This was expected for species with net lifetimes longer than Saturn's year: any seasonal patterns are damped. Our results also suggest that the meridional transport is axisymmetric.

\section{Propane distribution}

Our study extends the first propane detection of Greathouse et al. (2006), who measured two points at $20^{\circ} \mathrm{S}$ and $80^{\circ} \mathrm{S}$, whereas we do measure a meridional distribution from $45^{\circ} \mathrm{N}$ to $80^{\circ} \mathrm{S}$ with a step of $\sim 5^{\circ}$. Our measurements are in conflict with the Greathouse et al. (2006) conclusion of a meridionally uniform distribution: we measure an abundance at $1 \mathrm{hPa}$ that rises from $9 \times 10^{-8}$ at mid-northern latitudes to $1.45 \times 10^{-7}$ at mid-southern latitudes and reaches $2.4 \times 10^{-7}$ at $80^{\circ} \mathrm{S}$. This distribution resembles more closely the current insolation flux than do the $\mathrm{C}_{2} \mathrm{H}_{2}$ and $\mathrm{C}_{2} \mathrm{H}_{6}$ distributions. In fact, propane is mostly produced around the 1-hPa pressure level (Moses et al., 2000a). However, Greathouse et al. (2006) stated that the net lifetime of $\mathrm{C}_{3} \mathrm{H}_{8}$ in the lower stratosphere is larger than a Saturnian year, intermediate between that of $\mathrm{C}_{2} \mathrm{H}_{2}$ and $\mathrm{C}_{2} \mathrm{H}_{6}$. If it was the case, the $\mathrm{C}_{3} \mathrm{H}_{8}$ meridional 
distribution would be intermediate between those of $\mathrm{C}_{2} \mathrm{H}_{2}$ and $\mathrm{C}_{2} \mathrm{H}_{6}$. Our study rather suggests that the actual net chemical lifetime of $\mathrm{C}_{3} \mathrm{H}_{8}$ at $1 \mathrm{hPa}$ is shorter than estimated by the models, maybe slightly shorter than a Saturnian year. In fact, Greathouse et al. (2006) mentioned that the reactions involved in the production of propane, especially three-body reactions, suffer from uncertainties in their reaction rates at the appropriate $T, p$ conditions, but whether these uncertainties could change the meridional distribution remains to be investigated.

\section{Equatorial enhancement}

As mentioned in section 4.2.1, we report an enhancement of the volume mixing ratios of the hydrocarbons at the equator relative to the tropical north and south latitudes. This enhancement is maximum at $1 \mathrm{hPa}$, and more prominent for $\mathrm{C}_{2} \mathrm{H}_{2}$ than for $\mathrm{C}_{3} \mathrm{H}_{8}$ and $\mathrm{C}_{2} \mathrm{H}_{6}$. Since the latitudinal extent of the enhancement is narrow, confined to the equator, it does not seem compatible with a chemical origin. We rather suggest that its origin lies in a dynamical process. Indeed, the equatorial temperature shows a local maximum at $1 \mathrm{hPa}$ and a local minimum at $0.1 \mathrm{hPa}$ associated with the quasi-periodic equatorial oscillation. These local extrema are linked to a descent of air between 0.1 and $1 \mathrm{hPa}$, which should transport down chemical species. On one hand, the $\mathrm{C}_{2} \mathrm{H}_{6}$ mixing ratio vertical profile is rather uniform in this pressure range, and the $\mathrm{C}_{3} \mathrm{H}_{8}$ abundance even decreases above 0.5-hPa. On the other hand, the $\mathrm{C}_{2} \mathrm{H}_{2}$ profile exhibits a strong vertical gradient. Hence $\mathrm{C}_{2} \mathrm{H}_{2}$ is more sensitive to a local descent of air than $\mathrm{C}_{2} \mathrm{H}_{6}$ and $\mathrm{C}_{3} \mathrm{H}_{8}$ and shows a large equatorial enhancement. Such a vertical transport associated with an equatorial oscillation is known to exist on Earth, as the 
ozone equatorial stratospheric column density is modulated by the phase of the QBO (Baldwin et al., 2001, and references therein).

In order to estimate the speed of the vertical winds needed to bring the corresponding quantity of hydrocarbons, we solve the continuity equation. In the Transformed Eulerian Mean formulation, it can be expressed (Holton, 1992, chap. 12):

$$
\left(\frac{\partial}{\partial t}+\bar{\omega}^{*} \frac{\partial}{\partial z}\right) \bar{\chi}_{i}=\bar{S}+\bar{D}
$$

where $\chi_{i}$ is the mixing ratio profile of a given chemical species indexed by $i$, $\omega^{*}$ is the vertical speed of the residual circulation, $S$ represents the chemical sources and sinks and $D$ the horizontal and vertical transport by eddies. Horizontal bars stand for zonally averaged variables.

We start by building a theoretical vertical profile for $\mathrm{C}_{2} \mathrm{H}_{2}$ at the equator, as if it followed the yearly-averaged solar insolation. We assume it should be equal to the mean of the $\mathrm{C}_{2} \mathrm{H}_{2}$ profiles at $10^{\circ} \mathrm{N}$ and $10^{\circ} \mathrm{S}$ multiplied by 1.05 (the predicted $10^{\circ}$-to-equator enhancement). At high altitudes (0.01 $\mathrm{hPa}$ ), the observed and theoretical profiles have similar abundances, which is consistent as the descent of air between 0.1 and $1 \mathrm{hPa}$ should not affect the $\mathrm{C}_{2} \mathrm{H}_{2}$ abundance at $0.01 \mathrm{hPa}$. We can thus estimate the amount of $\mathrm{C}_{2} \mathrm{H}_{2}$ brought by the descent of air from the difference of the two profiles. For the theoretical $\mathrm{C}_{2} \mathrm{H}_{2}$ profile, there is no assumed residual circulation and Eq. 5 reduces to $\frac{\partial \chi_{i}^{t h e o}}{\partial t}=\bar{S}+\bar{D}$, whereas the complete Eq. 5 applies to the observed $\mathrm{C}_{2} \mathrm{H}_{2}$ profile.

We assume $\bar{S}$ and $\bar{D}$ are identical whether or not there is a residual vertical circulation, so that we can eliminate those terms by making the difference of Eq. 5 applied to the observed and to the theoretical profiles. As we do not 
have access to the temporal evolution, we assume that the downward motion occurs on a timescale of one season or less (typically $\Delta t \sim 5-7$ years). We end up solving the following equation:

$$
\left(\frac{\Delta \bar{\chi}_{i}}{\Delta t}+\bar{\omega}^{*} \frac{\partial \chi_{i}^{\bar{o} b s}}{\partial z}\right) \equiv 0
$$

where $\Delta \chi_{i}=\chi_{i}^{o b s}-\chi_{i}^{\text {theo }}$. This equation leads to a vertical speed of $\omega^{*}=0.25 \pm 0.1 \mathrm{~mm} / \mathrm{s}$ at $1 \mathrm{hPa}$ and of $\omega^{*}=0.4 \pm 0.15 \mathrm{~mm} / \mathrm{s}$ at $0.1 \mathrm{hPa}$. A similar speed (within the error bars) is obtained when we apply Eq. 6 to the ethane abundance, which also displays an enhanced equatorial value (though not as prominent as for acetylene). In comparison, we estimated the eddy diffusion vertical speed $v \equiv K / H$ using the eddy diffusion coefficient $K$ adopted by Moses et al. (2000a). We found values of $0.02 \mathrm{~mm} / \mathrm{s}$ at $1 \mathrm{hPa}$ and $0.13 \mathrm{~mm} / \mathrm{s}$ at $0.1 \mathrm{hPa}$, respectively ten and three times lower than the speed of the vertical advection we inferred.

\subsubsection{Hydrocarbons: upper stratosphere}

At high altitudes $(0.1$ to $0.01 \mathrm{hPa})$, the meridional profiles of $\mathrm{C}_{2} \mathrm{H}_{2}$ and $\mathrm{C}_{2} \mathrm{H}_{6}$ differ completely from those at the 1-hPa level. In the upper stratosphere, hydrocarbon abundances show large and sharp meridional variations, whereas their variations are rather small and smooth in the lower stratosphere (with the exception of the equatorial enhancement). Moreover, the variations at $0.01 \mathrm{hPa}$ differ completely from the predictions of the 1-D seasonal model. At this pressure level, the vertical mixing timescales are short; hence the 1-D model predicts meridional abundance profiles that mimic the solar irradiation: roughly constant in the southern hemisphere, then rapidly decreasing 
from the equator to the north pole. In contrast, we observe (Fig. 14) a maximum abundance at $25^{\circ} \mathrm{N}$ and a minimum abundance at $25^{\circ} \mathrm{S}-45^{\circ} \mathrm{S}$. In the southern hemisphere, the abundances measured at $25^{\circ} \mathrm{S}-45^{\circ} \mathrm{S}$, smaller by a factor of 5 than the abundances retrieved in the equatorial and southern polar regions, could be explained either by a chemical or a dynamical process.

For the chemical process, Moses et al. (2000b) have shown that an external oxygen flux lessens the abundance of hydrocarbons and is more efficient on $\mathrm{C}_{2} \mathrm{H}_{2}$ than on alkanes like $\mathrm{C}_{2} \mathrm{H}_{6}$ and $\mathrm{C}_{3} \mathrm{H}_{8}$. This part is consistent with the fact that $\mathrm{C}_{2} \mathrm{H}_{2}$ shows a larger depletion than $\mathrm{C}_{2} \mathrm{H}_{6}$ with respect to the polar or equatorial abundances in our observations. A localized oxygen influx at southern mid-latitudes could reduce the hydrocarbon production rates relative to that at the south pole and at the equator. Northrop and Hill (1982, 1983) have indeed predicted a precipitation of oxygen-bearing molecules from the rings, the influx being concentrated at mid-latitudes. However, this precipitation has not yet been confirmed from observations. Water and carbon dioxide have been detected in Saturn's stratosphere (Feuchtgruber et al., 1997), but only from planetary-averaged observations. Prangé et al. (2006) tentatively identified a water abundance at $41^{\circ} \mathrm{S}$ higher than anywhere else on the planet, but they acknowledged that their measurements were ambiguous. Hence, our explanation remains speculative as long as this external oxygen flux confined to mid-latitudes has not been firmly detected. This chemical hypothesis is also lessened by another result from Moses et al. (2000b), who show that the effects of the oxygen influx should not be as pronounced at $0.01 \mathrm{hPa}$ as at 0.1 and $1 \mathrm{hPa}$.

For the dynamical origin we suggest that the vertical transport timescales 
are longer at southern mid-latitudes than that at the south pole and at the equator. $\mathrm{C}_{2} \mathrm{H}_{2}$ and $\mathrm{C}_{2} \mathrm{H}_{6}$ are produced at higher levels, around $10^{-4} \mathrm{hPa}$, and transported downwards. In the 1D seasonal model of Moses and Greathouse (2005) the vertical transport is induced by eddy mixing which is assumed seasonally and meridionally uniform. Roughly, it takes 1-2 years for molecules to be transported from the production level to the 0.01-hPa level. A longer transport timescale at mid-latitudes than for the rest of the southern hemisphere would imply that the hydrocarbon abundances at $25^{\circ} \mathrm{S}-45^{\circ} \mathrm{S}$ and 0.01 $\mathrm{hPa}$ reflect a period of lower production rates, associated with the lower solar irradiance in spring or late winter, than on the rest of the hemisphere, where they should reflect the summer production rates. Following this hypothesis, mid-latitudes have a different phase lag than other latitudes. Such a difference could arise from a smaller eddy mixing coefficient at mid-latitudes resulting from a lower wave activity in this region, or possibly from a vertical updraft induced by the solar heating.

These two explanations would also impact the homopause level: a smaller eddy mixing coefficient would lower the homopause altitude, decreasing the chemical production rates, whereas a vertical updraft would rise the homopause, increasing the production rates. Hence our explanation induces feedback mechanisms which need to be tested numerically.

In the northern hemisphere, the maximum in abundances centered at $25^{\circ} \mathrm{N}$ cannot be explained by a chemical origin. Situated below the rings, this region has experienced a very low solar irradiation, implying lower production rates for $\mathrm{C}_{2} \mathrm{H}_{2}$ and $\mathrm{C}_{2} \mathrm{H}_{6}$. We hence suggest a dynamical origin for the northern maximum. Fouchet et al. (2008) showed that the radiative cooling 
rates at $0.01 \mathrm{hPa}$ were similar at $25^{\circ} \mathrm{N}$ and $30^{\circ} \mathrm{S}$. Since the solar heating rates differ by a factor of 5 , this situation is sustainable only if an adiabatic heating compensates the radiative cooling at $25^{\circ} \mathrm{N}$, the adiabatic heating being associated with the downward branch of an Hadley circulation. Such a circulation could also transport hydrocarbon molecules from the southern summer hemisphere to the northern one.

Finally, we note that the hydrocarbon meridional profiles at 0.01 and $0.1 \mathrm{hPa}$, showing large and sharp extrema, are incompatible with a meridional transport that should smooth out the latitudinal gradient. The meridional transport starts playing a major role only at the 1-hPa level, where its timescale becomes shorter than photochemical net lifetimes and vertical diffusion transport timescales.

\section{Conclusion}

Using limb-viewing geometry data from the Cassini/CIRS instrument, we have determined the temperature and abundance profiles of $\mathrm{C}_{2} \mathrm{H}_{6}$ and $\mathrm{C}_{2} \mathrm{H}_{2}$ in Saturn's stratosphere in the latitudinal range $80^{\circ} \mathrm{S}$ to $70^{\circ} \mathrm{N}$. Our retrievals cover the range 3 to $10^{-2} \mathrm{hPa}$ at a resolution of $\sim 1.5$ scale height. We also retrieve the $\mathrm{C}_{3} \mathrm{H}_{8}$ distribution around $1 \mathrm{hPa}$ at the same latitudes. Information on the temperature and on the abundance vertical profiles are retrieved from the same datasets (same latitudes and dates), which precludes any temperature or temporal bias. In addition, for the first time at this latitudinal resolution, we retrieve detailed information on the winter (northern) hemisphere.

As concerns the temperature field, we find a $70^{\circ} \mathrm{N}$ to $80^{\circ} \mathrm{S}$ gradient of $37 \mathrm{~K}$ 
at $1 \mathrm{hPa}$, consistent with recent measurements by Greathouse et al. (2005b); Howett et al. (2007); Fletcher et al. (2007). At high altitudes and in the equatorial region $\left(20^{\circ} \mathrm{N}\right.$ to $\left.20^{\circ} \mathrm{S}\right)$, we derive both meridional and temporal variations of temperature, which may be evidence for wave activity.

For the composition, our results show that at $1 \mathrm{hPa}$, the three hydrocarbons exhibit very different distributions: $\mathrm{C}_{2} \mathrm{H}_{6}$ is rather homogeneous in latitude, with a mean volume mixing ratio of $5.2 \times 10^{-6}$; the $\mathrm{C}_{2} \mathrm{H}_{2}$ distribution lies close to the yearly-averaged insolation, except for a high equatorial abundance and finally, the $\mathrm{C}_{3} \mathrm{H}_{8}$ abundance globally increases from north to south by a factor of 1.9. Except for $\mathrm{C}_{2} \mathrm{H}_{2}$ (to first order), 1-D photochemical models (Moses and Greathouse, 2005) fail to reproduce the observed distributions. More complete models are needed, taking into account meridional and seasonal variations of temperature, meridional transport, vertical advection and a better estimation of the eddy mixing coefficient and its variation with latitude. Indeed, the $\mathrm{C}_{2} \mathrm{H}_{6}$ distribution we inferred at $1 \mathrm{hPa}$ suggests that meridional transport mixes efficiently the atmosphere in both hemispheres, symmetrically with respect to the equator, on a timescale estimated between 150 and 450 years. In addition, we find evidence for downward vertical advection at the equator, highlighted by an abnormally high abundance of $\mathrm{C}_{2} \mathrm{H}_{2}$ in this region. We infer a vertical wind speed of about $0.25 \mathrm{~mm} / \mathrm{s}$ at $1 \mathrm{hPa}$ and $0.4 \mathrm{~mm} / \mathrm{s}$ at $0.1 \mathrm{hPa}$, about three to ten times greater than the estimated vertical diffusion speed in the Moses and Greathouse (2005) model. The propane meridional distribution cannot be explained in terms of meridional transport, as its lifetime is currently estimated to lie between ethane's and acetylene's lifetimes. As its distribution resembles the current insolation 
pattern, contrary to the photochemical model predictions, we suggest that its lifetime is similar to or shorter than a Saturn year. More laboratory data on reaction rates involving propane at relevant $T, p$ conditions are needed to confirm or deny this hypothesis.

At higher altitudes ( 0.1 to $0.01 \mathrm{hPa}$ ), the $\mathrm{C}_{2} \mathrm{H}_{6}$ and $\mathrm{C}_{2} \mathrm{H}_{2}$ mole fractions exhibit strong meridional variations, at odds with photochemical model predictions. Abundances of $\mathrm{C}_{2} \mathrm{H}_{6}$ and $\mathrm{C}_{2} \mathrm{H}_{2}$ at high southern latitudes do not show an enrichment with respect to the equator, as predicted. This implies that large-scale meridional transport is less efficient than photochemical processes in this pressure range. The strongest departures from the chemical model of Moses and Greathouse (2005) are found in the $25^{\circ} \mathrm{S}$ to $45^{\circ} \mathrm{S}$ region, where our derived hydrocarbon abundances present a marked depletion, and at $25^{\circ} \mathrm{N}$, where we find a local enhancement. The former could either have a chemical origin via a localized influx of oxygen-bearing molecules, or a dynamical origin (longer vertical eddy mixing timescales at these latitudes, or an upward motion). The enhancement at $25^{\circ} \mathrm{N}$ cannot be explained by photochemical arguments. As it coincides with the region undergoing ring shadowing, we suggest it might be evidence for a downward branch of an insolation-induced Hadley circulation (see also Fouchet et al. (2008)).

Future work could include a re-analysis of Voyager IRIS data, which were acquired at a wide range of latitudes but only analyzed in detail around $40^{\circ} \mathrm{N}$. It would provide information on the temperature and composition of the stratosphere under other insolation conditions than in our study. Voyager data were acquired in 1981, close to northern spring equinox, whereas Cassini observations analyzed in this study were acquired shortly after sum- 
mer solstice in the southern hemisphere. In addition, Voyager observations were performed at similar insolation conditions as will be achieved in 2011 . Indeed, future datasets acquired by Cassini in the incoming extended mission could be compared to Voyager observations and improve our knowledge of the stratospheric temperature and composition. These further observations would help with monitoring localized features reported in this study and in Fouchet et al. (2008). For example, the thermal structure at the equator is expected to evolve with a period of 15 years (Orton et al., 2008). Observations conducted around 2012 (7 years following our study) should show an equatorial maximum of temperature at $0.1 \mathrm{hPa}$ instead of the currently observed minimum, and vice versa at $1 \mathrm{hPa}$. This will also affect the dynamics: the descent of air reported here should reverse to an upward motion and modify the hydrocarbon vertical profiles at the equator. Another awaited phenomenon is the change in the configuration of the rings' shadow projected on the planet. As equinox will occur in August 2009, the rings' shadow will move from the northern to the southern hemisphere. The region of maximum hydrocarbon abundances observed near $25^{\circ} \mathrm{N}$, if linked to ring shadowing, should then relax towards a normal state in the incoming years.

\section{Acknowledgements}

We would like to thank the many people in the CIRS investigation team involved in planning the observational sequences and calibration of the data. We also thank Julianne Moses for providing model outputs for comparison to our results. This research was supported by the Centre National d'Etudes Spatiales (CNES) and the Programme National de Planétologie 


\section{ACCEPTED MANUSCRIPT}

(PNP/INSU).

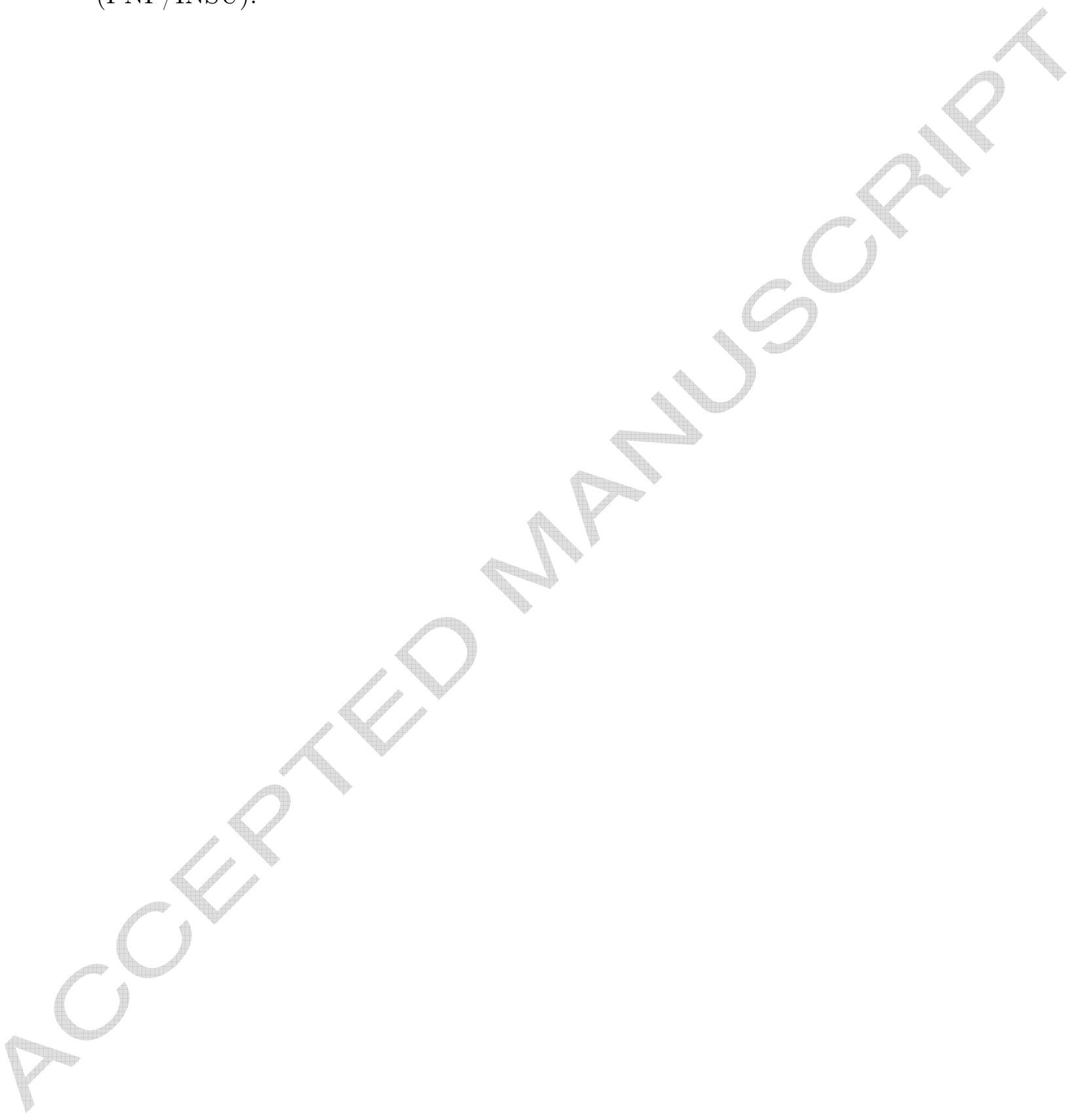




\section{References}

Arié, E. and Johns, J. W. C., 1992. The bending energy levels of $\mathrm{C}_{4} \mathrm{H}_{2}$. J. Mol. Spectrosc., 155, 195-204.

Atreya, S. K. and Romani, P. N., 1985. Photochemistry and clouds of Jupiter, Saturn and Uranus, pp. 17-91. Recent Advances in Planetary Meteorology. Cambridge University Press.

Baldwin, M. P., Gray, L. J., Dunkerton, T. J., Hamilton, K., Haynes, P. H., Randel, W. J., Holton, J. R., Alexander, M. J., Hirota, I., Horinouchi, T., Jones, D. B. A., Kinnersley, J. S., Marquardt, C., Sato, K., and Takahashi, M., 2001. The quasi-biennial oscillation. Rev. Geophys., 39, 179-230.

Borysow, A. and Frommhold, L., 1986. Theoretical collision-induced rototranslational absorption spectra for the outer planets $-\mathrm{H}_{2}-\mathrm{CH}_{4}$ pairs. Astrophys. J., 304, 849-865.

Borysow, J., Frommhold, L., and Birnbaum, G., 1988. Collison-induced rototranslational absorption spectra of $\mathrm{H}_{2}$-He pairs at temperatures from 40 to 3000 K. Astrophys. J., 326, 509-515.

Borysow, J., Trafton, L., Frommhold, L., and Birnbaum, G., 1985. Modeling of pressure-induced far-infrared absorption spectra Molecular hydrogen pairs. Astrophys. J., 296, 644-654.

Conrath, B. J. and Gautier, D., 2000. Saturn helium abundance: A reanalysis of Voyager measurements. Icarus, 144, 124-134. 
Conrath, B. J., Gierasch, P. J., and Ustinov, E. A., 1998. Thermal structure and para hydrogen fraction on the outer planets from Voyager IRIS measurements. Icarus, 135, 501-517.

Cooray, A. R., Elliot, J. L., Bosh, A. S., Young, L. A., and Shure, M. A., 1998. Stellar occultation observations of Saturn's north-polar temperature structure. Icarus, 132, 298-310.

Courtin, R., Gautier, D., Marten, A., Bézard, B., and Hanel, R. , 1984. The composition of Saturn's atmosphere at northern temperate latitudes from Voyager IRIS spectra - $\mathrm{NH}_{3}, \mathrm{PH}_{3}, \mathrm{C}_{2} \mathrm{H}_{2}, \mathrm{C}_{2} \mathrm{H}_{6}, \mathrm{CH}_{3} \mathrm{D}, \mathrm{CH}_{4}$, and the Saturnian D/H isotopic ratio. Astrophys. J., 287, 899-916.

de Graauw, T., Feuchtgruber, H., Bézard, B., Drossart, P., Encrenaz, T., Beintema, D. A., Griffin, M., Heras, A., Kessler, M., Leech, K., Lellouch, E., Morris, P., Roelfsema, P. R., Roos-Serote, M., Salama, A., Vandenbussche, B., Valentijn, E. A., Davis, G. R., and Naylor, D. A., 1997. First results of ISO-SWS observations of Saturn: Detection of $\mathrm{CO}_{2}, \mathrm{CH}_{3} \mathrm{C}_{2} \mathrm{H}$, $\mathrm{C}_{4} \mathrm{H}_{2}$ and tropospheric $\mathrm{H}_{2} \mathrm{O}$. Astron. Astrophys., 321, L13-L16.

Feuchtgruber, H., Lellouch, E., de Graauw, T., Bézard, B., Encrenaz, T., and Griffin, M., 1997. External supply of oxygen to the atmospheres of giant planets. Nature, 389, 159-162.

Flasar, F. M., Achterberg, R. K., Conrath, B. J., Pearl, J. C., Bjoraker, G. L., Jennings, D. E., Romani, P. N., Simon-Miller, A. A., Kunde, V. G., Nixon, C. A., Bézard, B., Orton, G. S., Spilker, L. J., Spencer, J. R., Irwin, P. G. J., Teanby, N. A., Owen, T. C., Brasunas, J., Segura, M. E., Carl- 
son, R. C., Mamoutkine, A., Gierasch, P. J., Schinder, P. J., Showalter, M. R., Ferrari, C., Barucci, A., Courtin, R., Coustenis, A., Fouchet, T., Gautier, D., Lellouch, E., Marten, A., Prangé, R., Strobel, D. F., Calcutt, S. B., Read, P. L., Taylor, F. W., Bowles, N., Samuelson, R. E., Abbas, M. M., Raulin, F., Ade, P., Edgington, S., Pilorz, S., Wallis, B., and Wishnow, E. H., 2005. Temperatures, winds, and composition in the Saturnian system. Science, 307, 1247-1251.

Flasar, F. M., Kunde, V. G., Abbas, M. M., Achterberg, R. K., Ade, P., Barucci, A., Bézard, B., Bjoraker, G. L., Brasunas, J. C., Calcutt, S., Carlson, R., Césarsky, C. J., Conrath, B. J., Coradini, A., Courtin, R., Coustenis, A., Edberg, S., Edgington, S., Ferrari, C., Fouchet, T., Gautier, D., Gierasch, P. J., Grossman, K., Irwin, P., Jennings, D. E., Lellouch, E., Mamoutkine, A. A., Marten, A., Meyer, J. P., Nixon, C. A., Orton, G. S., Owen, T. C., Pearl, J. C., Prangé, R., Raulin, F., Read, P. L., Romani, P. N., Samuelson, R. E., Segura, M. E., Showalter, M. R., Simon-Miller, A. A., Smith, M. D., Spencer, J. R., Spilker, L. J., and Taylor, F. W., 2004. Exploring the Saturn system in the thermal infrared: The composite infrared spectrometer. Space Sci. Rev., 115, 169-297.

Flasar, F. M., Schinder, P. J., Achterberg, R. K., Conrath, B. J., Cassini/CIRS Investigation Team and Cassini/RSS Team, 2008. On combining thermal-infrared and radio-occultation data of Saturn's and Titan's atmospheres Bull. Am. Astron. Soc., 40, 495.

Fletcher, L. N., Irwin, P. G. J., Orton, G. S., Teanby, N. A., Achterberg, R. K., Bjoraker, G. L., Read, P. L., Simon-Miller, A. A., Howett, C., de 
Kok, R., Bowles, N., Calcutt, S. B., Hesman, B., and Flasar, F. M., 2008. Temperature and composition of Saturn's polar hot spots and hexagon. Science, 319, 79-81.

Fletcher, L. N., Irwin, P. G. J., Teanby, N. A., Orton, G. S., Parrish, P. D., de Kok, R., Howett, C., Calcutt, S. B., Bowles, N., and Taylor, F. W., 2007. Characterising Saturn's vertical temperature structure from Cassini/CIRS. Icarus, 189, 457-478.

Fouchet, T., Guerlet, S., Strobel, D. F., Simon-Miller, A. A., Bézard, B., and Flasar, F. M., 2008. An equatorial oscillation in Saturn's middle atmosphere. Nature, 453, 200-202.

Gillett, F. C. and Forrest, W. J., 1974. The 7.5- to 13.5-micron spectrum of Saturn. Astrophys. J. Lett., 187, L37-39.

Giver, L. P., Varanasi, P., and Valero, F. P. J., 1984. Propane absorption band intensities and band model parameters from 680 to $1580 \mathrm{~cm}^{-1}$ at 296 and 200K. J. Quant. Spectrosc. Radiat. Transfer, 31, 203-213.

Greathouse, T. K., Lacy, J. H., Bézard, B., Moses, J. I., Griffith, C. A., and Richter, M. J., 2005a. Meridional variations of temperature, $\mathrm{C}_{2} \mathrm{H}_{2}$ and $\mathrm{C}_{2} \mathrm{H}_{6}$ abundances in Saturn's stratosphere at southern summer solstice. Icarus, 177, 18-31.

Greathouse, T. K., Roe, H. G., and Richter, M. J., 2005b. Evidence for a mesosphere on Saturn and the seasonal variation of temperature between 2002 and 2004 in Saturn's southern hemisphere. Bull. Am. Astron. Soc., 37,657 . 
Greathouse, T. K., Lacy, J. H., Bézard, B., Moses, J. I., Richter, M. J., and Knez, C., 2006. The first detection of propane on Saturn. Icarus, 181, 266-271.

Holton, J. R., 1992. An introduction to dynamic meteorology. International geophysics series, San Diego, New York: Academic Press, 1992, 3rd ed.

Howett, C. J. A., Irwin, P. G. J., Teanby, N. A., Simon-Miller, A., Calcutt, S. B., Fletcher, L. N., and de Kok, R., 2007. Meridional variations in stratospheric acetylene and ethane in the southern hemisphere of the saturnian atmosphere as determined from Cassini/CIRS measurements. Icarus, 190, 556-572.

Hubbard, W. B., Porco, C. C., Hunten, D. M., Rieke, G. H., Rieke, M. J., McCarthy, D. W., Haemmerle, V., Haller, J., McLeod, B., Lebofsky, L. A., Marcialis, R., Holberg, J. B., Landau, R., Carrasco, L., Elias, J., Buie, M. W., Dunham, E. W., Persson, S. E., Boroson, T., West, S., French, R. G., Harrington, J., Elliot, J. L., Forrest, W. J., Pipher, J. L., Stover, R. J., Brahic, A., and Grenier, I., 1997. Structure of Saturn's mesosphere from the 28 SGR occultations. Icarus, 130, 404-425.

Jacquinet-Husson, N., Scott, N. A., Chédin, A., Garceran, K., Armante, R., Chursin, A. A., Barbe, A., Birk, M., Brown, L. R., Camy-Peyret, C., Claveau, C., Clerbaux, C., Coheur, P. F., Dana, V., Daumont, L., Debacker-Barilly, M. R., Flaud, J. M., Goldman, A., Hamdouni, A., Hess, M., Jacquemart, D., Köpke, P., Mandin, J. Y., Massie, S., Mikhailenko, S., Nemtchinov, V., Nikitin, A., Newnham, D., Perrin, A., Perevalov, V. I., Régalia-Jarlot, L., Rublev, A., Schreier, F., Schult, I., Smith, K. M., 
Tashkun, S. A., Teffo, J. L., Toth, R. A., Tyuterev, V. G., Vander Auwera, J., Varanasi, P., and Wagner, G., 2005. The 2003 edition of the GEISA/IASI spectroscopic database. J. Quant. Spectrosc. Radiat. Transfer, $95,429-467$.

Kim, J. H., Kim, S. J., Geballe, T. R., Kim, S. S., and Brown, L. R. , 2006. High-resolution spectroscopy of Saturn at 3 microns: $\mathrm{CH}_{4}, \mathrm{CH}_{3} \mathrm{D}, \mathrm{C}_{2} \mathrm{H}_{2}$, $\mathrm{C}_{2} \mathrm{H}_{6}, \mathrm{PH}_{3}$, clouds, and haze. Icarus, 185, 476-486.

Koops, T., 1984. The harmonic force field and absolute infrared intensities of diacetylene. J. Mol. Struct., 125, 179-196.

Kunde, V. G., Ade, P. A., Barney, R. D., Bergman, D., Bonnal, J.-F., Borelli, R., Boyd, D., Brasunas, J. C., Brown, G., Calcutt, S. B., Carroll, F., Courtin, R., Cretolle, J., Crooke, J. A., Davis, M. A., Edberg, S., Fettig, R., Flasar, M., Glenar, D. A., Graham, S., Hagopian, J. G., Hakun, C. F., Hayes, P. A., Herath, L., Horn, L., Jennings, D. E., Karpati, G., Kellebenz, C., Lakew, B., Lindsay, J., Lohr, J., Lyons, J. J., Martineau, R. J., Martino, A. J., Matsumura, M., McCloskey, J., Melak, T., Michel, G., Morell, A., Mosier, C., Pack, L., Plants, M., Robinson, D., Rodriguez, L., Romani, P., Schaefer, W. J., Schmidt, S., Trujillo, C., Vellacott, T., Wagner, K., and Yun, D., 1996. Cassini infrared Fourier spectroscopic investigation. In Horn, L., editor, Cassini/Huygens: A mission to the Saturnian systems, Linda Horn; Ed., volume 2803 of Proc. SPIE, p. 162-177.

Lellouch, E., Bézard, B., Fouchet, T., Feuchtgruber, H., Encrenaz, T., and de Graauw, T., 2001. The deuterium abundance in Jupiter and Saturn from ISO-SWS observations. Astron. Astrophys., 370, 610-622. 
Lindal, G. F., Sweetnam, D. N., and Eshleman, V. R., 1985. The atmosphere of Saturn - an analysis of the Voyager radio occultation measurements. Astrophys. J., 90, 1136-1146.

Moos, H. W. and Clarke, J. T., 1979. Detection of acetylene in the Saturnian atmosphere, using the IUE satellite. Astrophys. J., Lett., 229, L107-108.

Moses, J. I., Bézard, B., Lellouch, E., Gladstone, G. R., Feuchtgruber, H., and Allen, M., 2000a. Photochemistry of Saturn's atmosphere. I. Hydrocarbon chemistry and comparisons with ISO observations. Icarus, 143, $244-298$.

Moses, J. I., Lellouch, E., Bézard, B., Gladstone, G. R., Feuchtgruber, H., and Allen, M., 2000b. Photochemistry of Saturn's atmosphere. II. Effects of an influx of external oxygen. Icarus, 145, 166-202.

Moses, J. I. and Greathouse, T. K., 2005. Latitudinal and seasonal models of stratospheric photochemistry on Saturn: Comparison with infrared data from IRTF/TEXES. J. Geophys. Res., 110, 9007.

Moses, J. and Vervack, Jr., R. J., 2006. Saturn's upper atmospheric structure: forward modeling and comparison with a reanalysis of the Voyager UVS occultation data. Bull. Am. Astron. Soc., 38, 500.

Moses, J. I., Liang, M.-C., Yung, Y. L., and Shia, R.-L., 2007. Meridional distribution of hydrocarbons on Saturn: Implications for stratospheric transport. In Workshop on planetary atmospheres, LPI contribution No 1376, p. $85-86$. 
Northrop, T. G. and Hill, J. R., 1982. Stability of negatively charged dust grains in Saturn's ring plane. J. Geophys. Res., 87, 6045-6051.

Northrop, T. G. and Hill, J. R., 1983. The inner edge of Saturn's B ring. J. Geophys. Res., 88, 6102-6108.

Ollivier, J. L., Billebaud, F., Drossart, P., Dobrijévic, M., Roos-Serote, M., August-Bernex, T., and Vauglin, I., 2000a. Seasonal effects in the thermal structure of Saturn's stratosphere from infrared imaging at 10 microns. Astron. Astrophys., 356, 347-356.

Ollivier, J. L., Dobrijévic, M., and Parisot, J. P., 2000b. New photochemical model of Saturn's atmosphere. Planet. Space Sci., 48, 699-716.

Orton, G. S., Yanamandra-Fisher, P. A., Fisher, B. M., Friedson, A. J., Parrish, P. D., Nelson, J. F., Bauermeister, A. S., Fletcher, L., Gezari, D. Y., Varosi, F., Tokunaga, A. T., Caldwell, J., Baines, K. H., Hora, J. L., Ressler, M. E., Fujiyoshi, T., Fuse, T., Hagopian, H., Martin, T. Z., Bergstralh, J. T., Howett, C., Hoffmann, W. F., Deutsch, L. K., van Cleve, J. E., Noe, E., Adams, J. D., Kassis, M., and Tollestrup, E., 2008. Semi-annual oscillations in Saturn's low-latitude stratospheric temperatures. Nature, 453, 196-199.

Prangé, R., Fouchet, T., Courtin, R., Connerney, J. E. P., and McConnell, J. C., 2006. Latitudinal variation of Saturn photochemistry deduced from spatially-resolved ultraviolet spectra. Icarus, 180, 379-392.

Rodgers, C. D., 2000. Inverse methods for atmospheric sounding. World Scientific. 
Sada, P. V., Bjoraker, G. L., Jennings, D. E., Romani, P. N., and McCabe, G. H., 2005. Observations of $\mathrm{C}_{2} \mathrm{H}_{6}$ and $\mathrm{C}_{2} \mathrm{H}_{2}$ in the stratosphere of Saturn. Icarus, 173, 499-507.

Tokunaga, A., Knacke, R. F., and Owen, T., 1975. The detection of ethane on Saturn. Astron. Astrophys. J., Lett., 197, L77-78.

Vander Auwera, J., Moazzen-Ahmadi, N., and Flaud, J.-M., 2007. Toward an accurate database for the $12 \mu \mathrm{m}$ region of the ethane spectrum. Astrophys. J., 662, 750-757.

Winkelstein, P., Caldwell, J., Kim, S. J., Combes, M., Hunt, G. E., and Moore, V., 1983. A determination of the composition of the Saturnian stratosphere using the IUE. Icarus, 54, 309-318. 


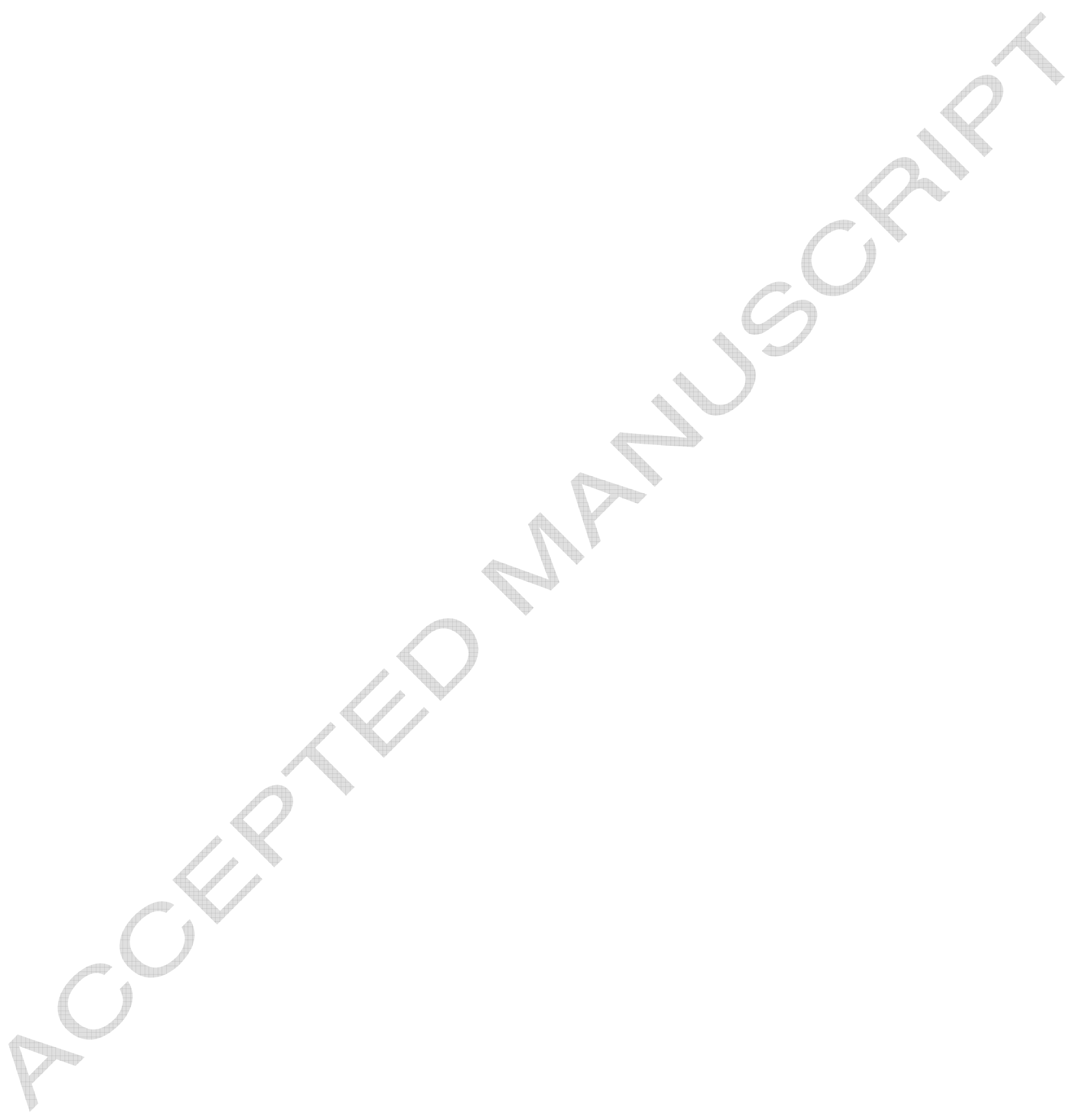




\begin{tabular}{cccc}
\hline Name & $\begin{array}{c}\text { Date } \\
(\mathrm{UT})\end{array}$ & Latitudinal coverage & $\begin{array}{c}\text { Spectral } \\
\text { resolution }\end{array}$ \\
\hline LMBFRNG002PRIME & $30 / 03 / 2005$ & $5^{\circ} \mathrm{S}$ to $35^{\circ} \mathrm{S}$ every $5^{\circ}$ & $15.5 \mathrm{~cm}^{-1}$ \\
LIMBMAPA005PRIME & $24 / 12 / 2005$ & $10,20,30,40^{\circ} \mathrm{N}$ & $15.5 \mathrm{~cm}^{-1}$ \\
LIMBMAPB005PRIME & $24 / 12 / 2005$ & $2^{\circ} \mathrm{N}, 10^{\circ} \mathrm{S}$ & $15.5 \mathrm{~cm}^{-1}$ \\
LIMBMAPC005PRIME & $25 / 12 / 2005$ & $20^{\circ} \mathrm{S}, 30^{\circ} \mathrm{S}$ & $15.5 \mathrm{~cm}^{-1}$ \\
LIMBMAPA006PRIME & $25 / 02 / 2006$ & $45^{\circ} \mathrm{S}, 35^{\circ} \mathrm{S}, 25^{\circ} \mathrm{S}$ & $15.5 \mathrm{~cm}^{-1}$ \\
LIMBMAPB006PRIME & $25 / 02 / 2006$ & $15^{\circ} \mathrm{S}$ to $45^{\circ} \mathrm{N}$ every $10^{\circ}$ & $15.5 \mathrm{~cm}^{-1}$ \\
LIMBMAP003PRIME & $16 / 08 / 2006$ & $45^{\circ} \mathrm{S}$ to $25^{\circ} \mathrm{S}$ every $5^{\circ}$ & $15.5 \mathrm{~cm}^{-1}$ \\
& & $25^{\circ} \mathrm{N}$ to $40^{\circ} \mathrm{N}$ every $5^{\circ}$ & $15.5 \mathrm{~cm}^{-1}$ \\
OCCLIMB008VIMS & $15 / 07 / 2005$ & $4^{\circ} \mathrm{S}$ & $3 \mathrm{~cm}^{-1}$ \\
OCCLIMB009VIMS & $02 / 08 / 2005$ & $7^{\circ} \mathrm{N}$ & $3 \mathrm{~cm}^{-1}$ \\
OCCLIMB001PRIME & $10 / 05 / 2007$ & $70^{\circ} \mathrm{S}$ & $15.5 \mathrm{~cm}^{-1}$ \\
OCCLIMB004PRIME & $19 / 12 / 2007$ & $62^{\circ} \mathrm{S}$ & $3 \mathrm{~cm}^{-1}$ \\
FTRACK009PRIME & $12 / 06 / 2007$ & $80^{\circ} \mathrm{S}$ & $3 \mathrm{~cm}^{-1}$ \\
LIMBINT004PRIME & $18 / 12 / 2007$ & $70^{\circ} \mathrm{N}$ & $0.5 \mathrm{~cm}^{-1}$ \\
LIMBINT007PRIME & $03 / 01 / 2008$ & $0^{\circ}$ & $1 \mathrm{~cm}^{-1}$ \\
& & $45^{\circ} \mathrm{N}$ & $3 \mathrm{~cm}^{-1}$ \\
\hline
\end{tabular}

Table 1: List and characteristics (name, date, latitude and spectral resolution) of the selected limb data analyzed in this study.

\begin{tabular}{|c|c|c|c|c|c|c|}
\hline $\begin{array}{c}\text { Pressure } \\
\text { level }\end{array}$ & $\begin{array}{l}\text { Noise and } \\
\text { smoothing }\end{array}$ & {$\left[\mathrm{CH}_{4}\right] /\left[\mathrm{H}_{2}\right]$} & $\begin{array}{c}\text { Homopause } \\
\text { level }\end{array}$ & {$[\mathrm{He}] /\left[\mathrm{H}_{2}\right]$} & Altitude & $\begin{array}{l}\text { Quadratic } \\
\text { sum }\end{array}$ \\
\hline & \pm 0.3 & $\leq 0.1$ & $\leq 0.1$ & $\begin{array}{l}+0.5 \\
-1.1\end{array}$ & $\begin{array}{l}+0.9 \\
-0.3\end{array}$ & $\begin{array}{l}+1.1 \\
-1.15\end{array}$ \\
\hline $1 \mathrm{hPa}$ & \pm 0.5 & $\begin{array}{l}+0.8 \\
-0.6\end{array}$ & \pm 0.5 & $\begin{array}{r}+0.2 \\
-0.35\end{array}$ & $\begin{array}{l}+0.2 \\
-0.9\end{array}$ & $\begin{array}{l}+1.1 \\
-1.35\end{array}$ \\
\hline $0.1 \mathrm{hPa}$ & \pm 0.8 & $\begin{array}{r}+0.9 \\
-0.75\end{array}$ & $\begin{array}{l}+0.8 \\
-1.1\end{array}$ & $\leq 0.1$ & \pm 0.15 & $\begin{array}{l}+1.4 \\
-1.55\end{array}$ \\
\hline $0.01 \mathrm{hPa}$ & \pm 0.95 & \pm 0.45 & \pm 0.6 & $\leq 0.1$ & $\leq 0.1$ & \pm 1.2 \\
\hline
\end{tabular}

Table 2: Estimation of the error on the temperature (in Kelvin) from several sources of uncertainty, at different pressure levels. 


\begin{tabular}{ccc|cc|cc}
\hline & \multicolumn{2}{c}{ Ethane } & \multicolumn{2}{c}{ Acetylene } & \multicolumn{2}{c}{ Propane } \\
\cline { 2 - 7 } & lower & upper & lower & upper & lower & upper \\
\hline \multirow{2}{*}{$1 \mathrm{hPa}$} & $22 \%$ & $25 \%$ & $33 \%$ & $29 \%$ & $25 \%$ & $25 \%$ \\
& $\mathbf{2 8 \%}$ & $\mathbf{3 1 \%}$ & $\mathbf{5 0 \%}$ & $\mathbf{3 7 \%}$ & $\mathbf{3 5 \%}$ & $\mathbf{3 5 \%}$ \\
$0.1 \mathrm{hPa}$ & $25 \%$ & $28 \%$ & $31 \%$ & $28 \%$ & - & - \\
& $\mathbf{2 9 \%}$ & $\mathbf{3 1 \%}$ & $\mathbf{3 6 \%}$ & $\mathbf{3 1 \%}$ & - & - \\
$0.01 \mathrm{hPa}$ & $27 \%$ & $33 \%$ & $53 \%$ & $50 \%$ & - & - \\
& $\mathbf{2 9 \%}$ & $\mathbf{3 5 \%}$ & $\mathbf{5 6 \%}$ & $\mathbf{5 2 \%}$ & - & - \\
\hline
\end{tabular}

Table 3: Lower and upper error bars on hydrocarbon abundances, at different pressure levels. The values in bold include all sources of error, while the other ones do not include systematic errors.

\begin{tabular}{cccc}
\hline Latitude & $\begin{array}{c}\text { Using GEISA } \\
2003(1)\end{array}$ & $\begin{array}{c}\text { Using Vander Auwera } \\
\text { et al. } 2007(2)\end{array}$ & Ratio $(1) /(2)$ \\
\hline $0^{\circ} \mathrm{S}$ & $10.2 \times 10^{-6}$ & $5.5 \times 10^{-6}$ & 1.85 \\
$20^{\circ} \mathrm{S}$ & $6.6 \times 10^{-6}$ & $4.0 \times 10^{-6}$ & 1.67 \\
$40^{\circ} \mathrm{S}$ & $7.5 \times 10^{-6}$ & $4.1 \times 10^{-6}$ & 1.83 \\
$62.5^{\circ} \mathrm{S}$ & $8.9 \times 10^{-6}$ & $4.7 \times 10^{-6}$ & 1.90 \\
\hline
\end{tabular}

Table 4: Comparison of ethane volume mixing ratios at $2 \mathrm{hPa}$ retrieved using the GEISA 2003 database (Jacquinet-Husson et al., 2005) and Vander Auwera et al. (2007) linelist. 


\section{List of Figures}

1 Examples of FP3 and FP4 spectra . . . . . . . . . 61

2 Functional derivatives of the temperature . . . . . . . . . 62

3 Reference temperature and abundance profiles . . . . . . . 62

4 Fits to the methane band and continuum . . . . . . . . 62

5 Retrieved temperature profiles . . . . . . . . . 62

6 Retrieved temperature profiles . . . . . . . . . . . . 62

7 Functional derivatives of hydrocarbons . . . . . . . . . . 62

8 Fits to the $\mathrm{C}_{2} \mathrm{H}_{6}$ band and $\mathrm{C}_{2} \mathrm{H}_{6}$ profiles . . . . . . . 63

9 Fits to the acetylene and propane band . . . . . . . . . . 63

10 Retrieved vertical profiles of $\mathrm{C}_{2} \mathrm{H}_{2}$ and $\mathrm{C}_{3} \mathrm{H}_{8} \ldots \ldots 63$

11 Pressure-latitude temperature maps . . . . . . . . . . . 63

12 Hydrocarbon meridional variations at $1 \mathrm{hPa} \ldots \ldots . . .663$

13 Hydrocarbon meridional variations at $0.1 \mathrm{hPa} \ldots \ldots . . .664$

14 Hydrocarbon meridional variations at $0.01 \mathrm{hPa}$. . . . . . . . 64

15 Ethane distribution at $2 \mathrm{hPa}$ compared to previous studies . . 64

16 Acetylene distribution at $1 \mathrm{hPa}$ compared to previous studies . 64

17 Acetylene distribution at $0.1 \mathrm{hPa}$ compared to previous studies 64

18 Comparison of FP3 and FP4 spectra at $5^{\circ} \mathrm{S}$, two dates . . . 64 


\section{ACCEPTED MANUSCRIPT}

(a)b)

Figure 1: Examples of co-added spectra acquired by several detectors at $15.5 \mathrm{~cm}^{-1}$ of resolution by CIRS Focal Plane 3 (top panel) and 4 (bottom panel) during a limb sequence at $20^{\circ} \mathrm{S}$. Spectral signatures of methane, ethane, acetylene, the propane contribution around $750 \mathrm{~cm}^{-1}$ as well as the collision-induced continuum emission are visible. The corresponding spectral ranges used in this study are outlined. The corrected tangent heights $z$ and the corresponding atmospheric pressure levels $P$ (calculated from the retrieved temperature at this latitude) are given for each detector. 
Figure 2: Functional derivatives of the temperature calculated at wavenumbers $\nu_{i}=605$, 1250 and $1305 \mathrm{~cm}^{-1}$ for five FP4 and three FP3 spectra at $30^{\circ} \mathrm{N}$. The corresponding tangent altitudes are indicated in the right-hand.

$(\mathrm{a} b \mathrm{~b})$

Figure 3: Left panel: a priori temperature profiles. Right panel: a priori abundance profiles (from Moses and Greathouse (2005)).

Figure 4: Examples of eight out of twelve synthetic spectra in the methane band (a) and the continuum emission (b). Solid lines are for the spectra calculated from the fictitious profile (with a 2- $\sigma$ random noise as indicated), dashed lines correspond to the retrieval starting from the warm a priori profile and dotted lines are from the cold a priori profile. In this example, the retrieval starting from the warmer a priori profile provides the best fit of the data and the closest temperature profile to the fictitious profile.

Figure 5: Left panel: the retrieved profiles (dashed lines), starting from two different $a$ priori profiles (solid lines), are close to the fictitious profile (dashed triple-dotted line). Right panel: two retrieved temperature profiles (dashed and dot-dashed lines) at $30^{\circ} \mathrm{N}$ starting from different a priori profiles (solid lines). In this case, the warmer profile yields the best fit shown in Fig. 6 . In both panels, dotted lines stand for error envelops and horizontal bars define the vertical range of maximum sensitivity.

Figure 6: Comparison between CIRS observed spectra at $30^{\circ} \mathrm{N}$ (solid lines) and best-fit synthetic spectra (dashed lines) for different tangent heights. Panel a) compares observations and calculations in the $\nu_{4}$ band of methane, panel b) in the region of the collision-induced emission. Dotted lines are synthetic spectra calculated with a temperature profile equal to the solution profile \pm its estimated error.

$(\mathrm{a}(\mathrm{b})$

Figure 7: Left panel: functional derivatives in the ethane band at $820 \mathrm{~cm}^{-1}$. Right panel: functional derivatives in the acetylene band at $730 \mathrm{~cm}^{-1}$ (solid lines) and in the propane band at $750 \mathrm{~cm}^{-1}$ (dashed lines). Both are for the same sequence at $30^{\circ} \mathrm{N}$, with the corrected tangent altitudes as indicated. 
(a)b)

Figure 8: Left panel: synthetic spectra at the final stage of a retrieval (dashed lines) compared to ethane spectra calculated from the fictitious profile (solid lines). Right panel: the retrieved profiles (dashed lines), starting from two a priori profiles, are compared to the fictitious profile (dashed triple-dotted line). Dotted lines stand for error envelops and horizontal bars define the vertical range of maximum sensitivity.

Figure 9: Left panel: comparison between spectra calculated from fictitious profiles of $\mathrm{C}_{2} \mathrm{H}_{2}$ and $\mathrm{C}_{3} \mathrm{H}_{8}$ (solid line) and synthetic spectra in the case of the retrieval of $\mathrm{C}_{2} \mathrm{H}_{2}$ only (triple dot-dashed line) and for the simultaneous retrieval of $\mathrm{C}_{2} \mathrm{H}_{2}$ and $\mathrm{C}_{3} \mathrm{H}_{8}$ (dashed line). Residual radiances (observed - synthetic) are plotted on the right panel.

(a)b)

Figure 10: Vertical profiles of acetylene (left panel) and propane (right panel) as retrieved from different a priori profiles and compared to the fictitious profiles. Error envelopes that do not include systematic errors - are shown in dotted lines. Horizontal bars define the vertical range of maximum sensitivity.

Figure 11: Meridional temperature profiles at three pressure levels. The different symbols represent different datasets: squares, crosses, stars and triangles stand for LIMBMAP data from respectively March and December 2005 and February and August 2006. Diamond symbols stand for isolated OCCLIMB and LIMBINT data (see Table 1. for their acquisition dates). The gray shading refers to the $1-\sigma$ temperature retrieval at $1 \mathrm{hPa}$ of Fletcher et al. (2007, 2008).

Figure 12: Meridional profiles of $\mathrm{C}_{2} \mathrm{H}_{6}, \mathrm{C}_{2} \mathrm{H}_{2}$ and $\mathrm{C}_{3} \mathrm{H}_{8}$ abundance at $1 \mathrm{hPa}$. Smoothed spline interpolations are indicated with dotted lines, and the dot-dashed lines are the meridional profiles predicted by Moses and Greathouse (2005) photochemical model, scaled as indicated in the text. The symbol coding is the same as in Fig. 11. 
Figure 13: Meridional profiles of $\mathrm{C}_{2} \mathrm{H}_{6}$ and $\mathrm{C}_{2} \mathrm{H}_{2}$ abundance at $10^{-1} \mathrm{hPa}$. Smoothed spline interpolations are indicated with dotted lines. The symbol coding is the same as in Fig. 11.

Figure 14: Meridional profiles of $\mathrm{C}_{2} \mathrm{H}_{6}$ and $\mathrm{C}_{2} \mathrm{H}_{2}$ abundances at $10^{-2} \mathrm{hPa}$. Smoothed spline interpolations are indicated with dotted lines, and the dot-dashed lines are the meridional profiles predicted by Moses and Greathouse (2005) photochemical model, scaled as indicated in the text. Gray shading is added to emphasize the regions with strongest degree of confidence. The symbol coding is the same as in Fig. 11.

Figure 15: Ethane volume mixing ratio as retrieved in this study (diamonds) and from previous observations by Greathouse et al. (2005a) (squares) and Howett et al. (2007) (diagonal crosses). The two latter retrieved abundances were divided by 1.8 , as justified in the text.

Figure 16: Acetylene volume mixing ratio at $1.1 \mathrm{hPa}$ as retrieved in this study (diamonds) and from previous observations by Greathouse et al. (2005a) (squares) and Howett et al. (2007) (diagonal crosses).

Figure 17: Acetylene volume mixing ratio at $0.12 \mathrm{hPa}$ as retrieved in this study (diamonds) and from previous observations by Greathouse et al. (2005a) (squares).

Figure 18: Comparison of FP4 spectra (top panels) and FP3 spectra (bottom panels) acquired at $5^{\circ} \mathrm{S}$ in March 2005 (solid lines) and in February 2006 (dashed lines). Each panel compares spectra acquired one year apart, at similar tangent altitudes (ztan). 
Temperature functional derivatives
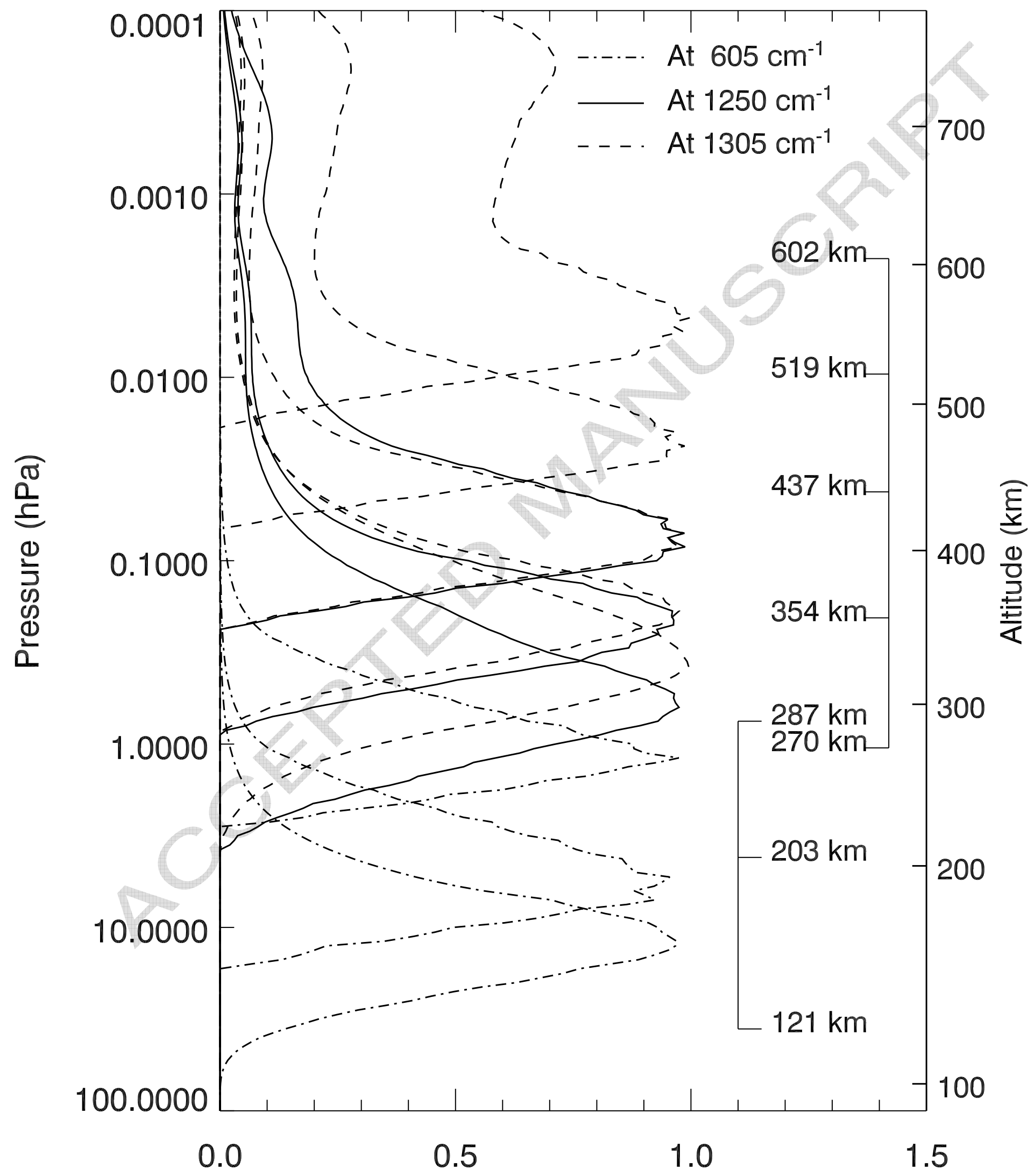

Normalized kernels 


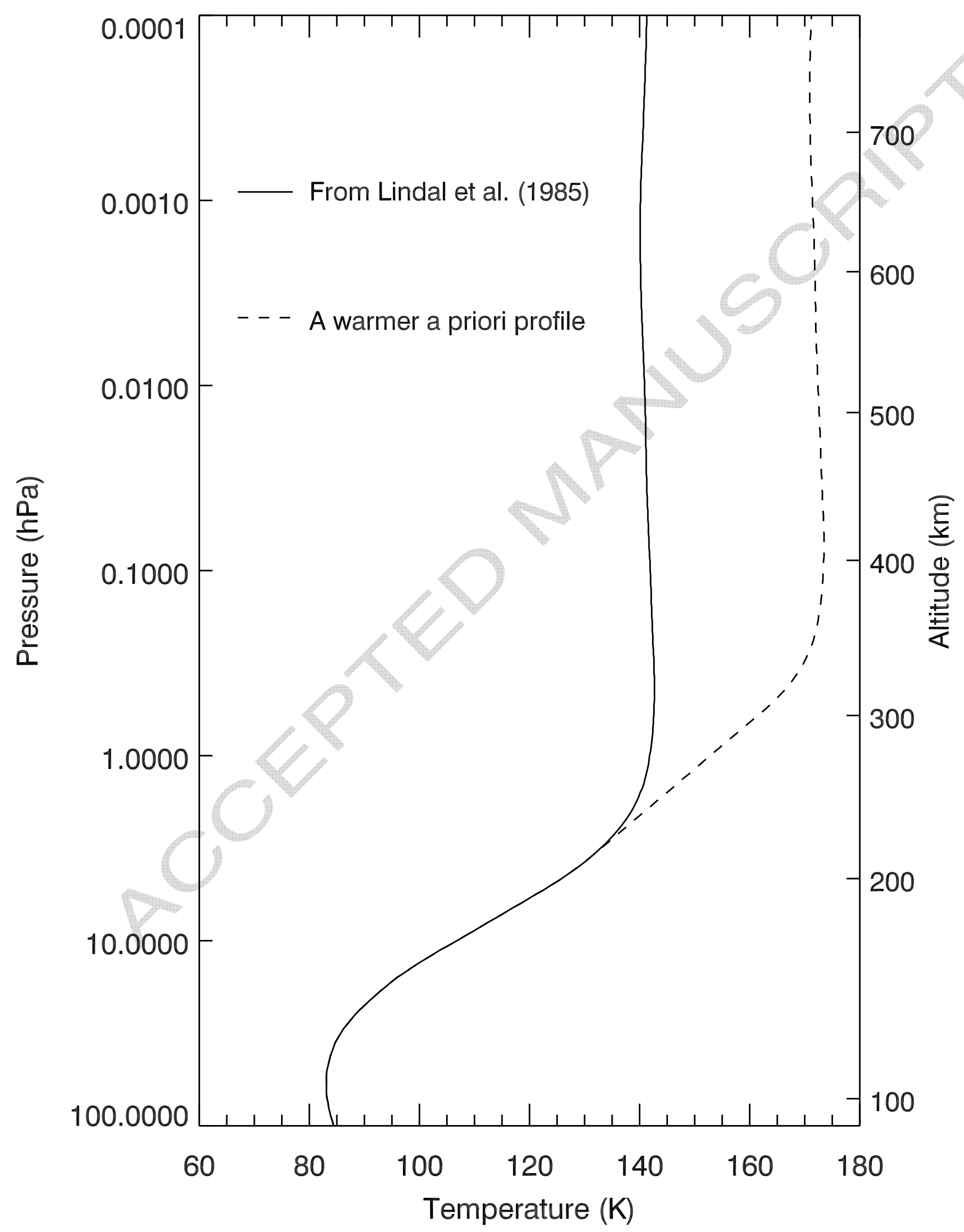




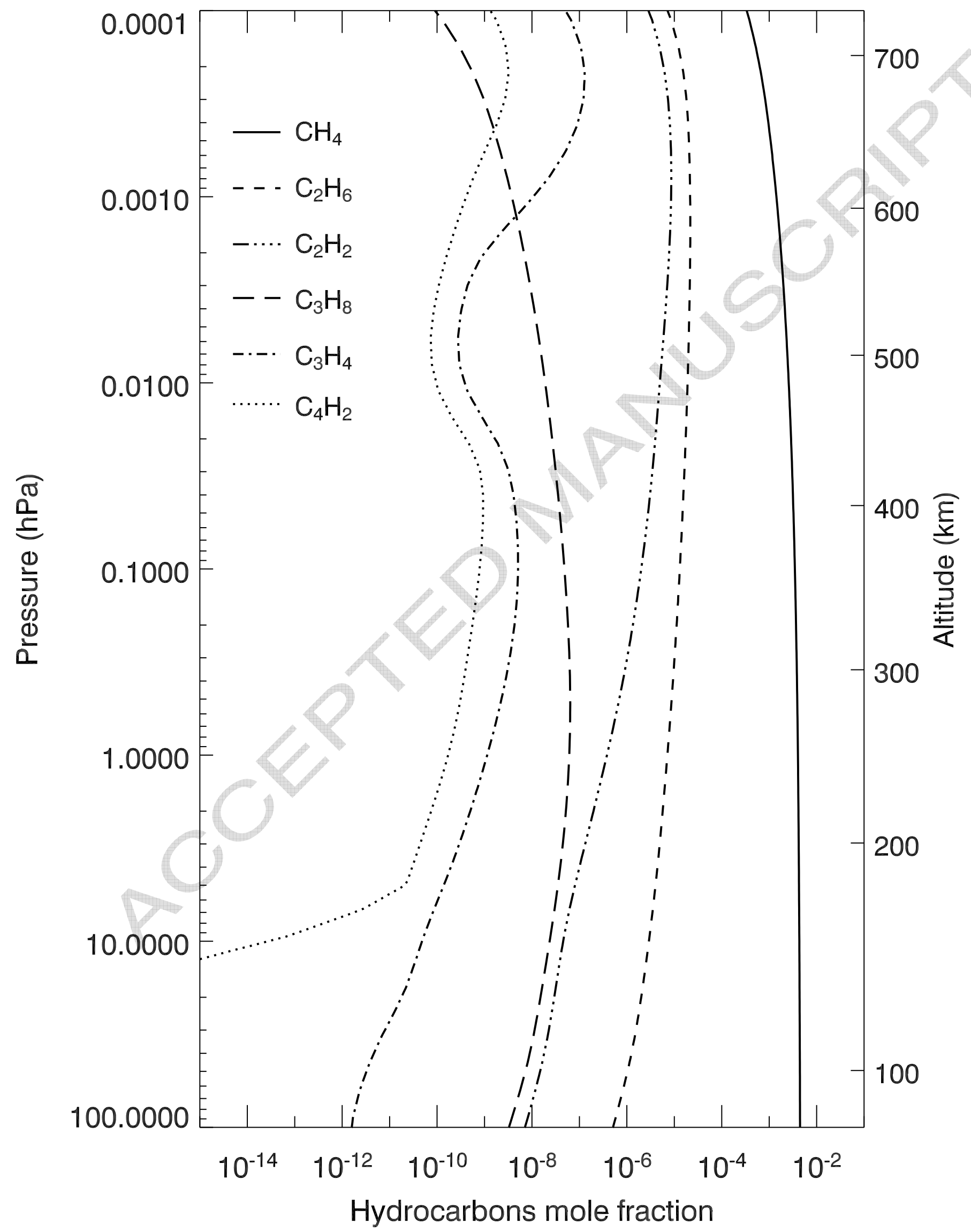




\section{ACCEPTED MANUSCRIPT}

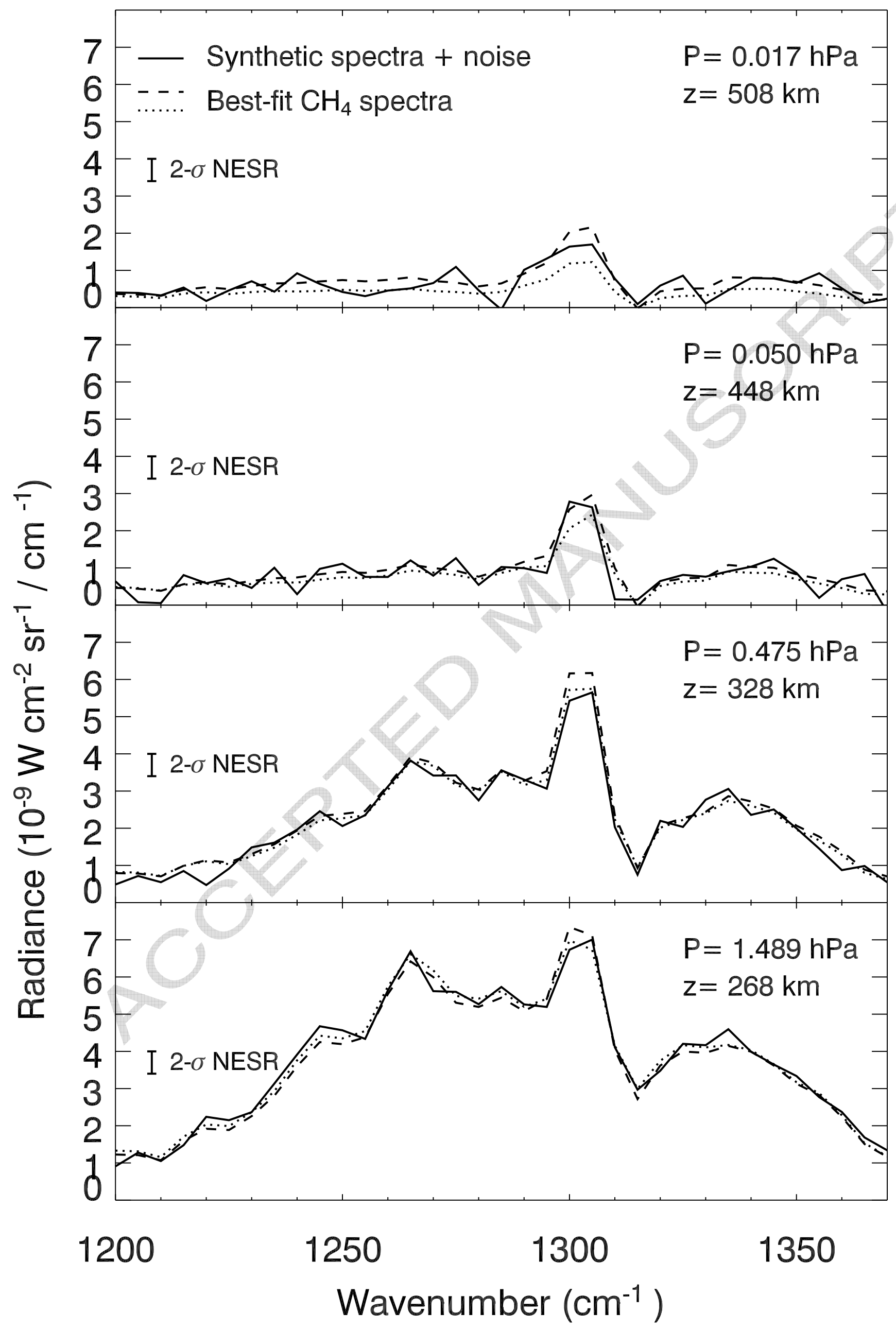




\section{ACCEPTED MANUSCRIPT}

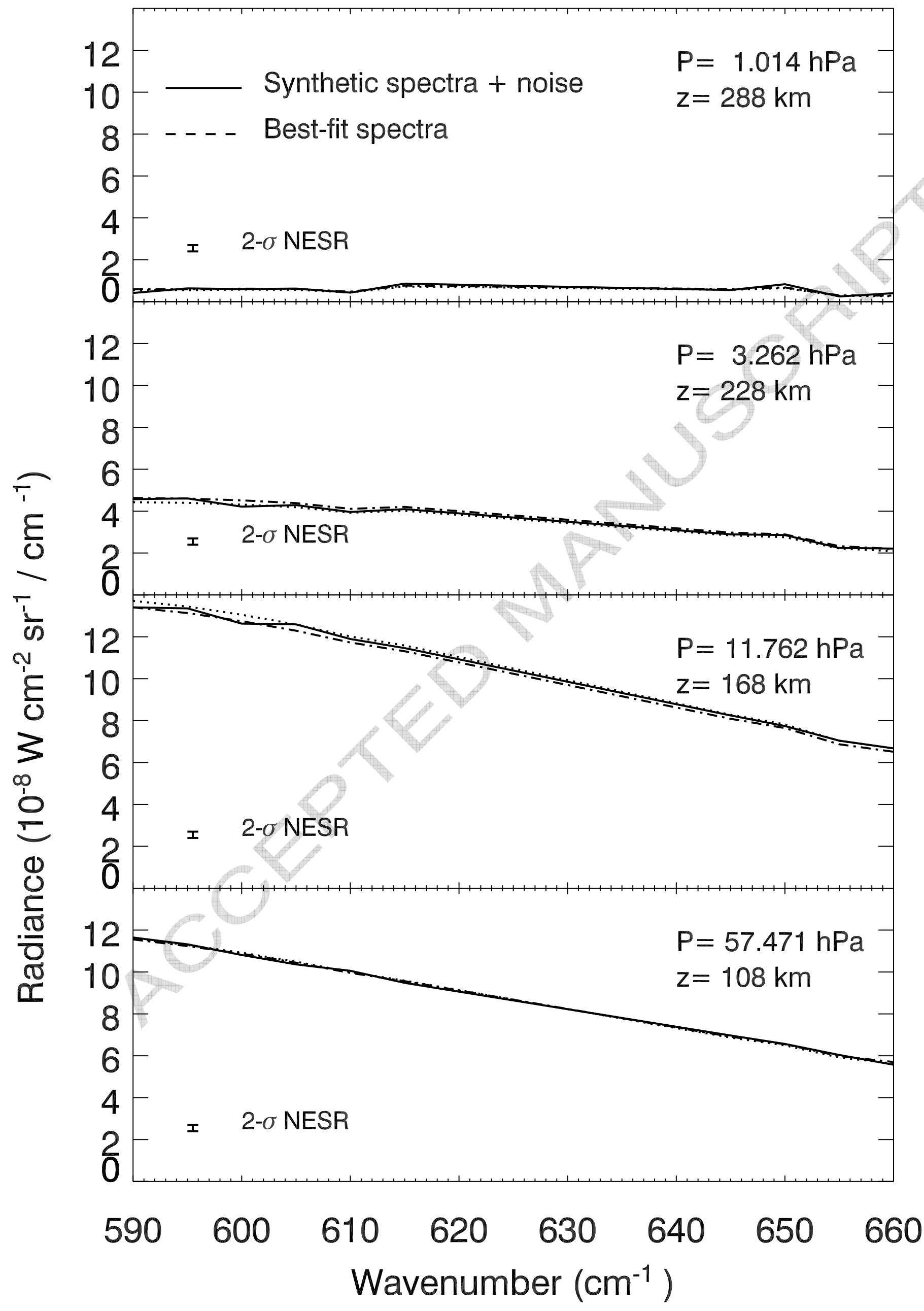




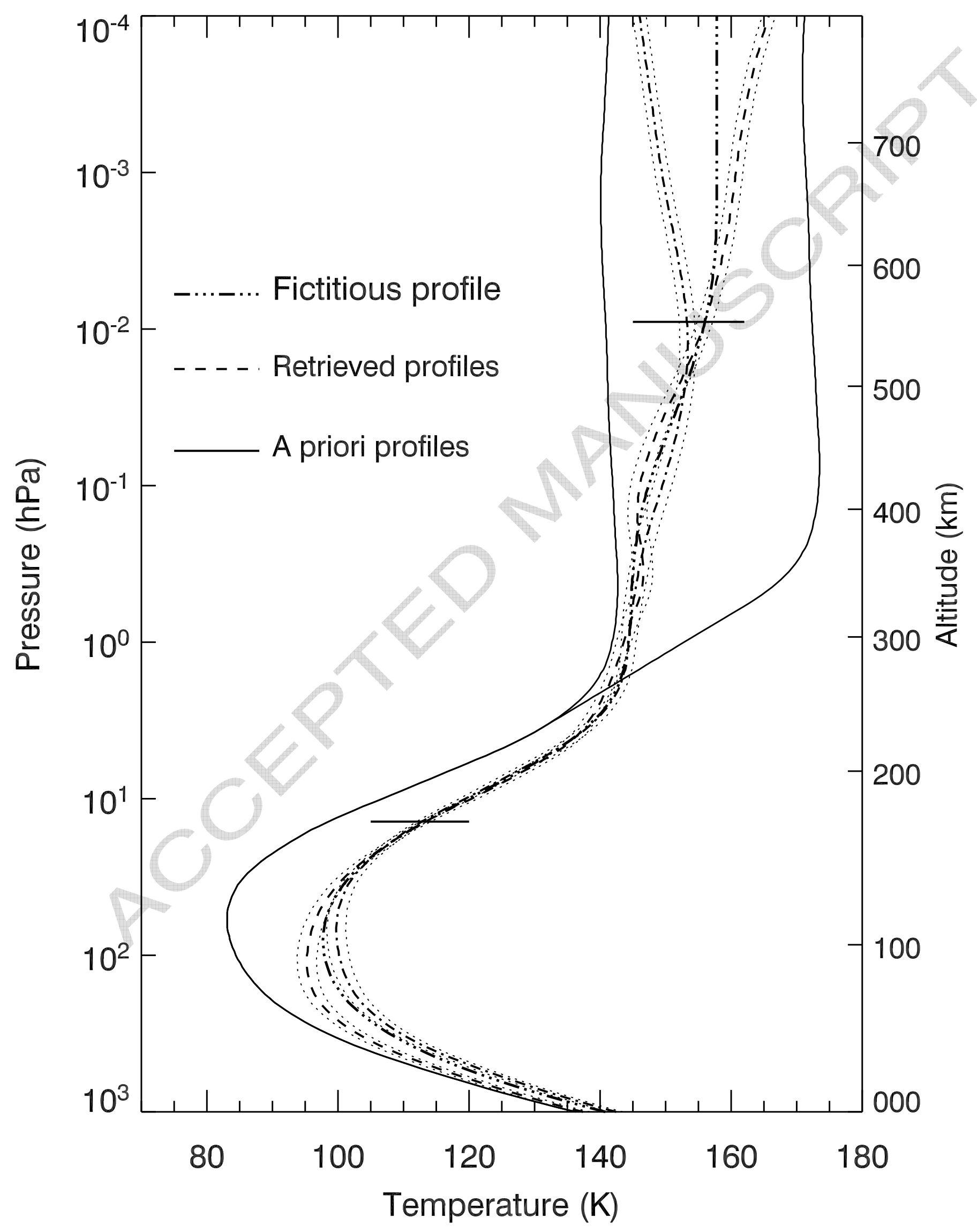




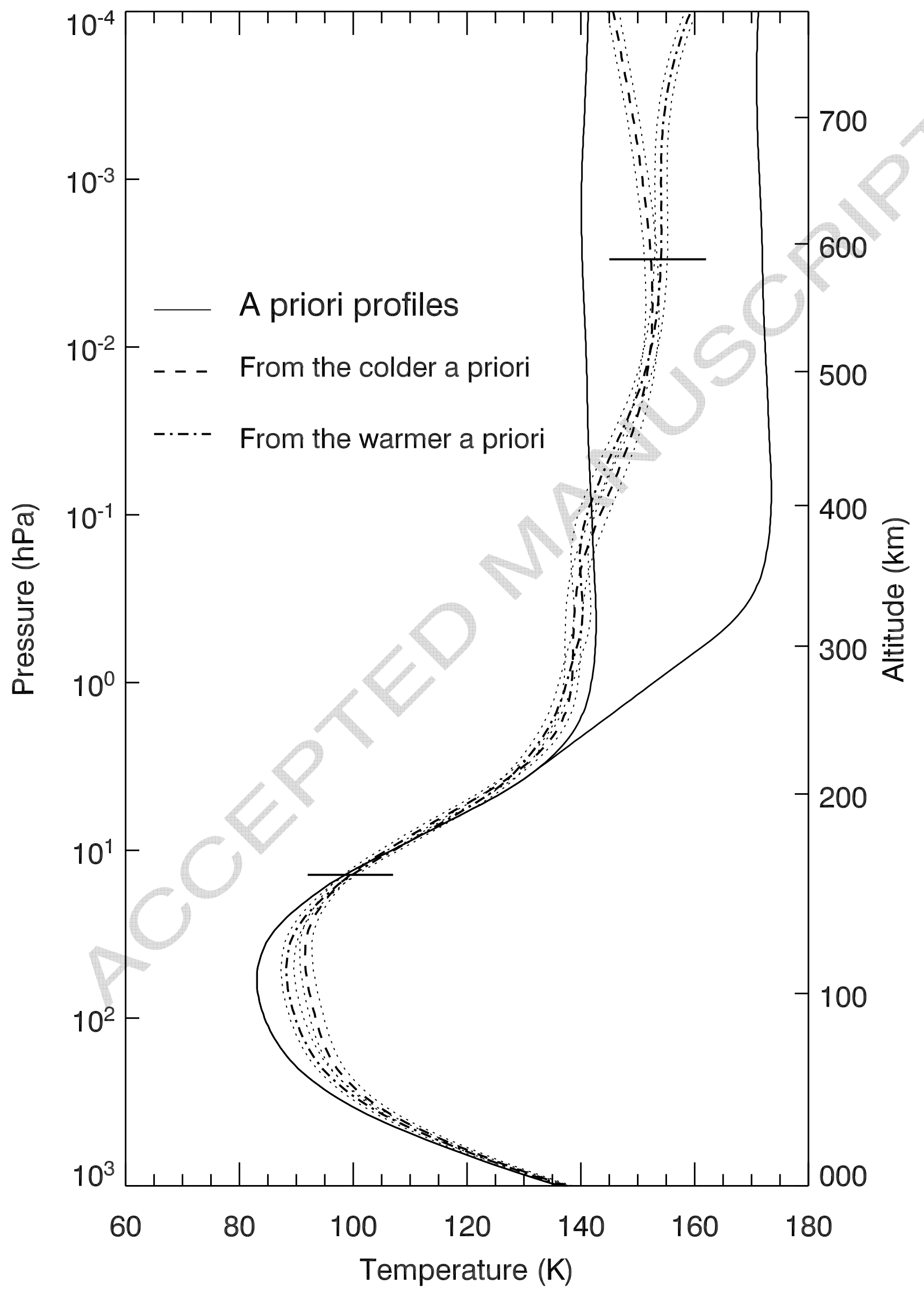




\section{ACCEPTED MANUSCRIPT}

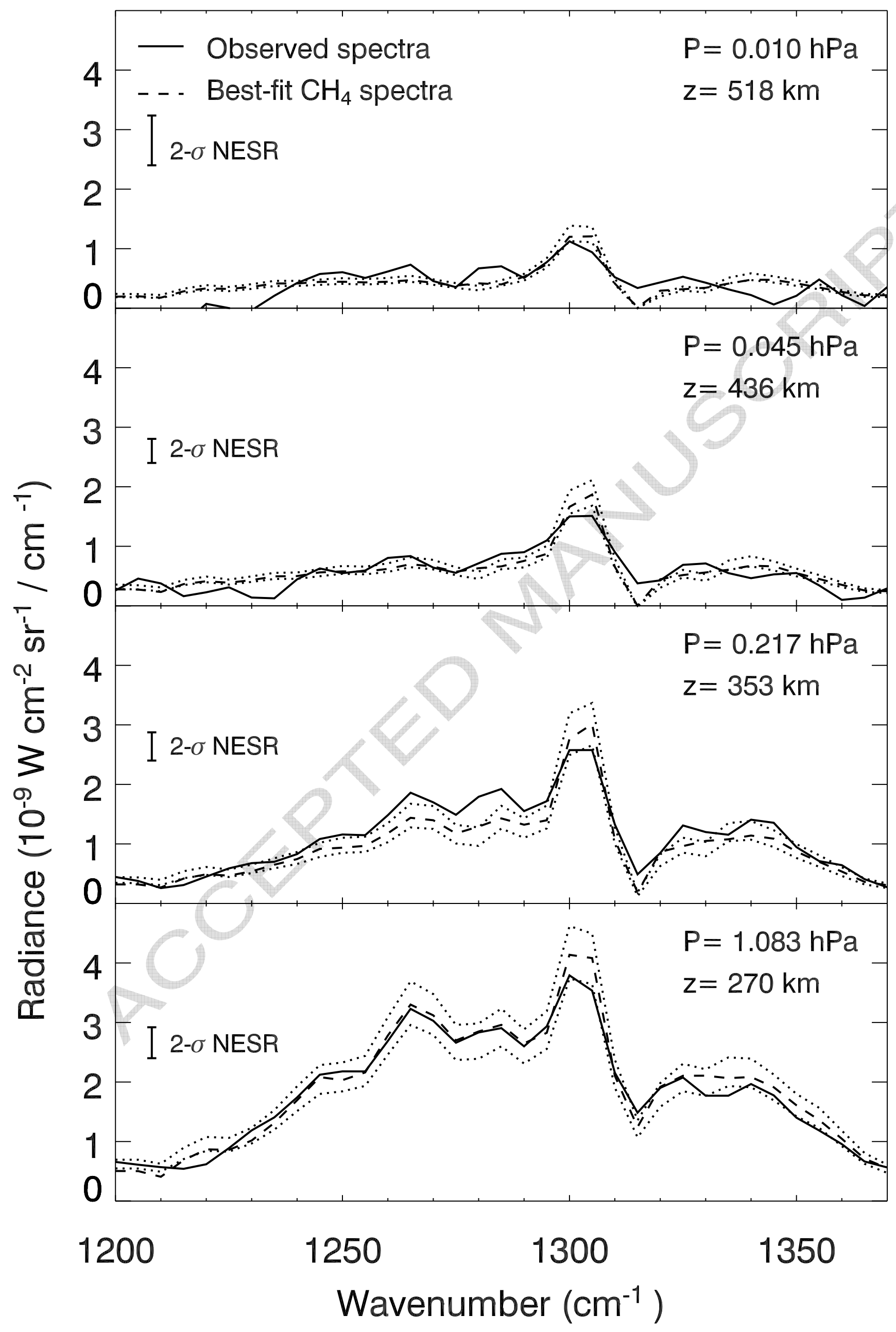




\section{ACCEPTED MANUSCRIPT}

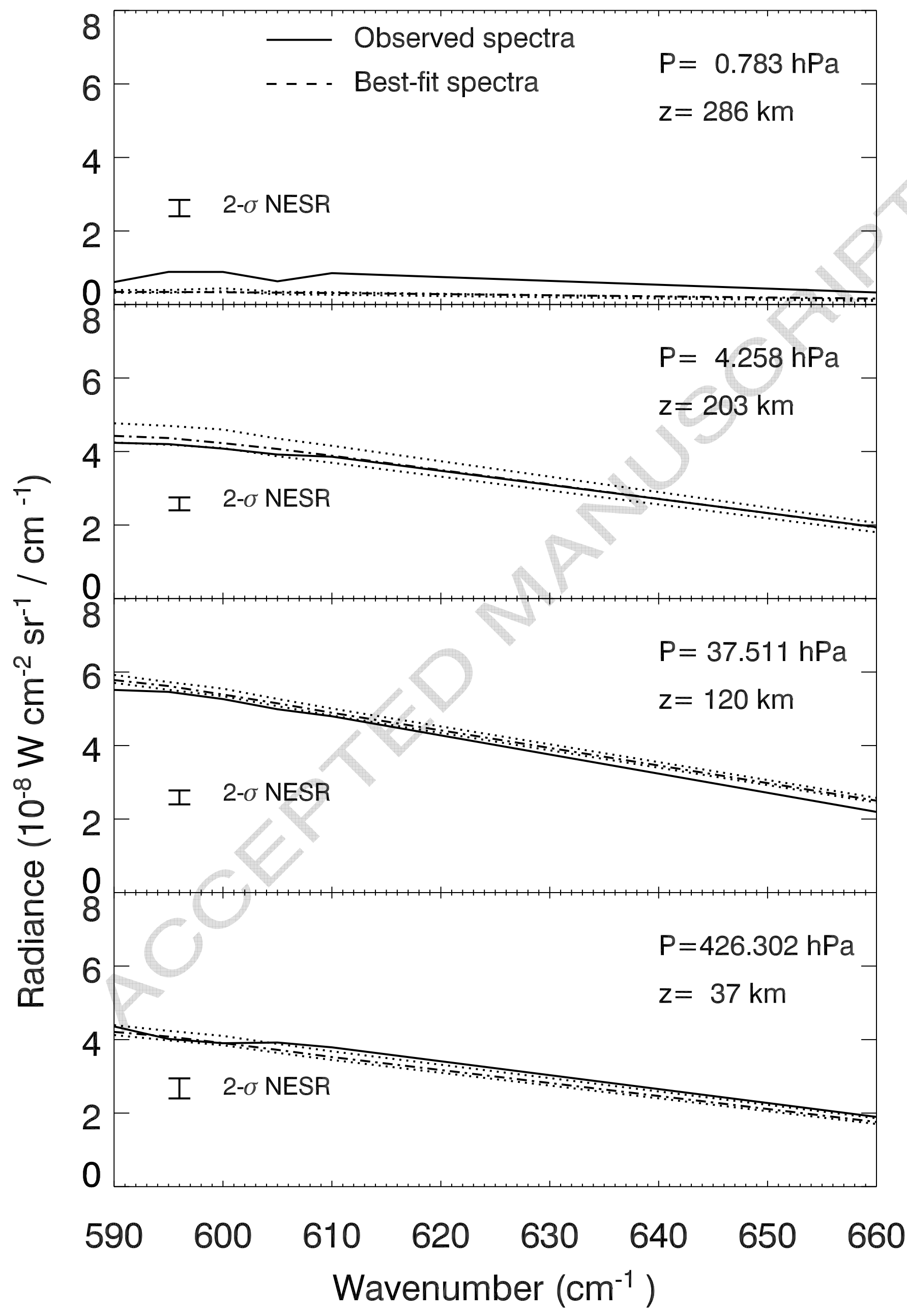


Ethane functional derivatives

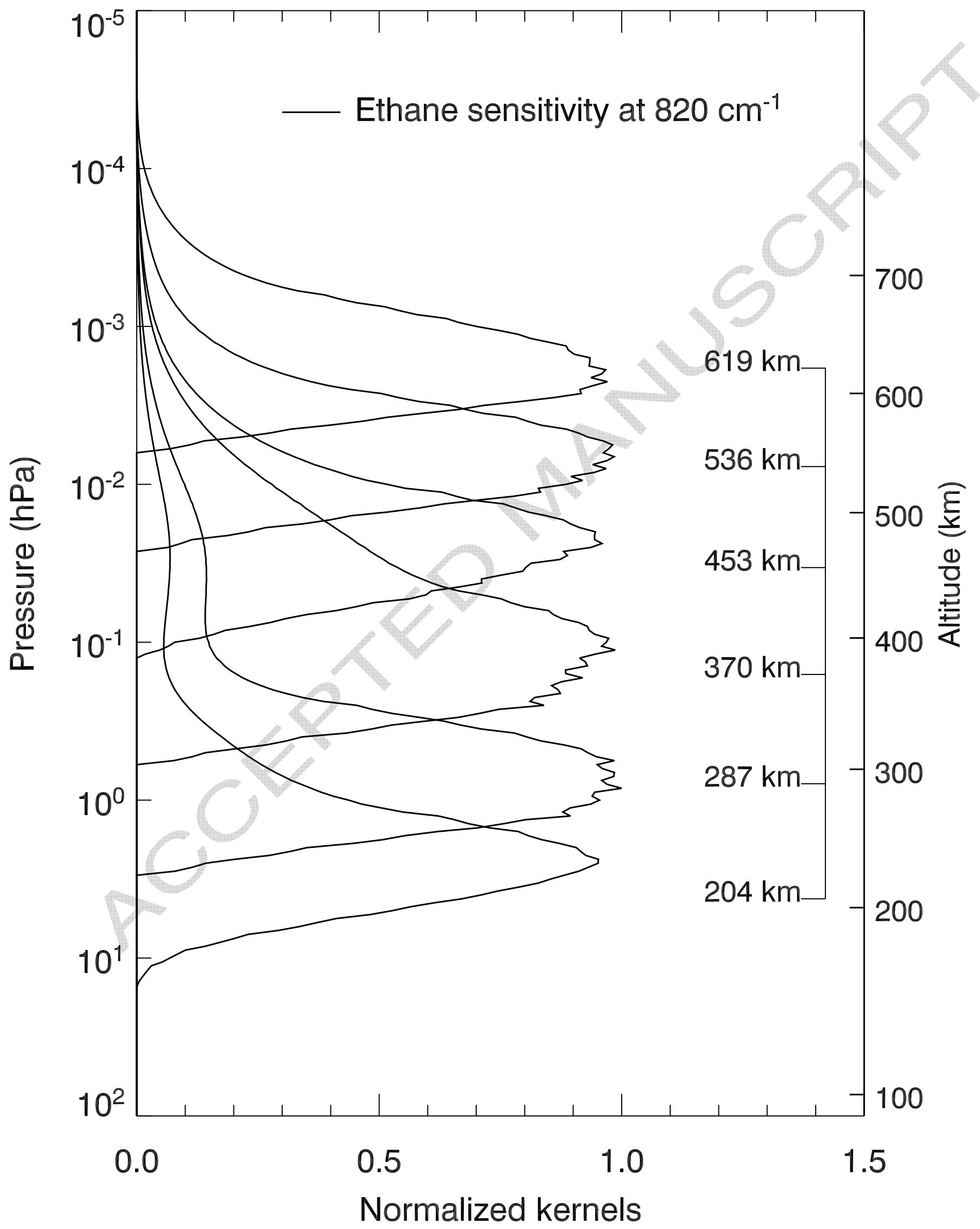




\section{Acetylene and propane functional derivatives}

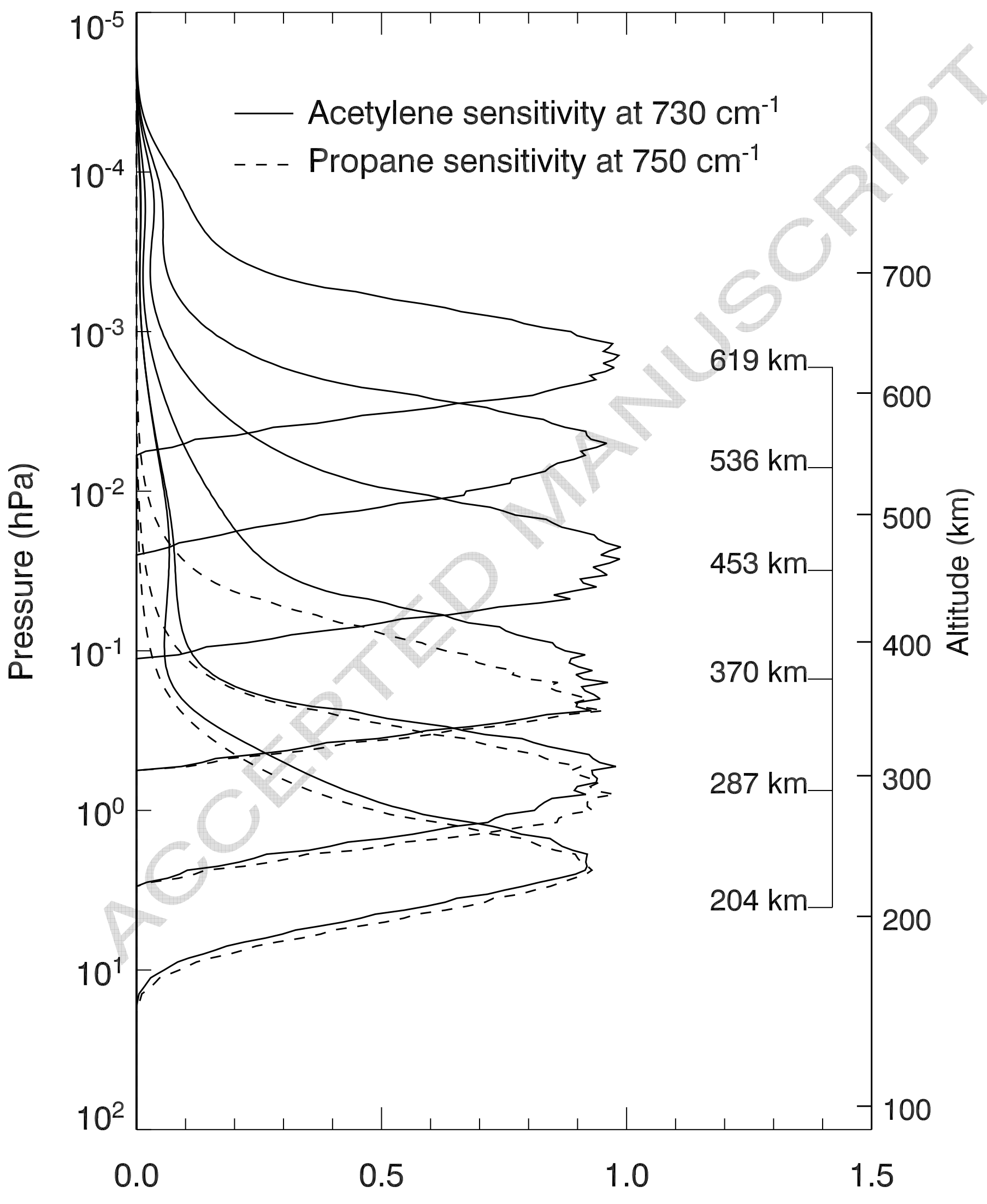

Normalized kernels 


\section{ACCEPTED MANUSCRIPT}

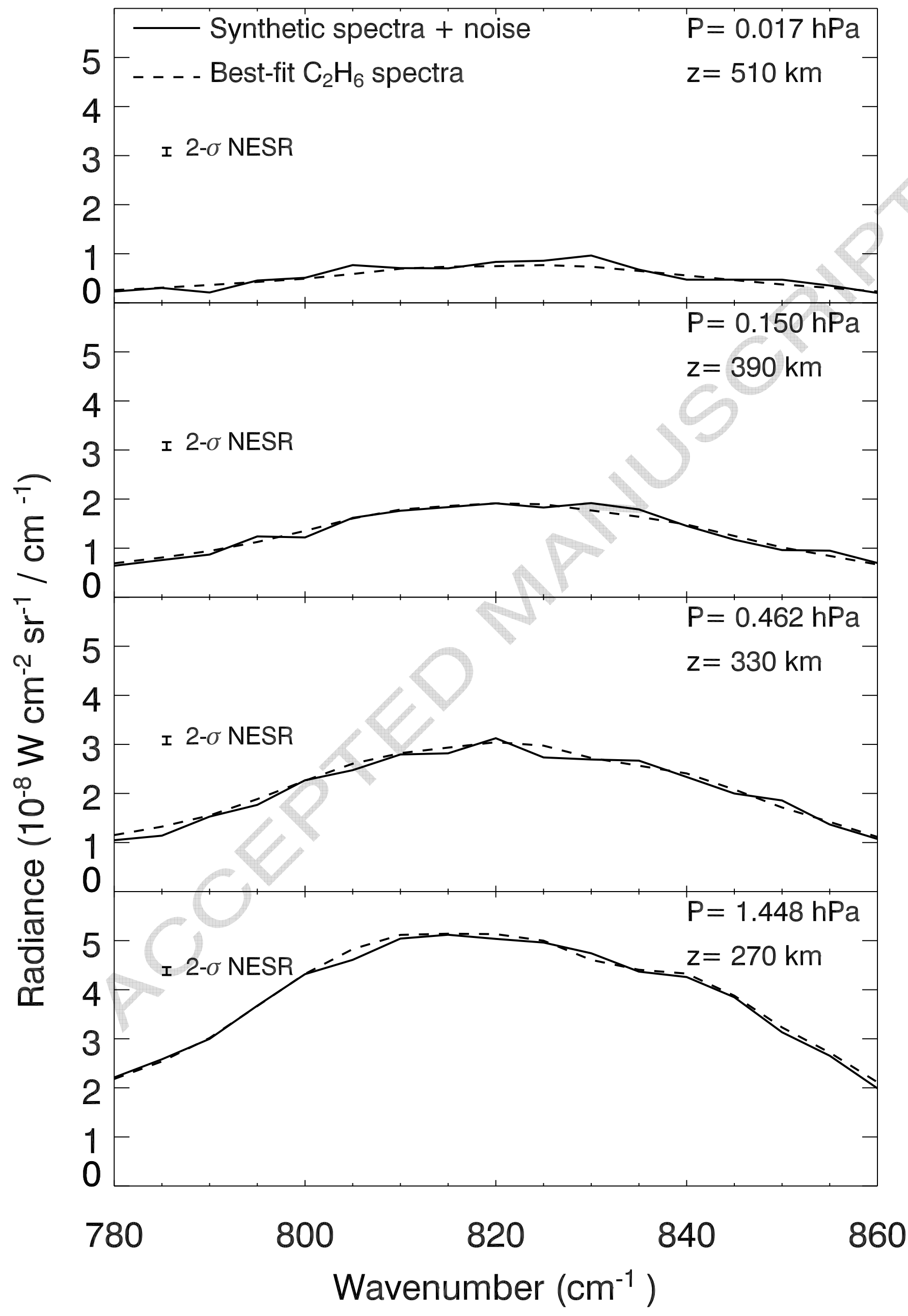




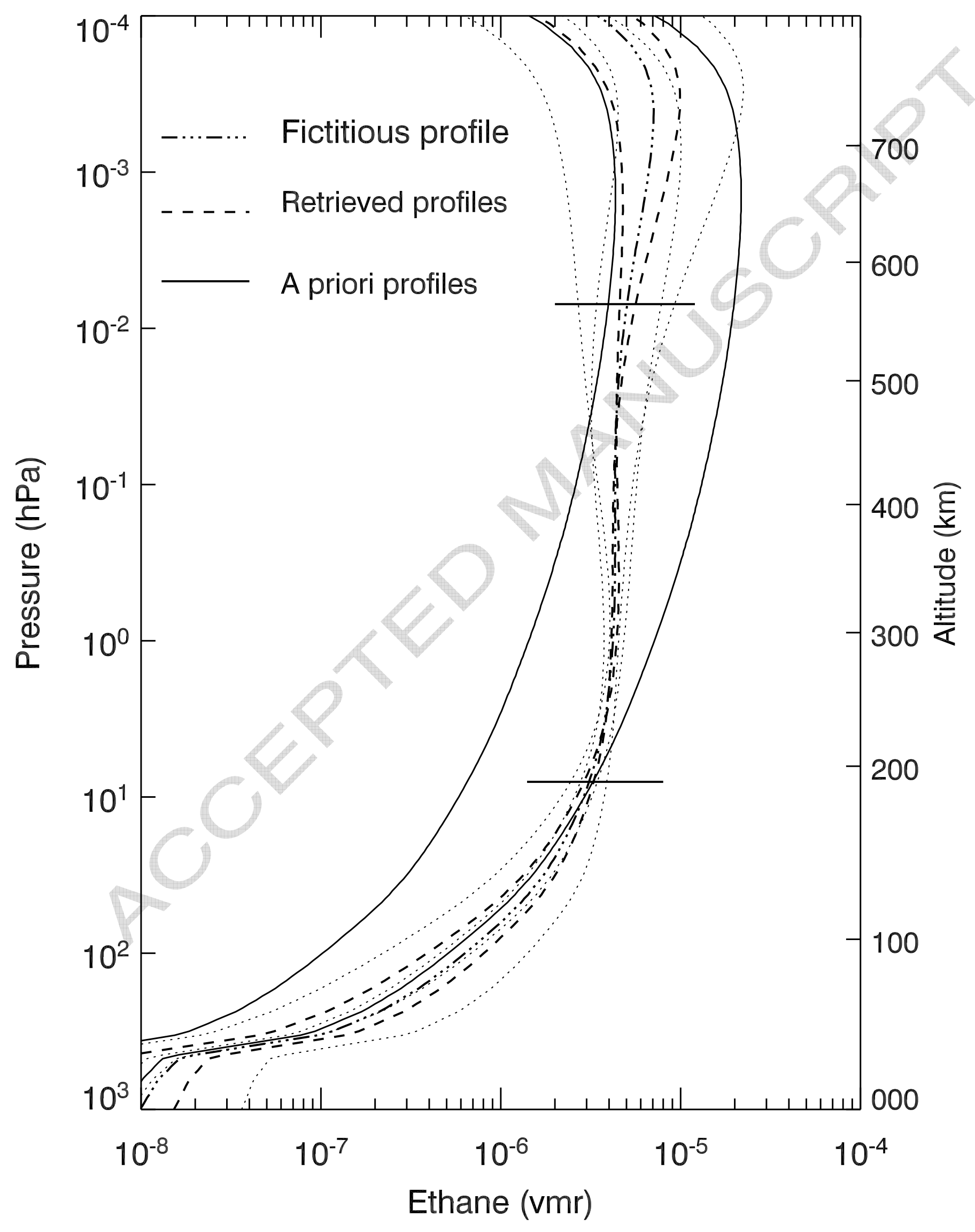




\section{ACCEPTED MANUSCRIPT}

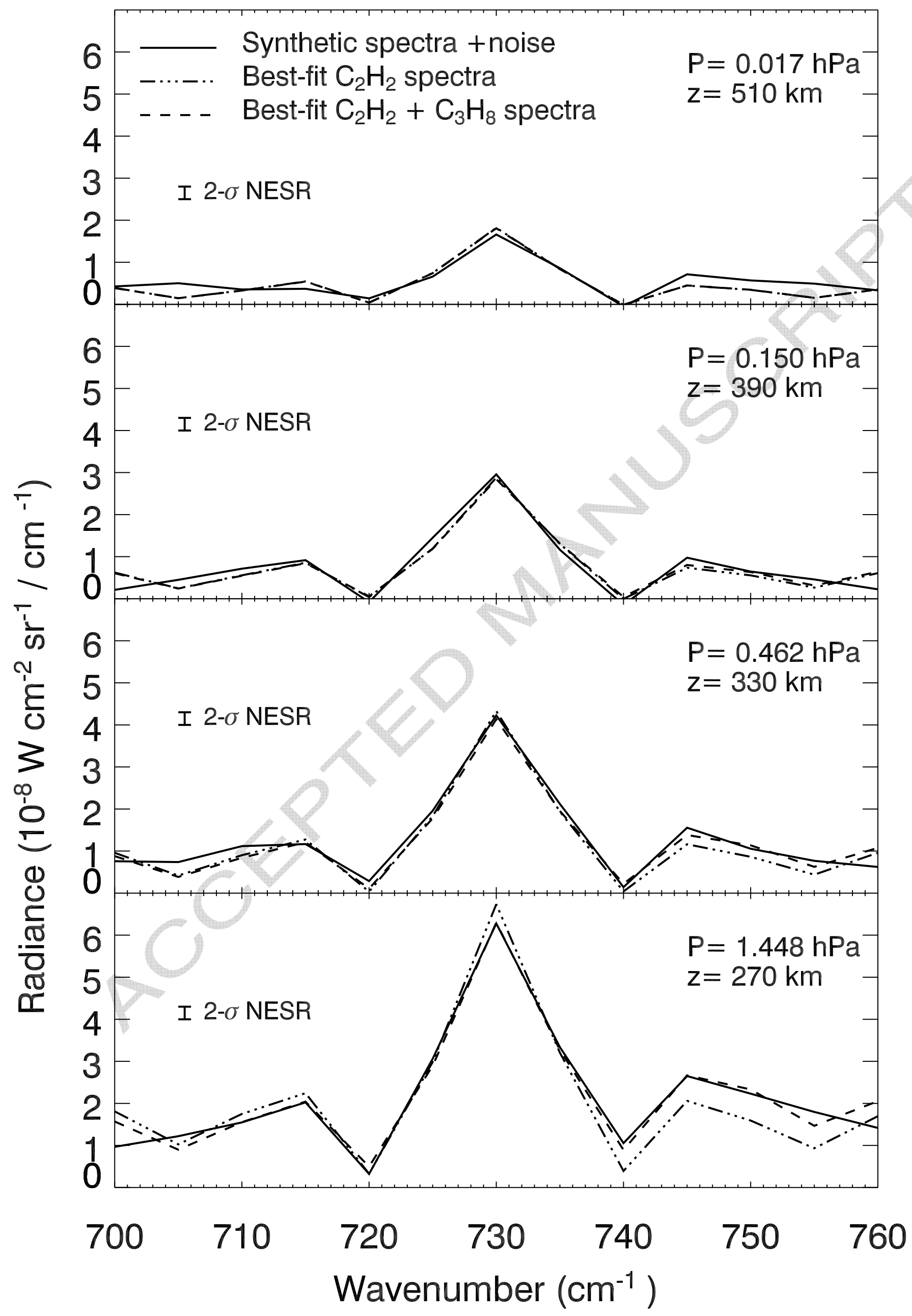




\section{ACCEPTED MANUSCRIPT}

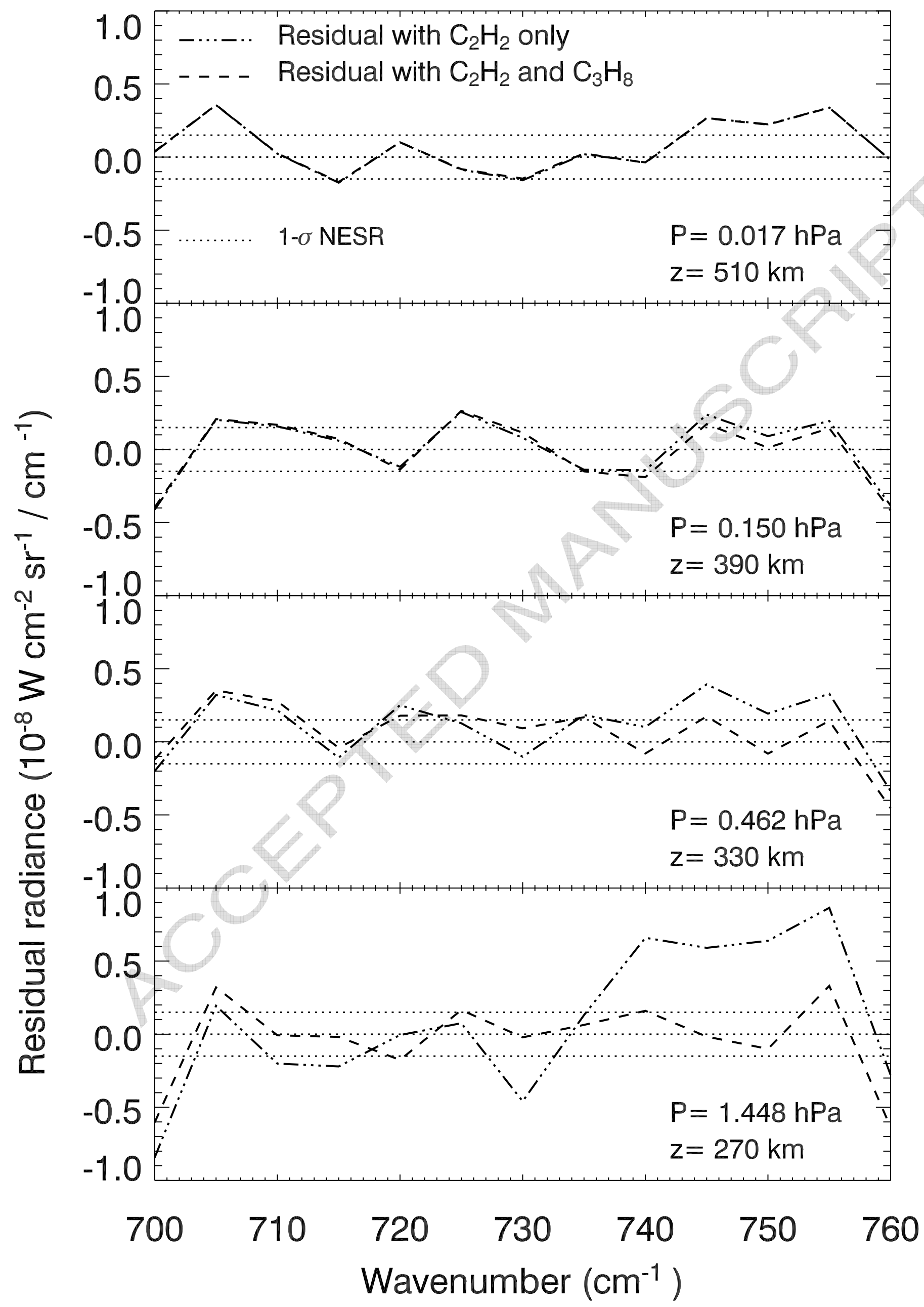




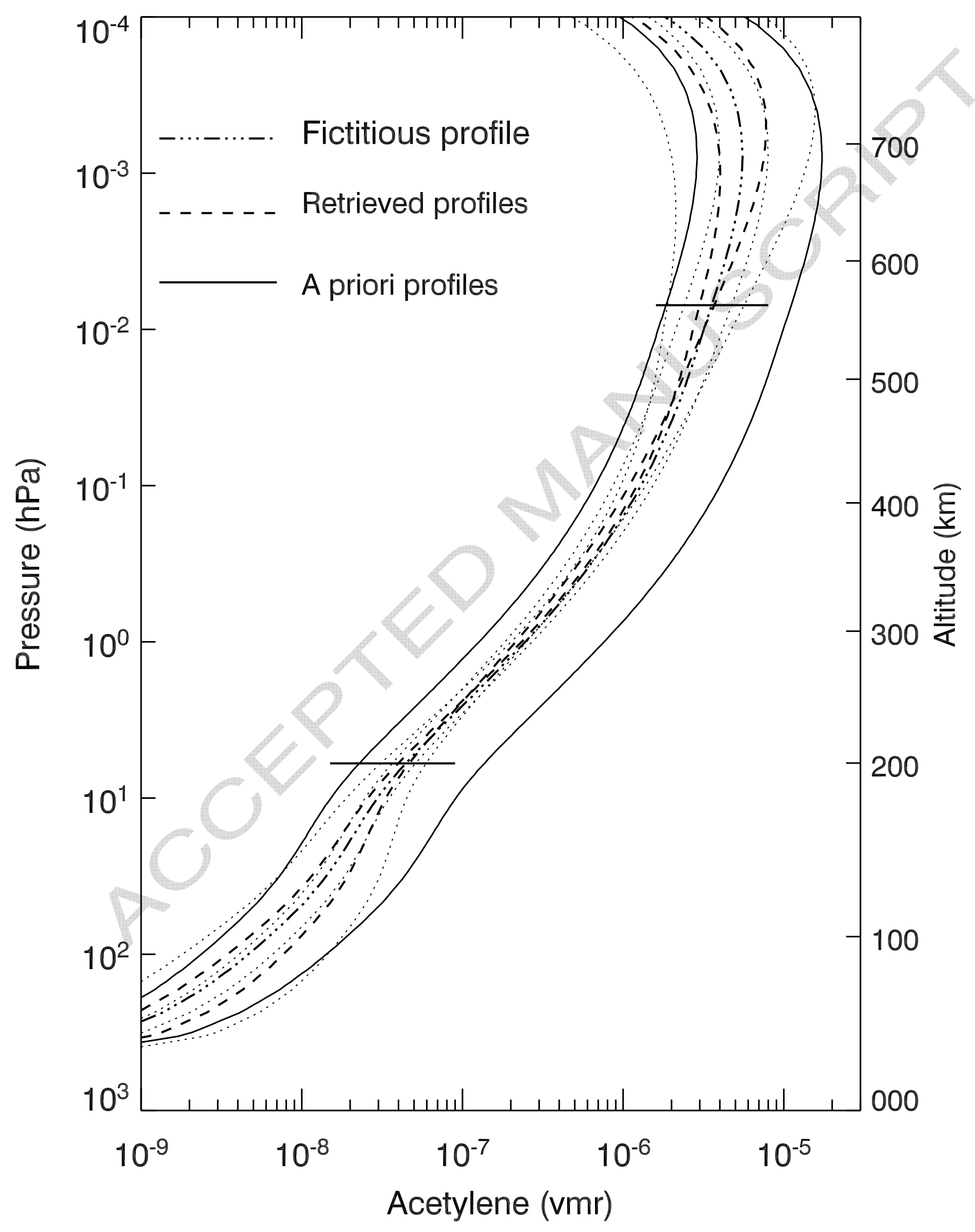




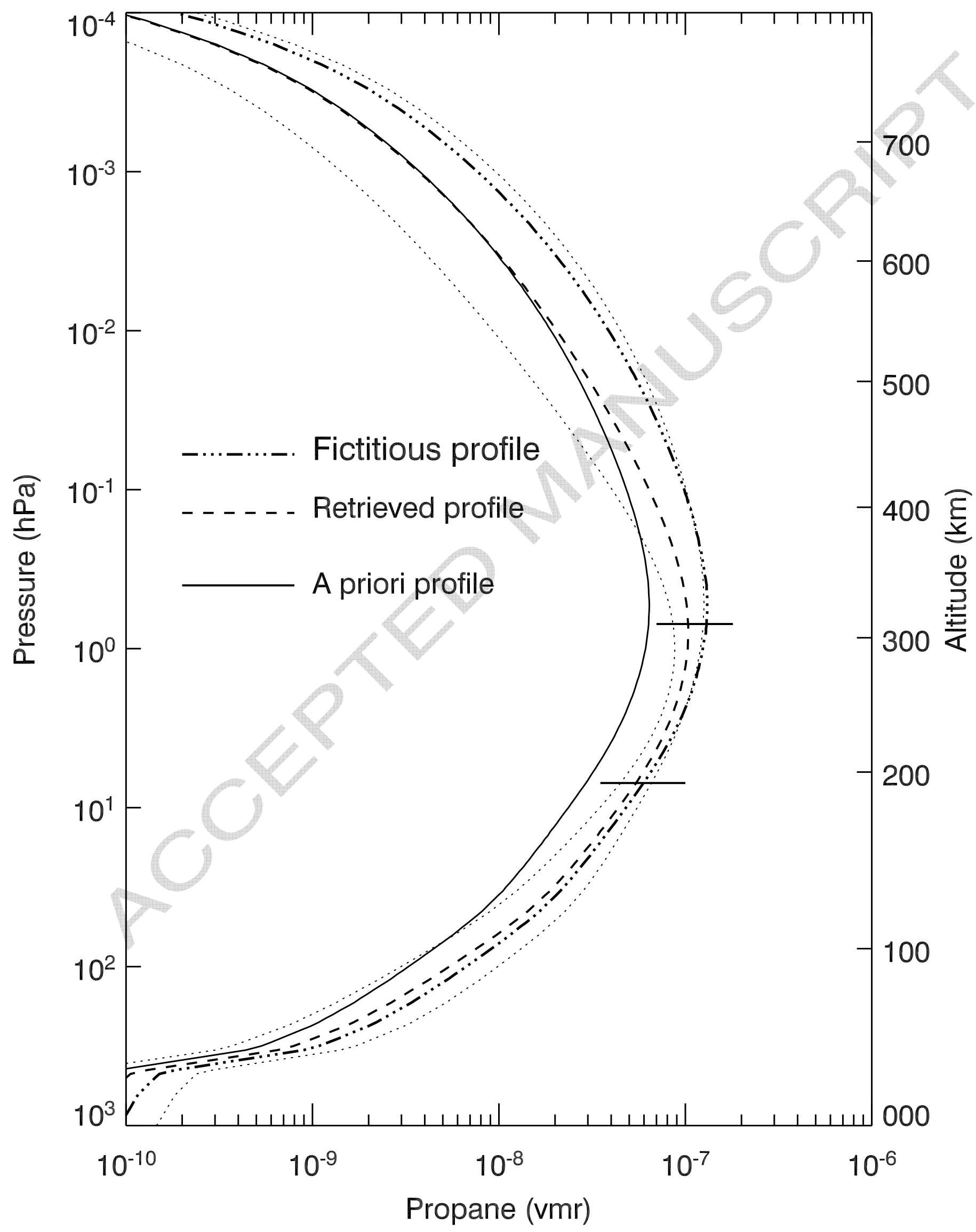




\section{ACCEPTED MANUSCRIPT}

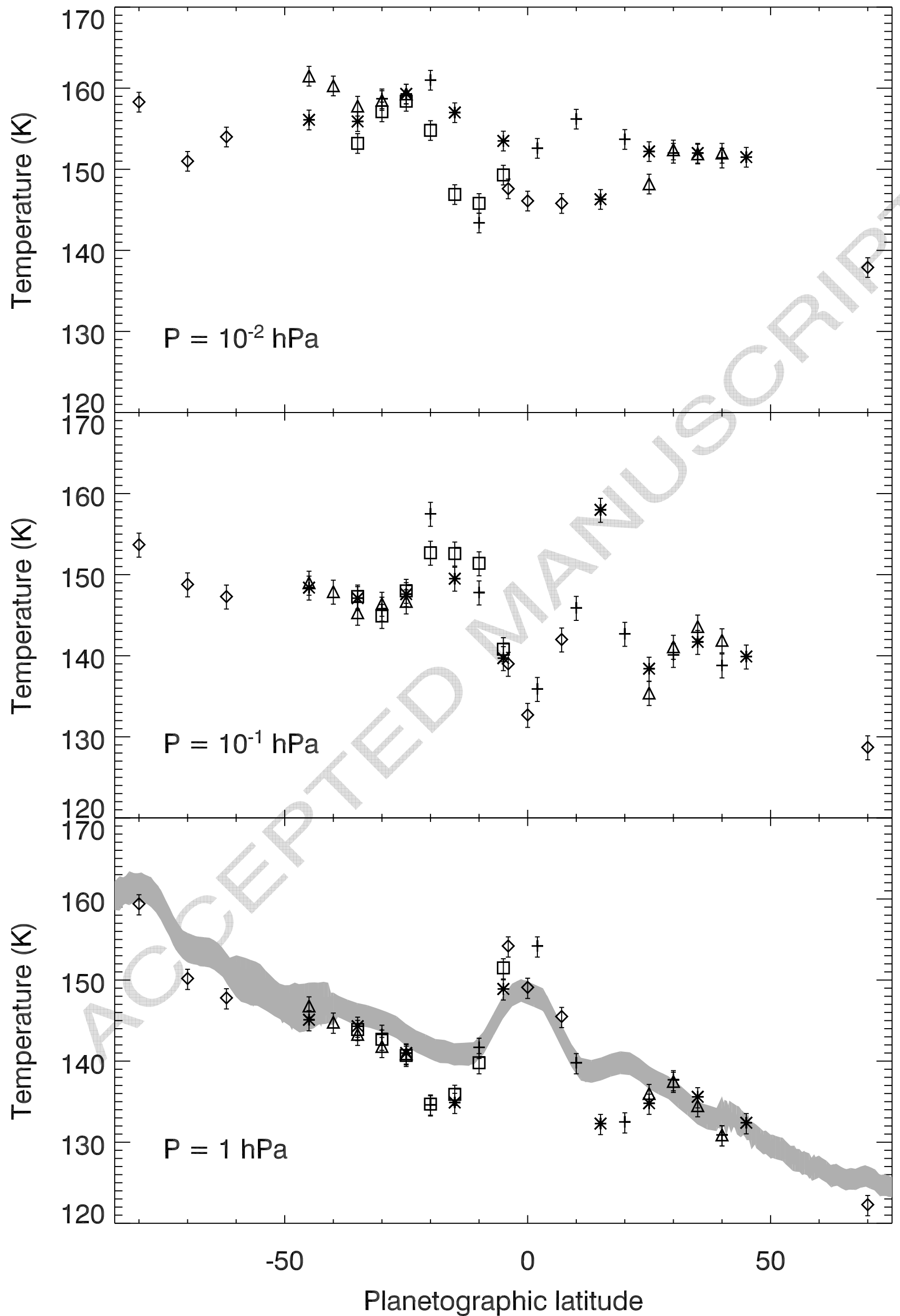


Hydrocarbon variations at $1 \mathrm{hPa}$

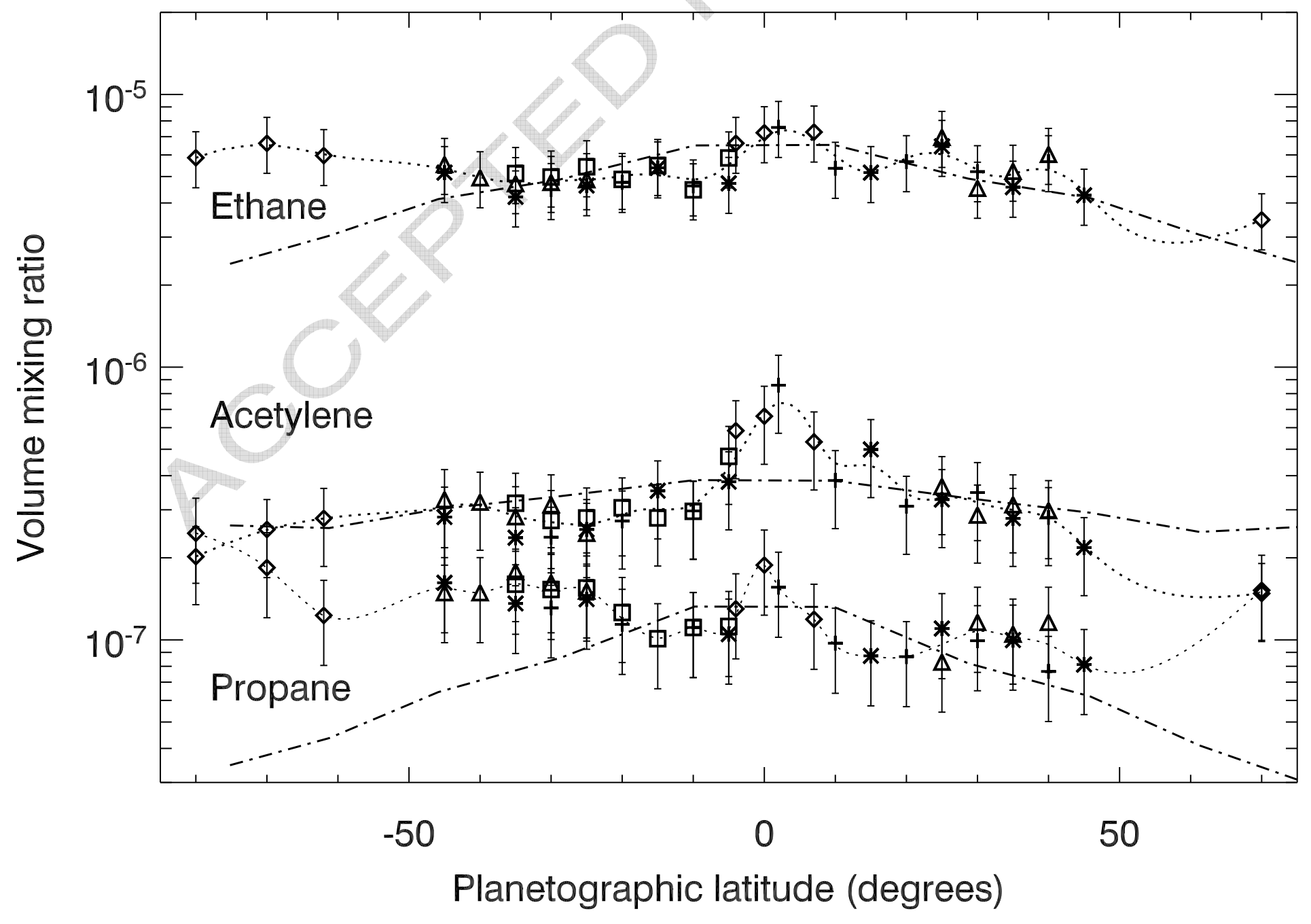


Hydrocarbon variations at $0.1 \mathrm{hPa}$

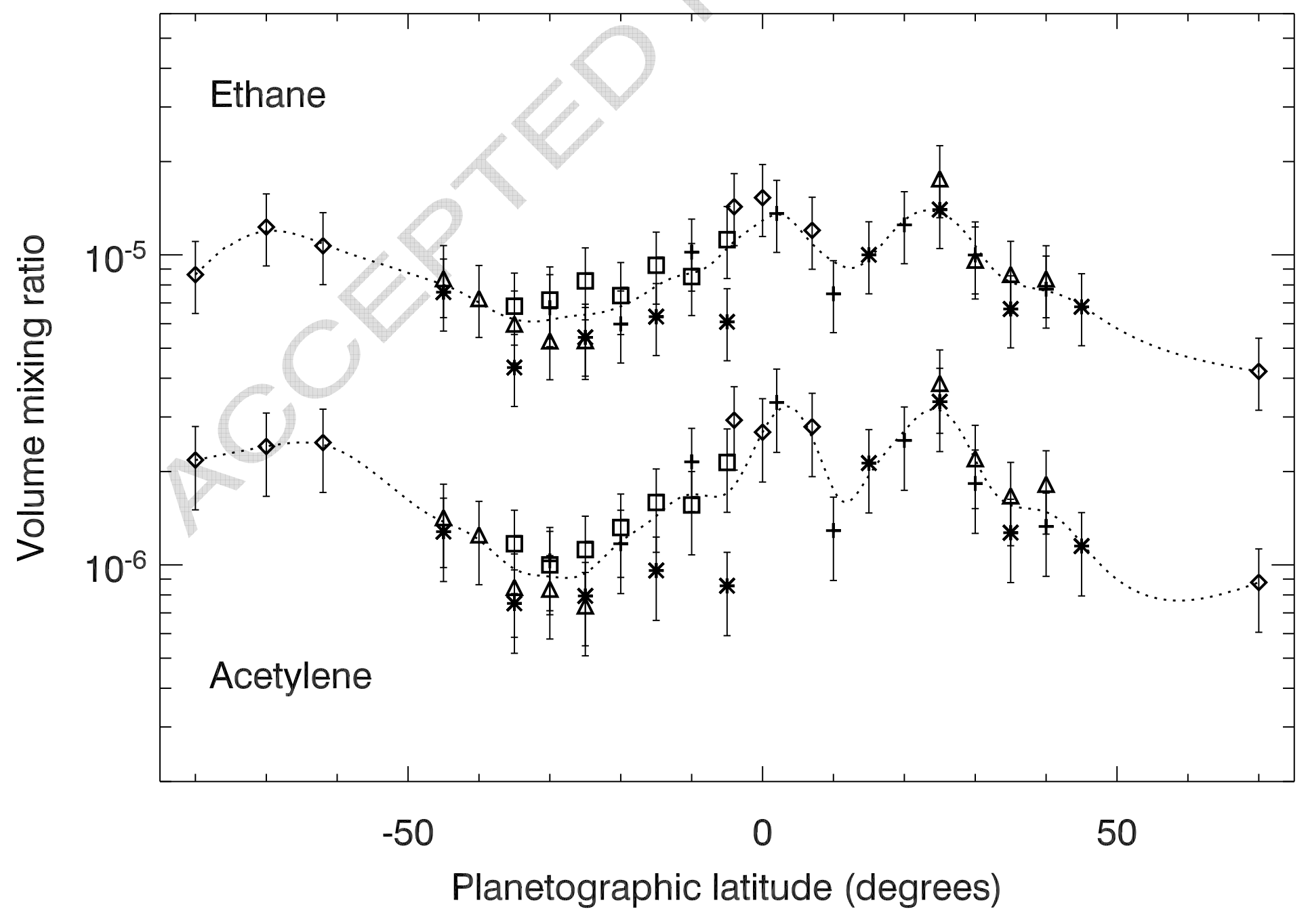


Hydrocarbon variations at $0.01 \mathrm{hPa}$

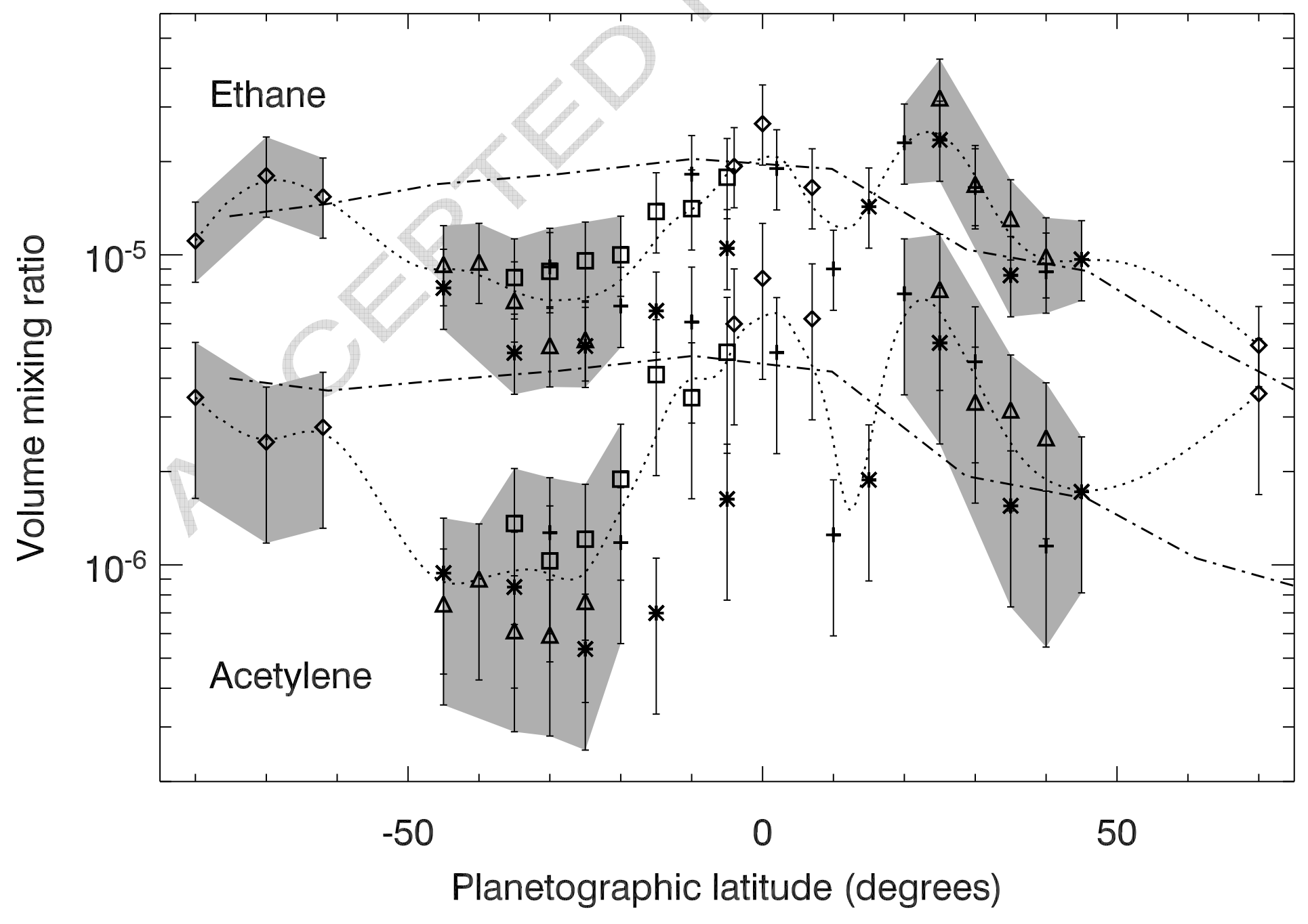


Ethane variation at $2.3 \mathrm{hPa}$

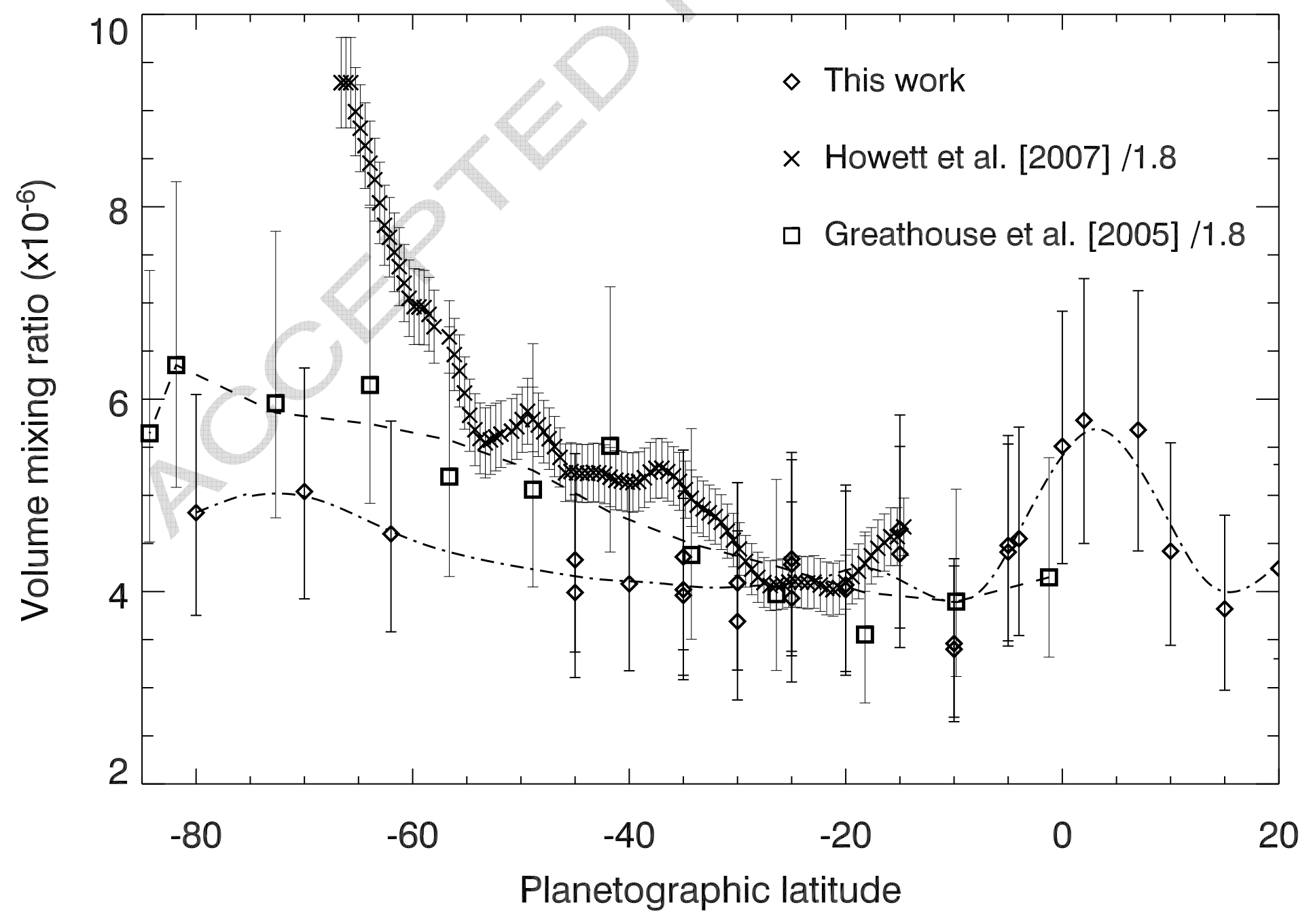


Acetylene variation at $1.1 \mathrm{hPa}$

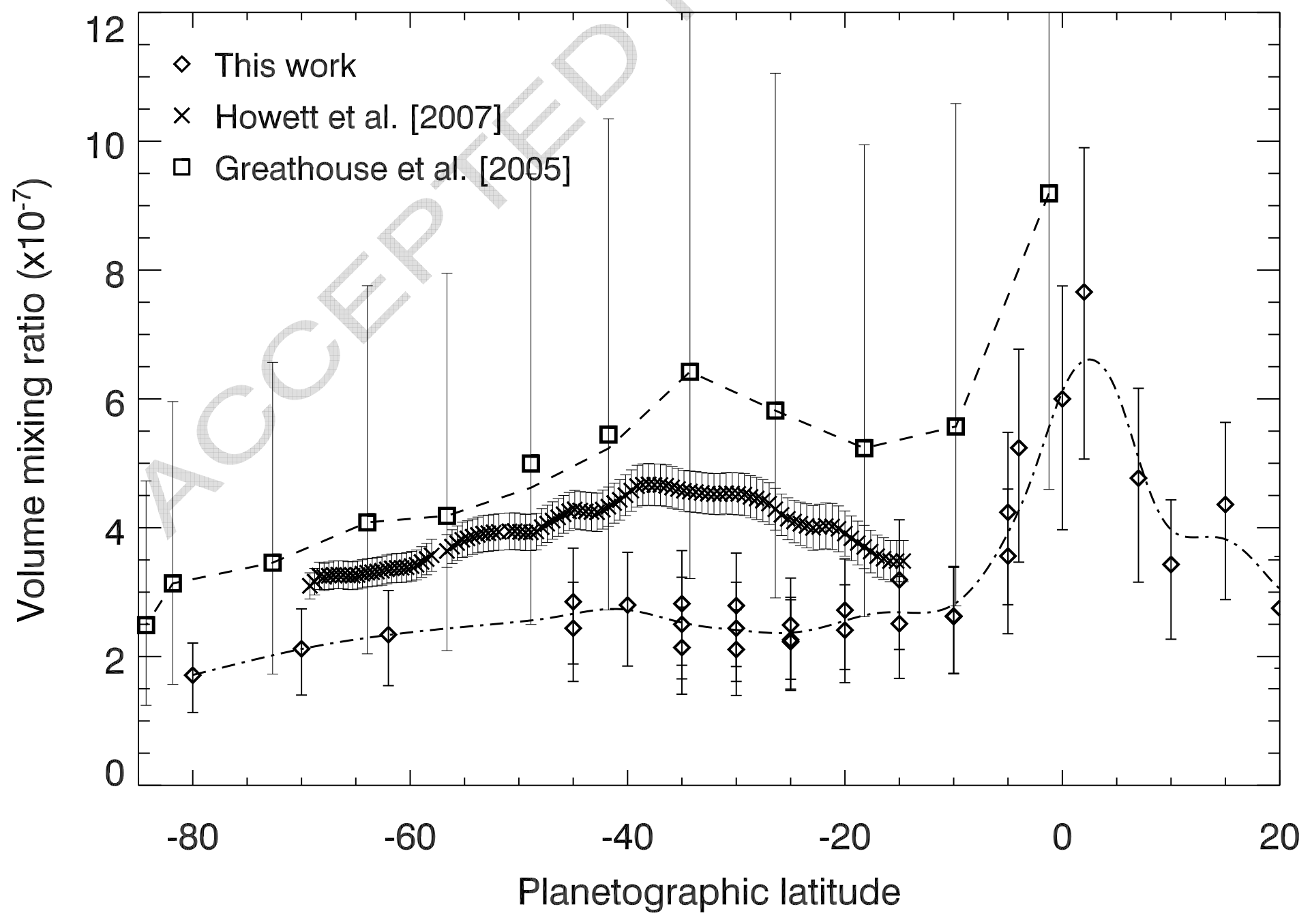


Acetylene variation at $0.12 \mathrm{hPa}$

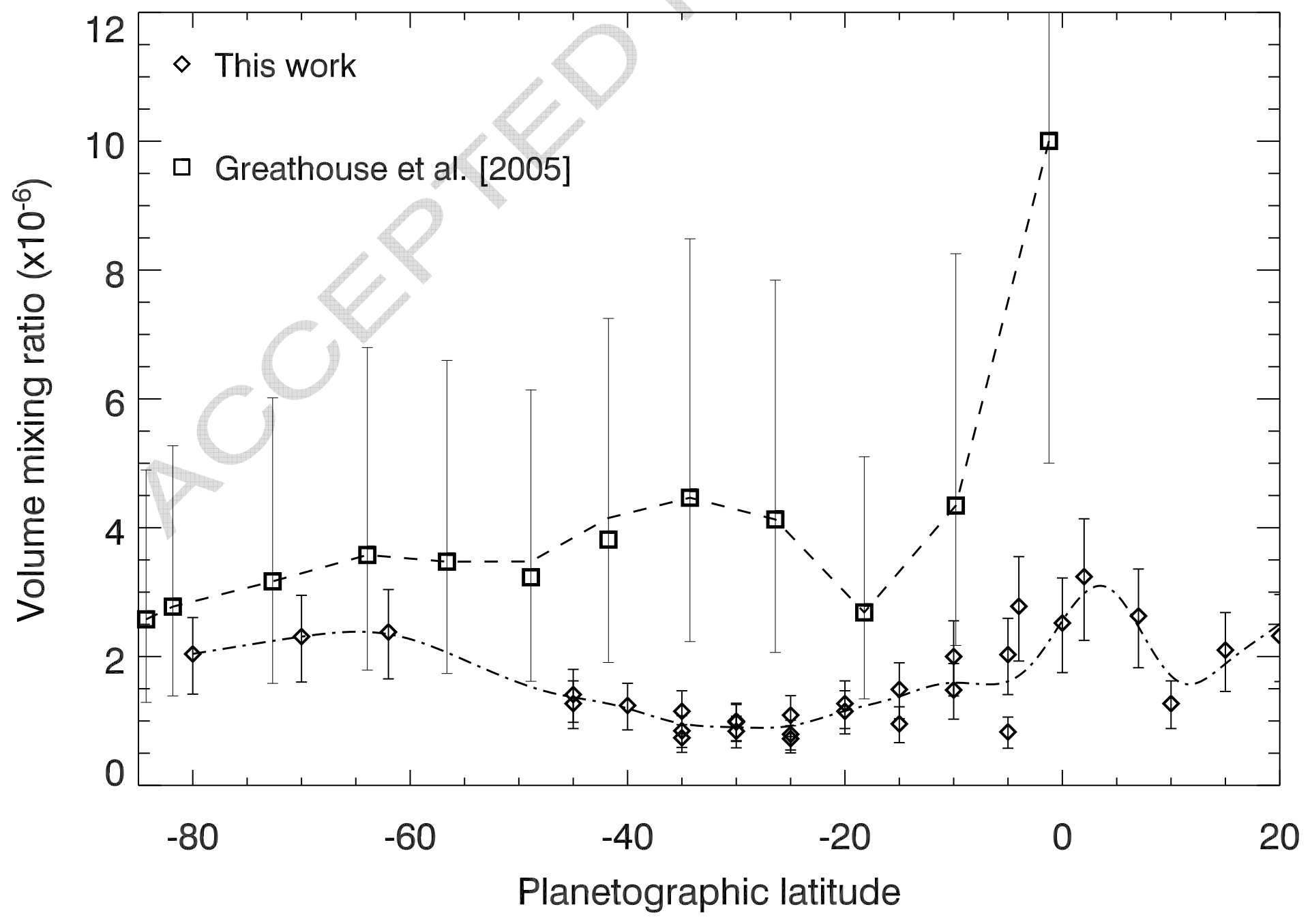



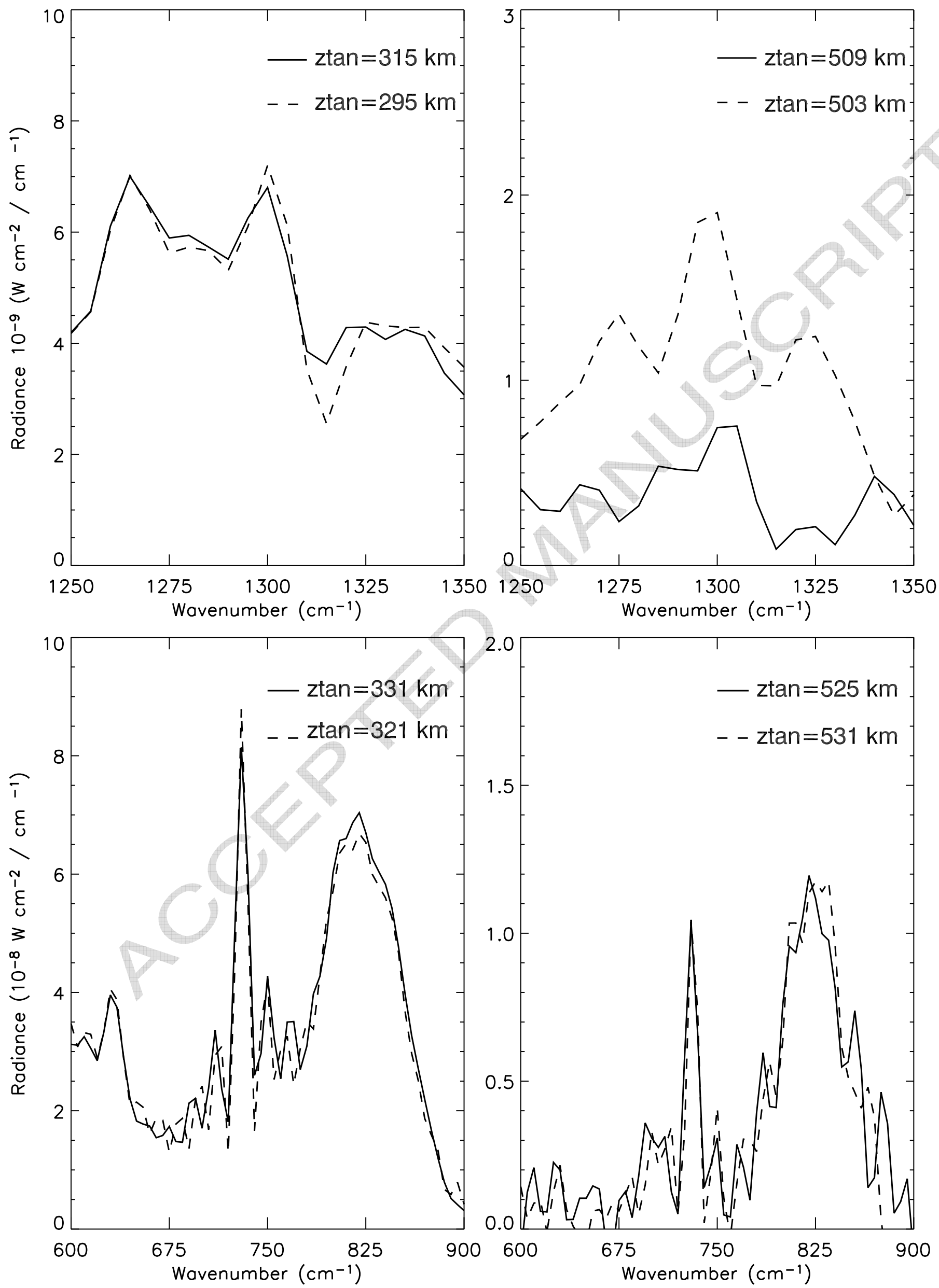